\title{
Design to Achieve Fault Tolerance and Resilience
}

Ted Quinn

Richard Bockhorst

Craig Peterson

Gregg Swindlehurst

September 2012

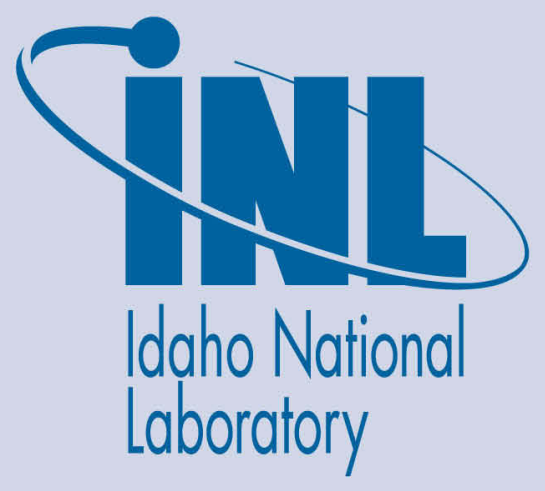

The INL is a U.S. Department of Energy National Laboratory operated by Battelle Energy Alliance 


\section{DISCLAIMER}

This information was prepared as an account of work sponsored by an agency of the U.S. Government. Neither the U.S. Government nor any agency thereof, nor any of their employees, makes any warranty, expressed or implied, or assumes any legal liability or responsibility for the accuracy, completeness, or usefulness, of any information, apparatus, product, or process disclosed, or represents that its use would not infringe privately owned rights. References herein to any specific commercial product, process, or service by trade name, trade mark, manufacturer, or otherwise, does not necessarily constitute or imply its endorsement, recommendation, or favoring by the U.S. Government or any agency 


\section{Design to Achieve Fault Tolerance and Resilience}

Ted Quinn, Richard Bockhorst, Craig Peterson, Technology Resources

Gregg Swindlehurst, GS Nuclear Consulting, LLC

September 2012

Idaho National Laboratory

Idaho Falls, Idaho 83415

http://www.inl.gov

Prepared for the

U.S. Department of Energy

Office of Nuclear Energy

Under DOE Idaho Operations Office

Contract DE-AC07-05ID14517 


\section{Executive Summary}

There are significant opportunities to improve nuclear power plant response to major transients by increasing the level of automation in control systems. The intent is to reduce dependence on operator actions in time-critical, complex responses to plant upsets and to make control systems more robust in their ability to manage non-steady state conditions. This report provides initial scoping for follow-on work designed to improve plant response in these areas.

The focus of this report is twofold. Selected reactor trips over the last five years are examined to determine if there are potential opportunities to automate tasks that are currently performed manually. The second area is to evaluate the potential for avoiding reactor trips by reducing power in a controlled manner upon the loss of turbine generator load.

Some candidate opportunities to reduce the frequency of reactor trips identified in this report are redundant feedwater controls, automated response to a feedwater or condensate pump trip, rapidly reducing power to avoid a reactor trip, and elimination of air operators for the feedwater control valves or providing redundant air supplies for these valves.

\section{$\underline{\text { Redundant Feedwater Control }}$}

The feedwater control system was identified as a cause of 27 reactor trips over the evaluation period. Twenty-three of those trips were due to a problem related to the electronic control system. A redundant electronic control system for each feedwater control valve offers a means for avoiding the majority (if not all) of the reactor trips from this cause. Some nuclear units have implemented redundant feedwater control.

\section{Improved Feedwater Regulating Valve Operators}

Most feedwater control valves utilize an air operator to position the valve. This requires an air supply, a pressure regulator, a current to pressure converter, and the air operator. These air components caused 8 trips over the evaluation period. A potential improvement is to replace the air components with an electric valve positioner. An electric positioner equipped with redundant power sources and electronic controls has the potential to significantly reduce trips caused by feedwater regulating valve air operator issues. Another possibility is to provide redundant air supply components with an automatic switchover when signal and air pressure do not match.

\section{Improved Feedwater Pump Turbine Control}

Similar to the opportunities to improve feedwater valve control, implementation of redundant electronic feedwater pump turbine control and/or electric governor valve positioning has the potential for reducing nuclear unit trips. 


\section{Automated Response to Feedwater Pump Trip}

An alternative (or complement) to changes to the feedwater turbine controls is to automate the response of the feedwater system to a feedwater pump trip. An integrated feedwater control system that can automatically lower power (turbine runback for Pressure Water Reactors [PWR]s, recirculation pump runback for Boiling Water Reactors [BWR]s) could prevent the number of scrams from this group.

\section{$\underline{\text { Reduction of Spurious Reactor Protection System Trips }}$}

After feedwater events, trips of the reactor protection system account for the most reactor trips over the evaluation period. Since reactor protection systems are not control systems, automation is not a prime option to reduce trips. The overwhelming majority of the reactor protection system (RPS) trips occurred during maintenance or testing. Utilizing probabilistic risk assessment tools, it may be possible to significantly increase the required surveillance test intervals for reactor protection systems. Of the 16 trips associated with reactor protection systems, 5 occurred due to a pre-existing unknown half trip condition. It may be possible to install an automatic indication of a half trip condition so that the failed component could be repaired prior to performing a trip test on an alternate channel.

The three control functions that must perform correctly for a plant to handle a load rejection are the rod control system (or the [reactor power cutback system [RPCS] for those Combustion Engineering [CE] design that have installed it), the steam dump system, and the pressurizer pressure control systems. Only certain plants can survive a full load rejection. There are several potential control modifications that would improve the capability to quickly recover from a loss of load event.

\section{Fast Reduction of Reactor Power}

The RPCS (partial reactor trip) design employed in the CE design would significantly improve the capability to survive load rejections in the other designs, provided that sufficient steam dump capacity exists. Without the power cutback feature a design change to increase the reactivity insertion rate (faster rod insertion speed and/or higher differential control rod worth) would improve the plant response to load rejections.

\section{Optimization of the Steam Dump System}

Optimization of the steam dump system may also be possible, such as designing an anticipatory strategy focused on load rejection capacity rather than simple secondary pressure control or simple primary temperature control. 


\section{Optimization of the Feedwater Control System}

Optimization of the feedwater control system may be possible, such that feedwater pump speed and control valve position, and the resulting steam generator inventory, would be better matched to the reactor heat generation during the reactor runback. This would assist in preventing a reactor trip on high pressure, and would also prevent a reactor trip on the trip functions that protect the fuel from departure from nucleate boiling (DNB).

Optimization of Westinghouse Set points

For the Westinghouse plants the turbine/reactor trip setpoint on loss of load could be optimized based on the time-in-cycle (by incorporating the moderator temperature coefficient (MTC) variation into the design), and with consideration for the end-of-cycle T-ave reduction (or reduced T-ave operation). Other optimizations of the over-power $\Delta \mathrm{T}$ and overtemperature $\Delta \mathrm{T}$ trip set points may be possible for Westinghouse plants.

\section{Increased Steam Dump Capacity}

Additional steam dump capacity would improve the capability to handle load rejections for all designs (except for those with 100\% capacity). These refinements would include actual plant performance parameters for structure systems component (SSC)s such as steam dump valve capacity and valve stroke times.

\section{Increased RCS Pressure Reduction Capability}

Additional pressurizer spray or power operated relief valve (PORV) capacity would also be an improvement for designs that are limited by the high reactor pressure trip. Refinements in the analysis inputs related to mechanical systems may also provide an opportunity to justify optimizing the set points to enable allow large load rejections. 


\section{Acronyms}

1E 4KV Safety-Related High Voltage Supply System

ABWR Advanced Boiling Water Reactor

ADV Atmospheric Dump Valve

AOO Anticipated Operational Occurrence

B\&W Babcock \& Wilcox

BWR Boiling Water Reactor

CE Combustion Engineering

CFM Centerline Fuel Melting

Condensate Condensate Supply to the Main Feedwater Pump Suction

CPC Core Protection Calculator

CPR Critical Power Ratio

DNB Departure from Nucleate Boiling

DNBR Minimum Departure-From-Nucleate Boiling Ratio

EHC Electro-Hydraulic Control System for the Main Turbine

ESFAS Engineered Safety Features Actuation System

FRV Feedwater Regulating Valve

FWCS Feedwater Control System

FWP Main Feedwater Pump including integral support equipment such as mini-flow

FWPT Main Feedwater Pump Turbine

ICS Integrated Control System

LOOP Loss-of-Offsite Power

MTC Moderator temperature coefficient 


\begin{tabular}{ll} 
Non-1E 4KV & Non-safety related high voltage supply system \\
NRC & U. S. Nuclear Regulatory Commission \\
PORV & Power Operated Relief Valve \\
PRA & Probability Risk Assessment \\
PWR & Pressurized Water Reactor \\
RCS & Reactor Coolant System \\
RFCS & Recirculation Flow Control System \\
Rod Control & Rod Control System \\
RPCS & Reactor Power Cutback System \\
RPM & Rotations per Minute \\
RPS & Reactor Protection System \\
RPV & Reactor Pressure Vessel \\
Rx Recirc & Reactor Recirculation System (BWR) \\
SAFDL & Specified Acceptable Fuel Design Limit \\
SBPCS & Steam Bypass and Pressure Control System \\
SCWS & Stator Cooling Water System \\
SSC & Structure Systems Component \\
TMI & Three Mile Island \\
TPS & Turbine Protection System \\
Turbine & Main Turbine Generator \\
UFSAR & Updated Final Safety Analysis Report \\
\hline
\end{tabular}




\section{Table of Contents}

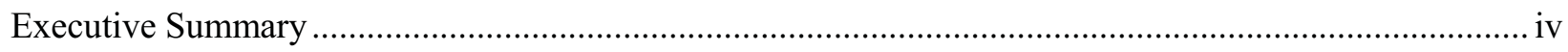

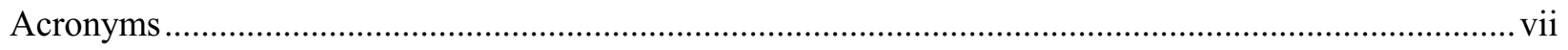

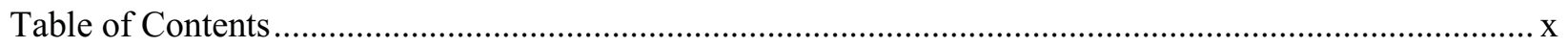

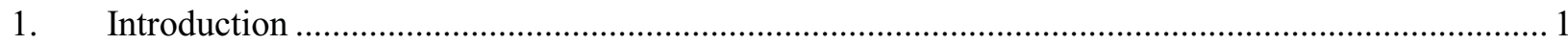

2. Task 1: Survey of U.S. Commercial Reactor Experience …...................................................... 3

2.1 Frequent Operating Transients Caused by Equipment Faults and At-Power

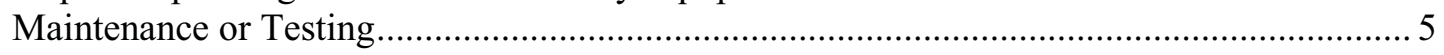

2.2 Frequent Operating Transients Caused Where At-Power Maintenance or Testing Was

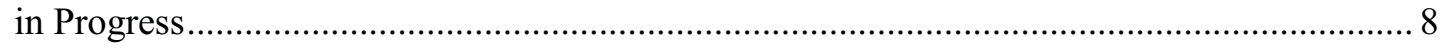

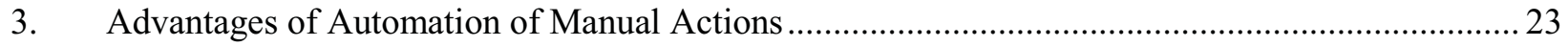

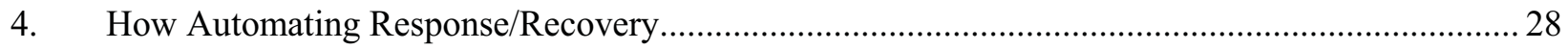

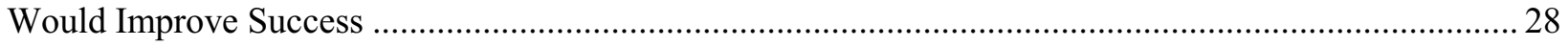

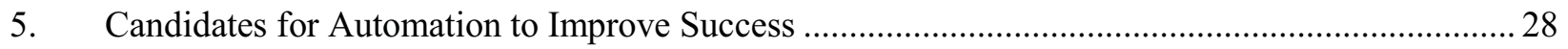

6. Task 2: Identify Issues and Approaches Associated with Runback to House Load on Loss-

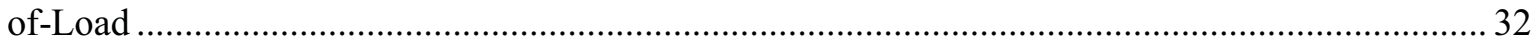

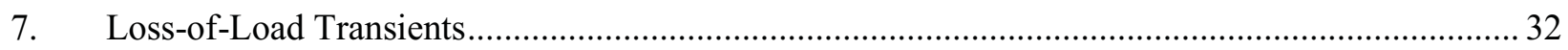

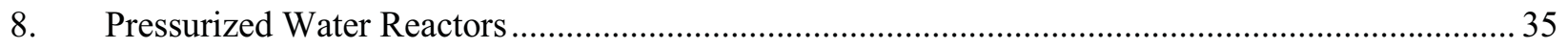

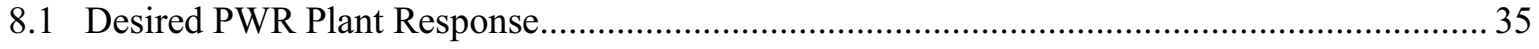

8.2 Overview of Loss-of-Load Transient for Various Plant Designs .......................................... 36

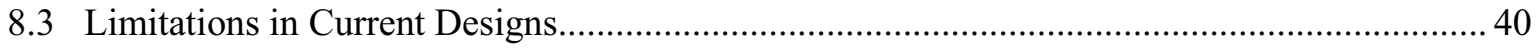

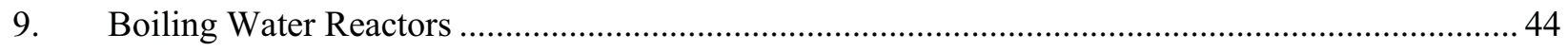

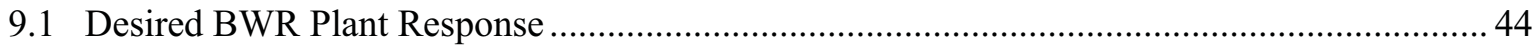

9.2 Overview of Loss-of-Load Transient for Various BWR Plant Designs .......................................... 45 


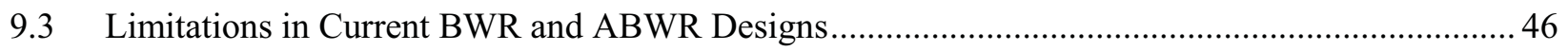

Appendix A Table A-1-Reactor Trip Events - Causes and Categorizations.......................................... 49

\section{TABLES}

Table 2-1 Summary of Reactor Trips 2007 - July 2012 …................................................................ 3

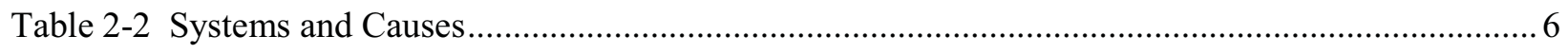

Table 2-3 Systems and Causes Related to Maintenance or Testing...................................................... 9

Table 2-4 Trip Recovery with Manual CVCS Actuations ................................................................. 12

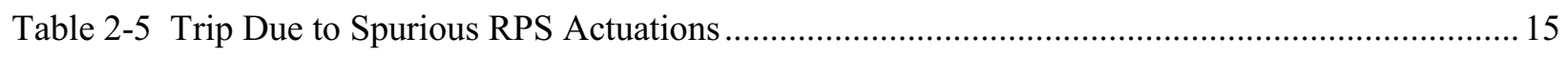

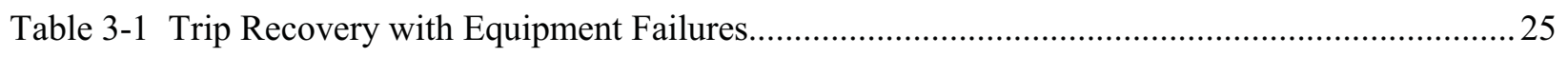

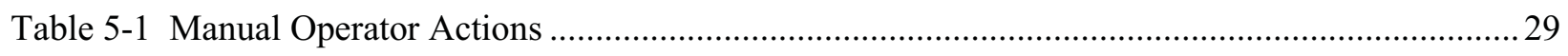

Table 8-1 Candidate Design Changes for PWR Plant Categories ..................................................... 43 


\section{Introduction}

There are significant opportunities to improve nuclear power plant response to major transients by increasing the level of automation in control systems. The intent is to reduce dependence on operator actions in time-critical, complex responses to plant upsets and to make control systems more robust in their ability to manage non-steady state conditions. This report provides initial scoping for follow-on work designed to improve plant response in these areas.

The focus of this report is twofold. Selected trips over the last five years are examined to determine if there are potential opportunities to automate tasks that are currently performed manually. The second area is to evaluate the potential for avoiding reactor trips by reducing power in a controlled manner upon the loss of turbine generator load.

The first area of potential improvement is to automate certain tasks currently performed manually by plant operators in response to off normal conditions such as plant transients or equipment failures. The objective is to improve the ability of nuclear units to remain online during upset conditions and to reduce error-likely situations involved with manual operator actions under stressful conditions.

The Nuclear Regulatory Commission (NRC) licensee event reports were searched for reactor scrams which occurred between January 1, 2007 and July 1, 2012 in which at least one of the following conditions was true and it appeared that a better designed system or process may have prevented the reactor scram:

- Maintenance or testing was in progress on any sort of control system that caused the reactor scram.

- Operators took manual control of a normally automatically controlled system and were unable to adequately control the system which resulted in a reactor scram.

- An automatically controlled system failed causing a reactor scram, but sufficient equipment remained in service that it may have been possible to remain online if the system could handle the perturbation.

The second area explores the issues and possible approaches for improving the capability of the current operating nuclear fleet to successfully run back to house load following a loss-of-load or load rejection event. A successful runback avoids tripping the reactor and the subsequent downtime of approximately two days before the unit can be back in service and providing power to the grid. It is desired for the unit to be reconnected to the grid rapidly following the runback to prevent minor grid disturbances from expanding into major grid disturbances like the grid collapse of 2003. 
The current operating nuclear fleet has varying capabilities to successfully run back to house loads following load rejection events. Some designs are already fully capable, and other designs would require significant designs changes to reach an equivalent capability. The design features that enhance or limit that capability are identified, and the opportunities to modify the plant designs to achieve the desired load rejection capability are discussed. A primary issue is to determine any impact on nuclear safety, which involves performing analyses to evaluate the impact of any proposed design changes on the regulatory requirements established by the U.S. NRC. The cost of designing and installing the design changes, performing the required analyses, and obtaining NRC approval, would then need to be evaluated against the benefit of the increased capability to handle a load rejection and avoid contributing to major grid disturbances. 


\section{Task 1: Survey of U.S. Commercial Reactor Experience}

The purpose of this section of the report is to provide initial scoping for follow on work designed to improve nuclear plant operation. The focus of the improvement is to automate certain tasks currently performed manually by plant operators in response to off normal conditions such as plant transients or equipment failures. The objective is to improve the ability of nuclear units to remain online during upset conditions and to reduce error-likely situations involved with manual operator actions under stressful conditions.

The NRC licensee event reports were searched for reactor scrams which occurred between January 1, 2007 and July 1, 2012 in which at least one of the following conditions was true and it appeared that a better designed system or process may have prevented the reactor scram:

- Maintenance or testing was in progress on any sort of control system that caused the reactor scram.

- Operators took manual control of a normally automatically controlled system and were unable to adequately control the system which resulted in a reactor scram.

- An automatically controlled system failed causing a reactor scram, but sufficient equipment remained in service that it may have been possible to remain online if the system could handle the perturbation.

Table 2-1 provides a summary of the reactor trips that met the above criteria.

Table 2-1 Summary of Reactor Trips 2007 - July 2012

\begin{tabular}{||l|r||}
\hline \multicolumn{1}{|c|}{ Category } & Events \\
\hline \hline Reactor trips, 2007 to July 2012 & 383 \\
\hline Reactor trips that met criteria & 96 \\
\hline Manual reactor trip & 40 \\
\hline Power decrease $>50 \%$ & 84 \\
\hline Power decrease $>10 \%,<50 \%$ & 12 \\
\hline $\begin{array}{l}\text { Maintenance or testing was being performed } \\
\text { which causes trip? }\end{array}$ & 45 \\
\hline $\begin{array}{l}\text { Operators took manual control of an } \\
\text { automatically controlled system? }\end{array}$ & 41 \\
\hline
\end{tabular}


Appendix A, Table A-1, provides a list of the licensee event reports (LER) and the cause evaluation from the LER. Over the five year period, there were 383 reactor trip events. Ninetysix (96) of those events met one of the above listed criteria.

The systems (and in some cases the sub-system) that caused the 96 trips were identified as follows. The purpose of this type of breakdown is to facilitate development of potential solutions to trips.

$\begin{array}{ll}\text { 1E 4KV } & \text { Safety related high voltage supply system } \\ \text { Condensate } & \text { Condensate supply to the main feedwater pump suction } \\ \text { CVCS } & \text { Chemical and volume control system } \\ \text { EHC } & \text { Electro-hydraulic control system for the main turbine } \\ \text { ESFAS } & \text { Engineered Safety Features Actuation System } \\ \text { FRV } & \text { Feedwater regulating valve } \\ \text { FWCS } & \text { Feedwater Control System } \\ \text { FWP } & \text { Main feedwater pump including integral support equipment such as mini-flow } \\ \text { FWPT } & \text { Main feedwater pump turbine } \\ \text { HDLC } & \text { Heater Drain Level Control System } \\ \text { Non-1E 4KV } & \text { Non-safety related high voltage supply system } \\ \text { Rod Control } & \text { Rod control system } \\ \text { RPS } & \text { Reactor Protection System } \\ \text { Rx Recirc } & \text { Reactor Recirculation System (BWR) } \\ \text { SCWS } & \text { Stator Cooling Water System } \\ \text { TPS } & \text { Turbine Protection System } \\ \text { Turbine } & \text { Main Turbine Generator }\end{array}$

For each of the failures, the cause of the failure was categorized according to the following.
Air
A component in the air supply failed.
Design A design failure was the direct cause of the trip.
Electronic An electronic component failed that caused the trip.
Error An error on the part of a technician or operator caused the trip.
Hyd A component in the hydraulic supply failed.
Motor A motor failed.
Procedure An error in a procedure directly resulted in a trip.
Pump A pump or component integral to the pump failed.
Relay A relay failed.
Valve A valve failed. 


\subsection{Frequent Operating Transients Caused by Equipment Faults and At-Power Maintenance or Testing}

Table 2-2 provides a matrix of the systems/subsystems and the causes. The six leading systems that were the source of trips are as follows.

FWCS Feedwater Control Systems were the source for 26 of the 96 reactor trips evaluated $(27 \%)$. Of the 26 trips, 22 were caused by a failure in an electronic component, 3 were caused by a technician or operator error, and 1 was attributed to the system design. A review of the LERs showed that the operators attempted (or were in) manual control of the feedwater flow for 16 of the trips. There was no manual control of feedwater identified in 10 of the trip events.

RPS Reactor Protection Systems were the source of 16 reactor trips. Of the 16 trips, 7 were caused by the failure of an electronic component failure, 5 were caused by a technician or operator error, 2 were caused by a procedural error, 1 due to a relay failure, and 1 by the system design. Table 2-5 lists the causes of the reactor protection system trips. Eight of the trips were caused by a component failure coupled with a surveillance test that placed the channel under test in the tripped condition.

FWPT A main feedwater pump turbines (including reactor feedwater pump turbines) were the source of 11 trips. Of the 11 trips, 4 were caused by electronic component failures, 2 were caused by a hydraulic component failure, 2 were caused by a technician or operator error, 2 by valve failures, and one due to a lube oil pump failure.

FRV Feedwater regulating valves were also the source of 10 trips. Of the 10 trips, 8 were caused by an air supply component failure, 1 was caused by a technician or operator error, and 1 was caused by a procedural error.

Condensate Condensate Systems (including Condensate Demineralizers) were the source of 7 trips. Of the 7 trips, 2 were caused by an electronic component failure, 2 were caused by a procedural error, and one each for a technician or operator error, a motor failure, and a pump failure.

FWP A main feedwater pumps (including reactor feedwater pumps) were the source of 7 trips. Of the 7 trips, 3 were caused by a pump problem, and 1 each due to an electronic component failure, a technician or operator error, a procedural error, and a motor failure. 


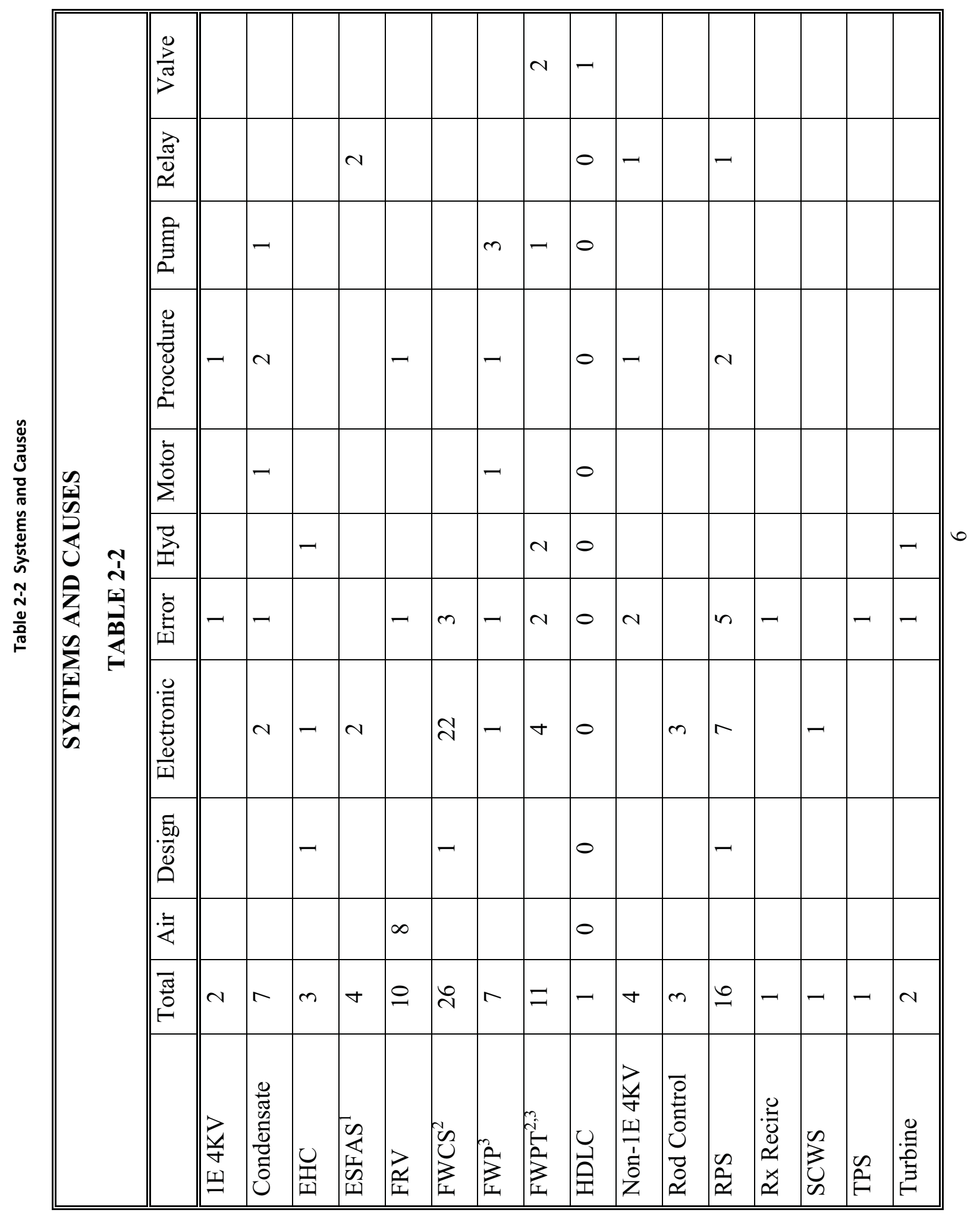



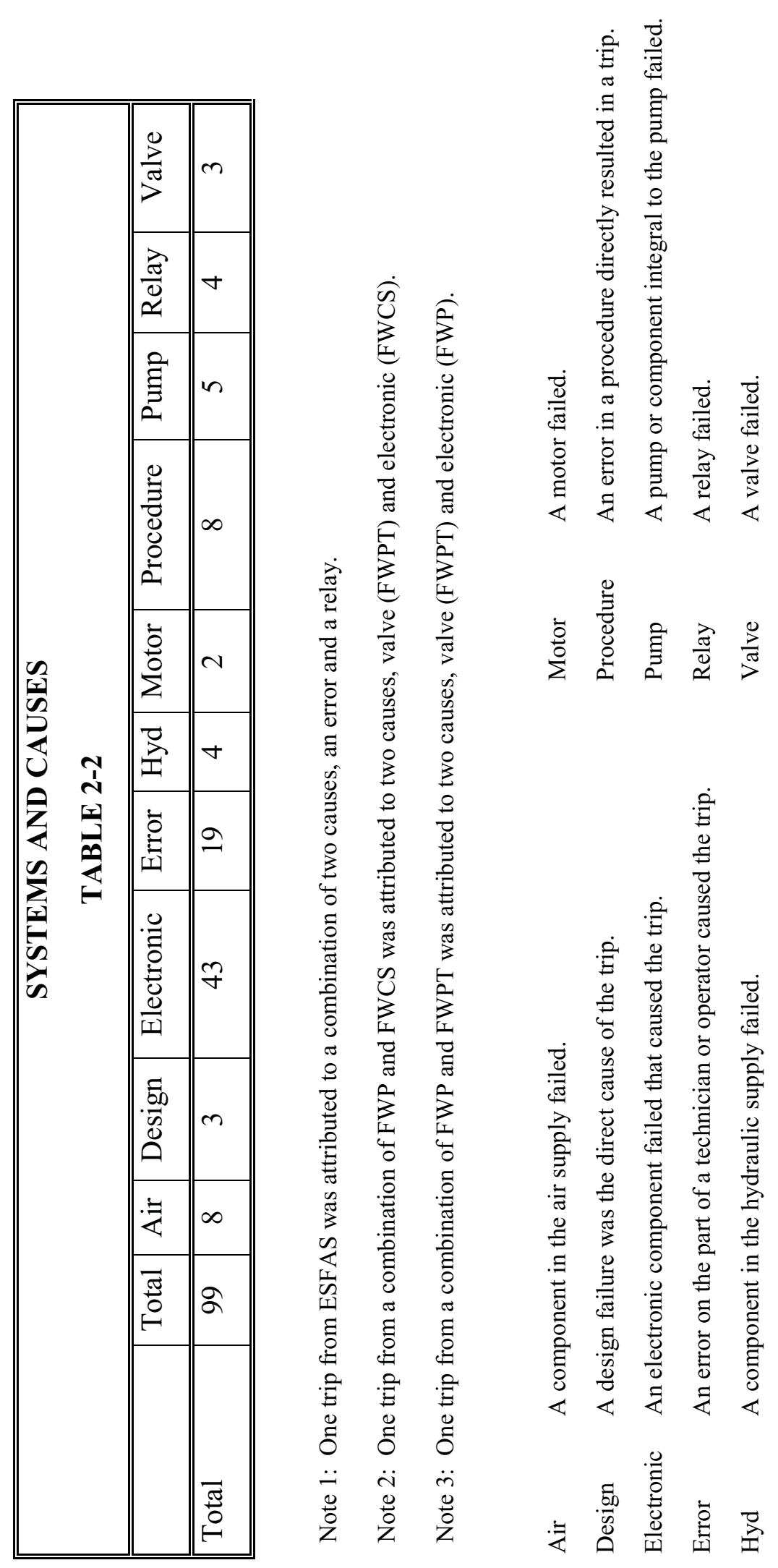


\subsection{Frequent Operating Transients Caused Where At-Power Maintenance or Testing Was in Progress}

Table 2-3 lists the systems and causes of reactor trips where maintenance or testing was in progress that directly contributed to the trip. Of the 99 system/causes of reactor trips, maintenance or testing was directly involved in 46 trips. The two leading systems involved in reactor trips were reactor protection systems (RPS) and feedwater control systems (FWCS).

RPS Testing or maintenance was in progress for 15 of the 16 trips related to RPS. The only trip where testing or maintenance was not involved was related to a design issue.

FWCS Testing or maintenance was in progress for 6 of the 27 trips related to FWCS. Of the 6 trips, 3 were caused by a failure in an electronic component, 2 were caused by a technician or operator error, and 1 was attributed to the system design. 


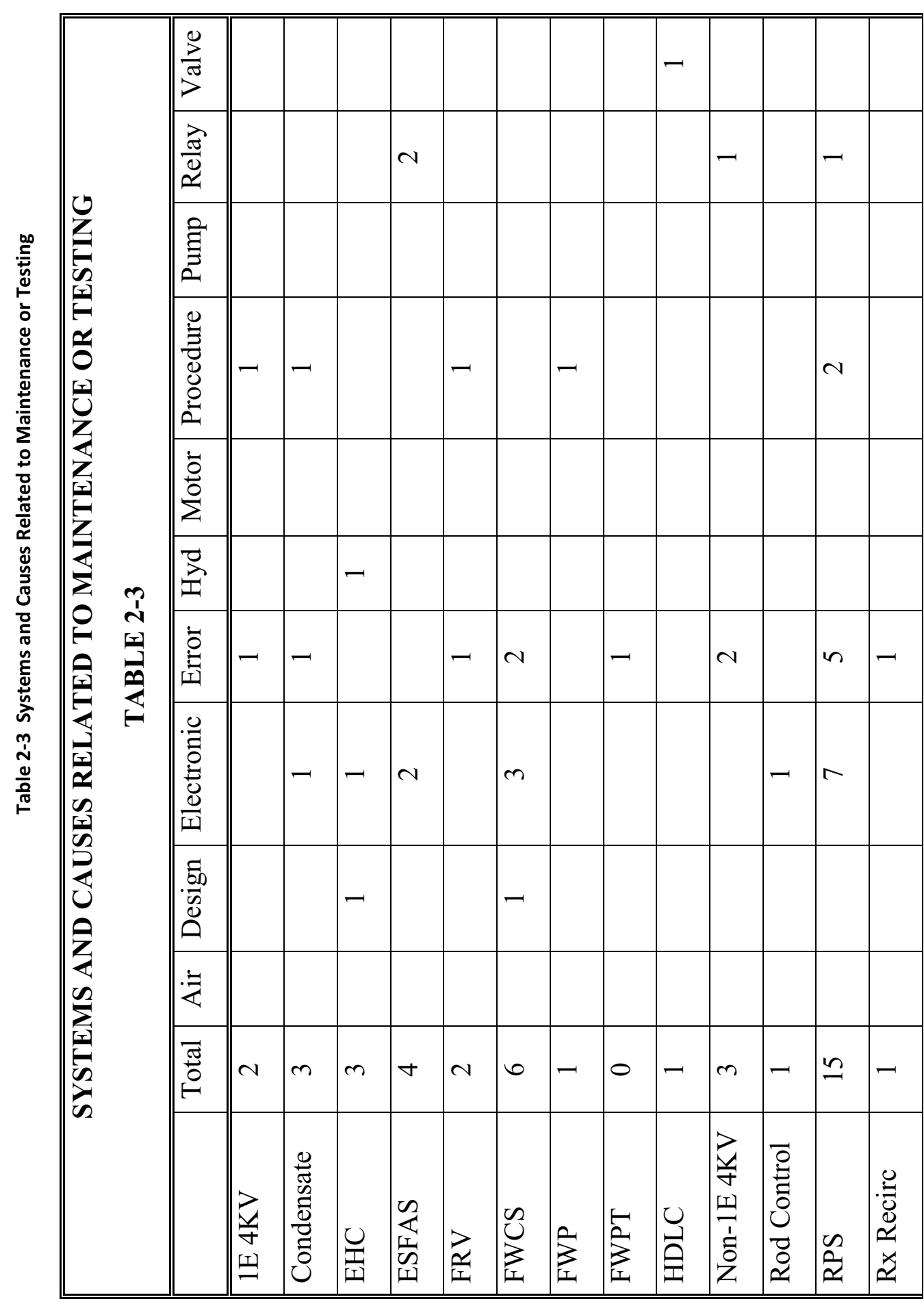




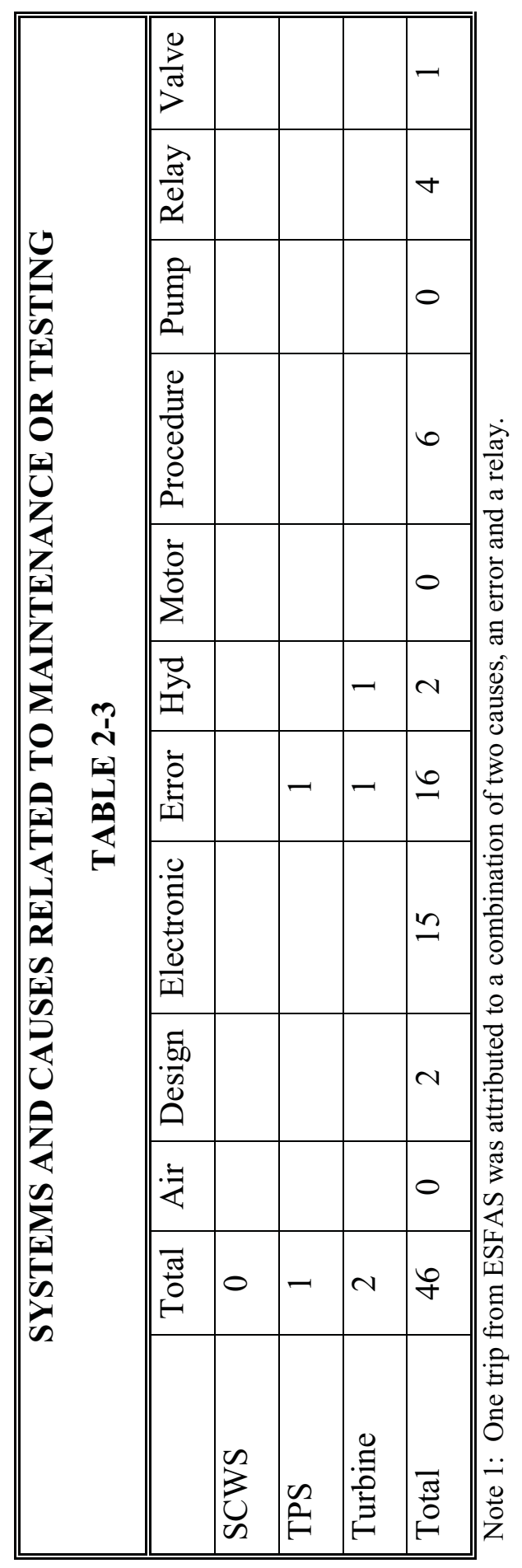


While the Chemical and Volume Control Systems (CVCS) did not contribute to the causes of reactor trips, this system was involved in manual actions associated with five of the trips. Three involved manual initiation of emergency boration and two involved manual control of charging and letdown. Table 2-4 lists the events and the manual actions taken.

CVCS does not contribute significantly to the number of reactor trips since the process is relatively slow moving with backup charging pumps and alternate letdown paths. Failure of a charging pump would typical result in automatic reduction in letdown flow and start of a backup charging pump. Failure of a letdown valve would either automatically start or secure a charging pump allowing time for an operator to place the alternate letdown valve in service.

RPS testing is the most common cause of spurious reactor actuations involving this system. This is because the reactor trips require coincident logic (two out of three channels or two out of four channels) to trip and it is relatively rare to have coincident random failures of channel components such as sensors and transmitters. A common situation for a spurious reactor actuations involving the RPS is where a channel is put in trip for maintenance (according to the plant's technical specifications) and there is a latent failure of a second channel undetected by the operators. A second common scenario involves human error, where two channels of the same RPS trip function are unintentionally worked on at the same time. This usually involves a component misidentification event.

As even further precaution against spurious RPS actuations, many plants have implemented a channel bypass system according to Regulatory Guide 1.47, which allows a channel to be placed in bypass rather than trip for a limited duration while the testing is in progress. In spite of all of these measures, spurious RPS actuations during maintenance and testing are still a large contributor to the number of avoidable reactor trips. Table 2-5 lists these events during the time frame considered under this study.

Even though spurious RPS trips are unacceptably high, the solution does not lend itself to the type of automation contemplated by this study - that of automating the response to a transient in lieu of manual procedure-based operator actions. There is a form of automation that would be beneficial in this category of trip and that is automation of configuration management for maintenance and testing. This would involve software control of which channels are taken out of service for maintenance and testing and related interlocks to prevent multiple channels being worked on at the same time. It would also involve real-time channel checks to detect and avoid interaction with latent failures. Again, while this might be helpful, it is out of the scope of this particular study. 


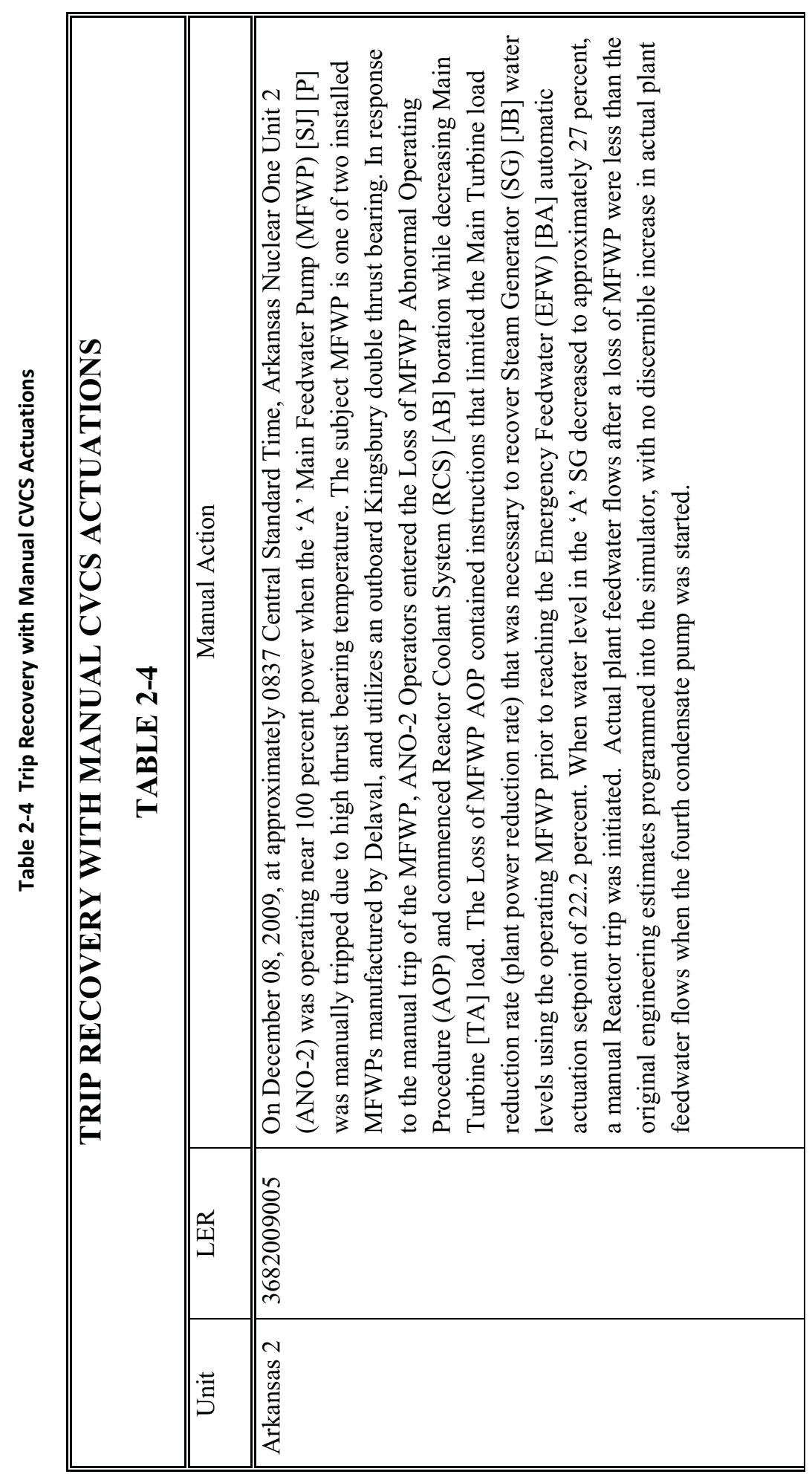




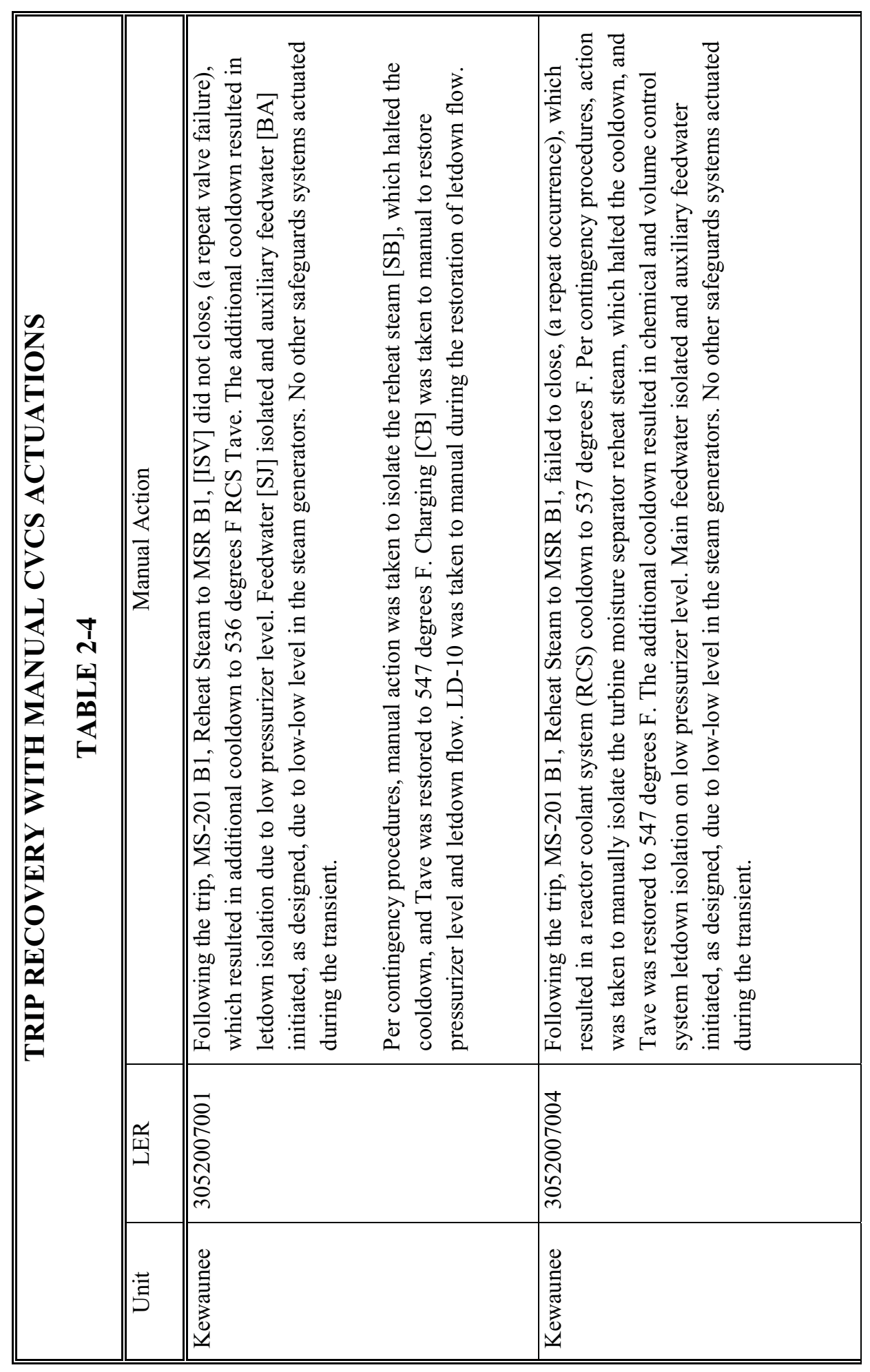




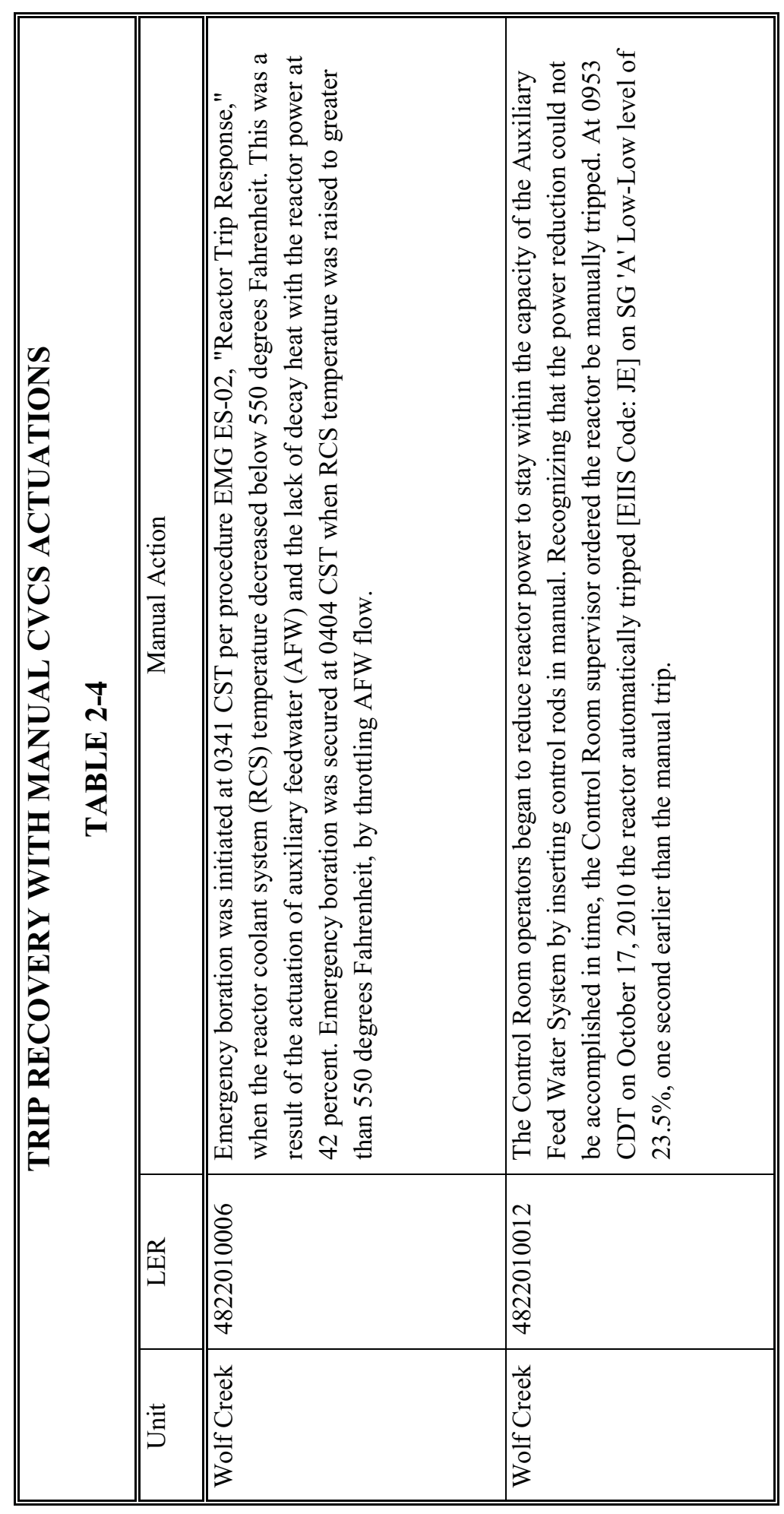




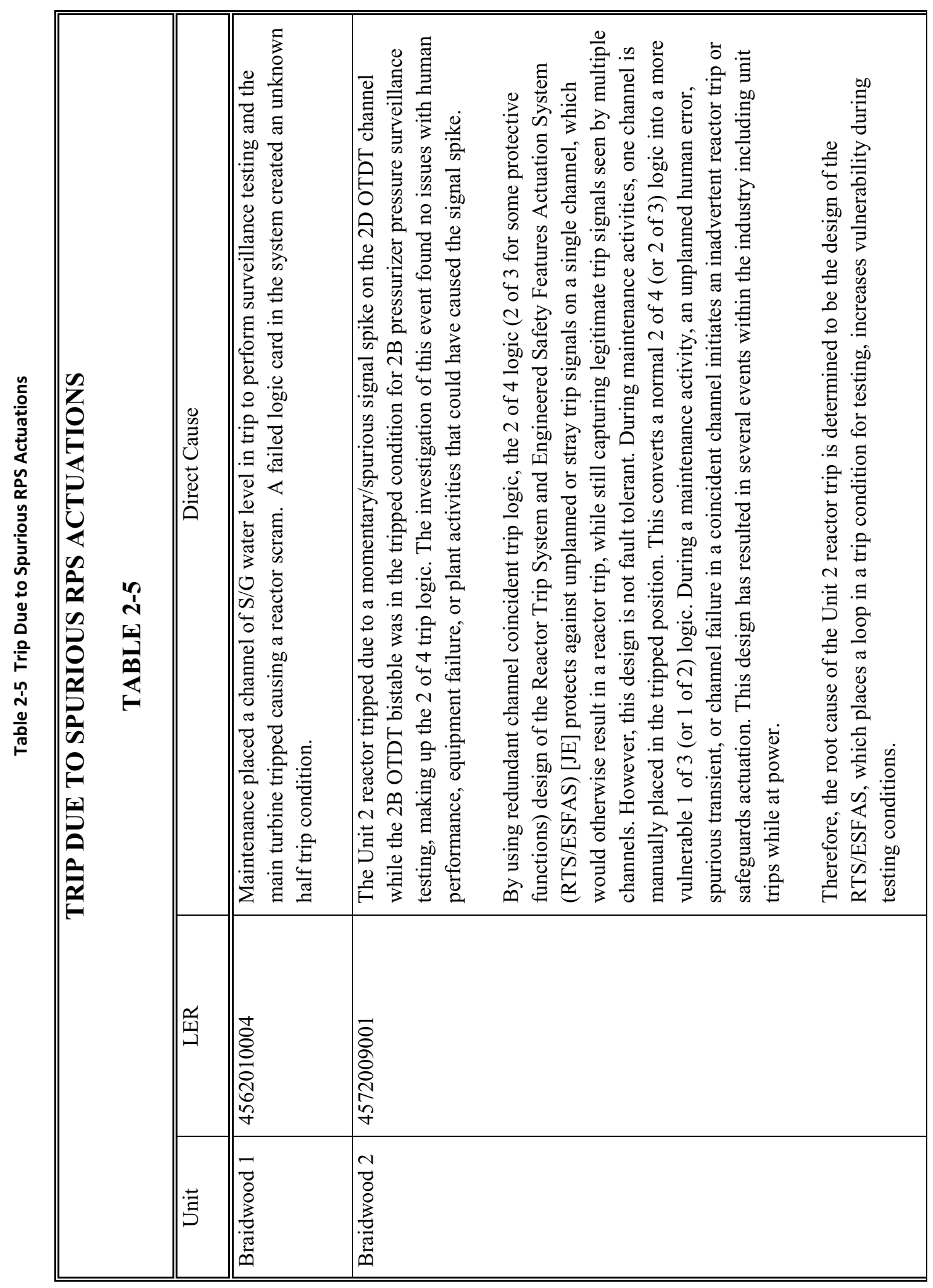




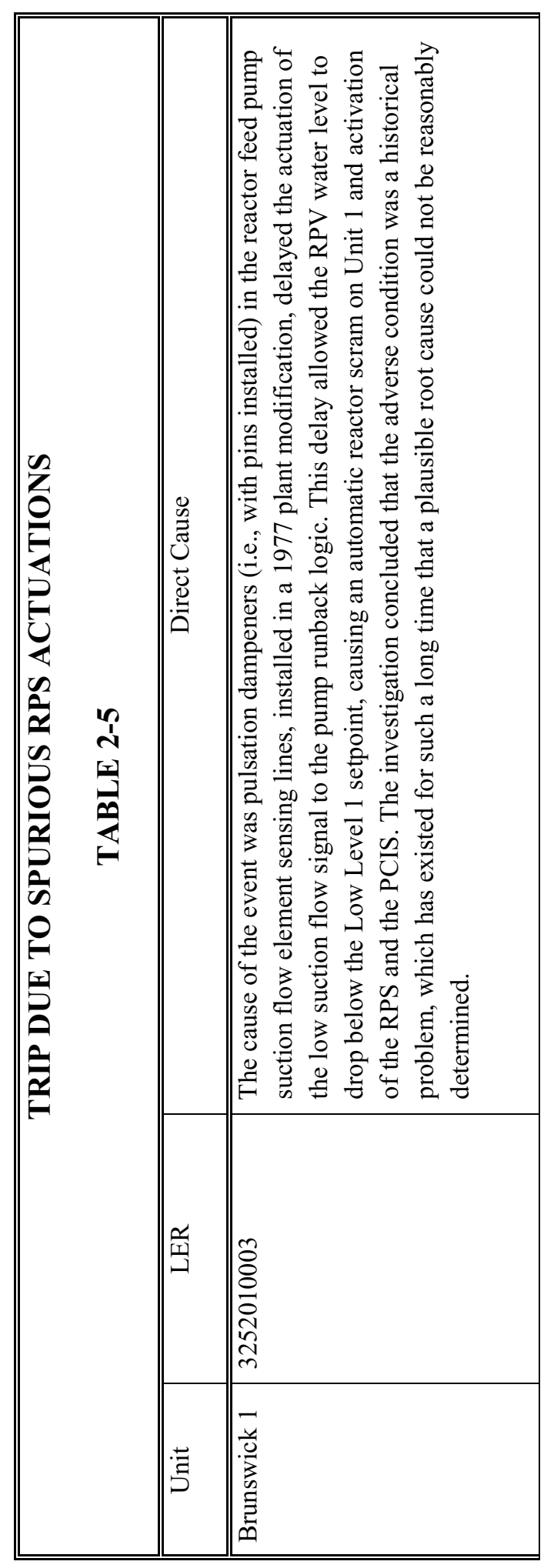




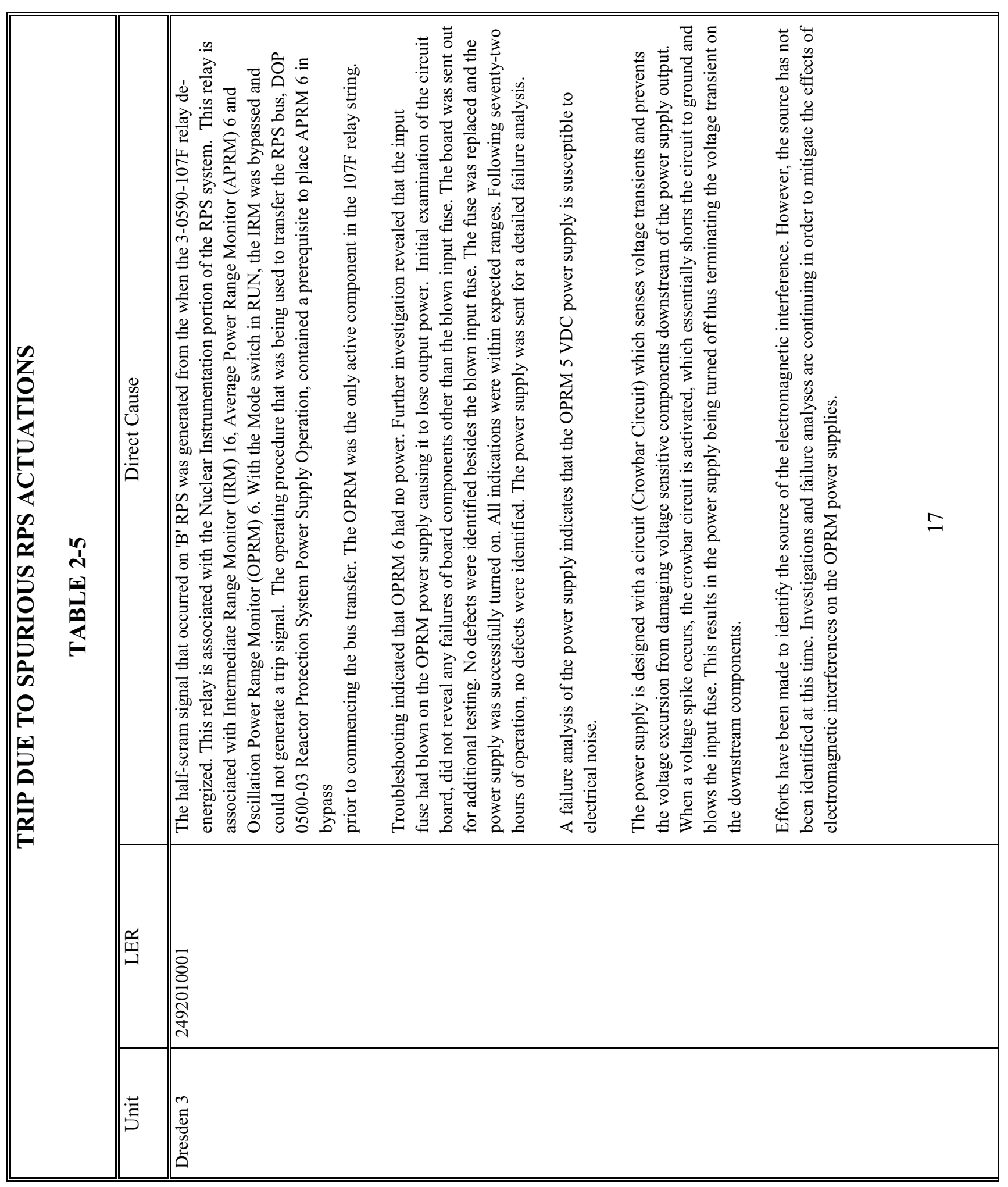




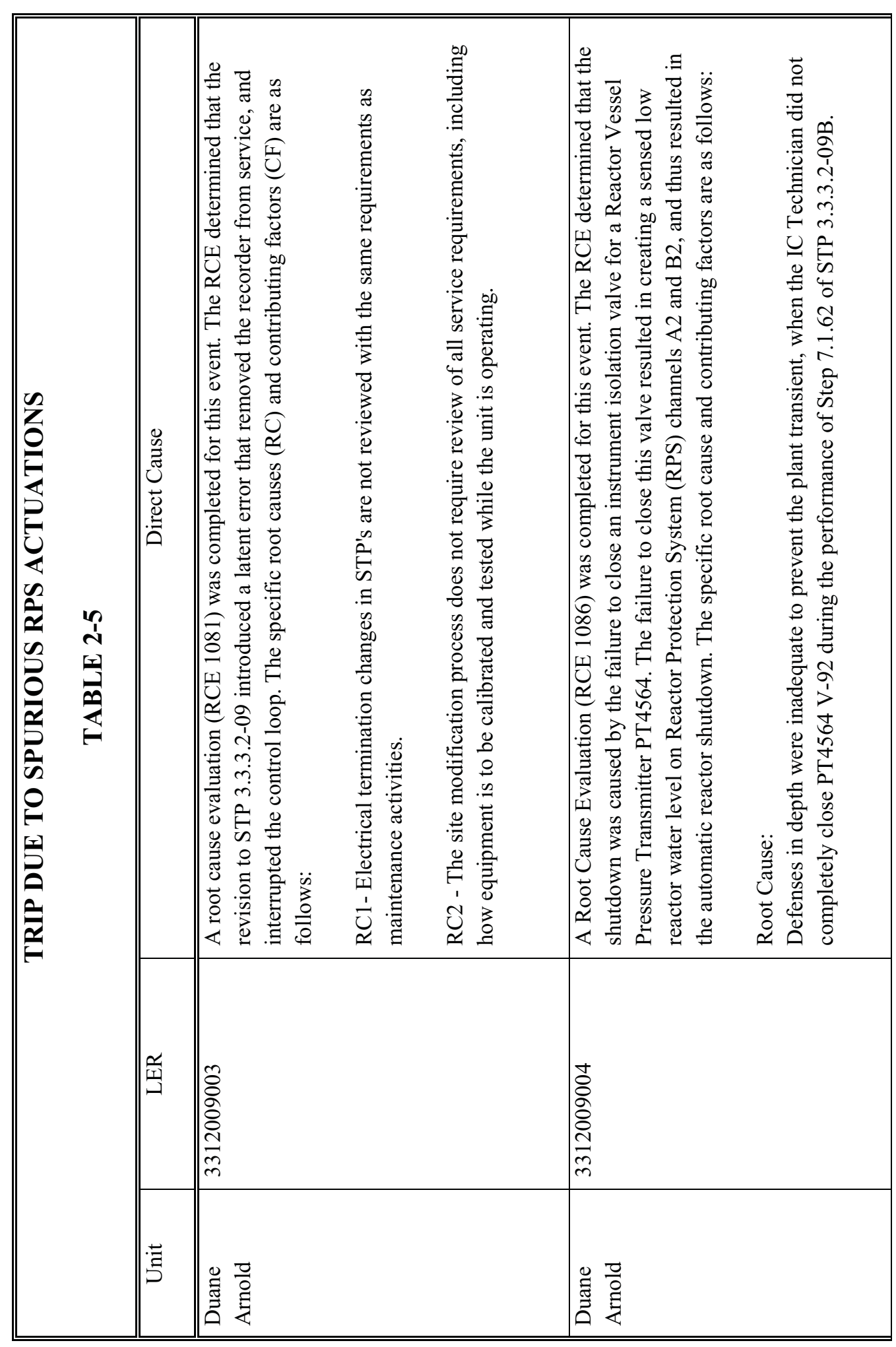




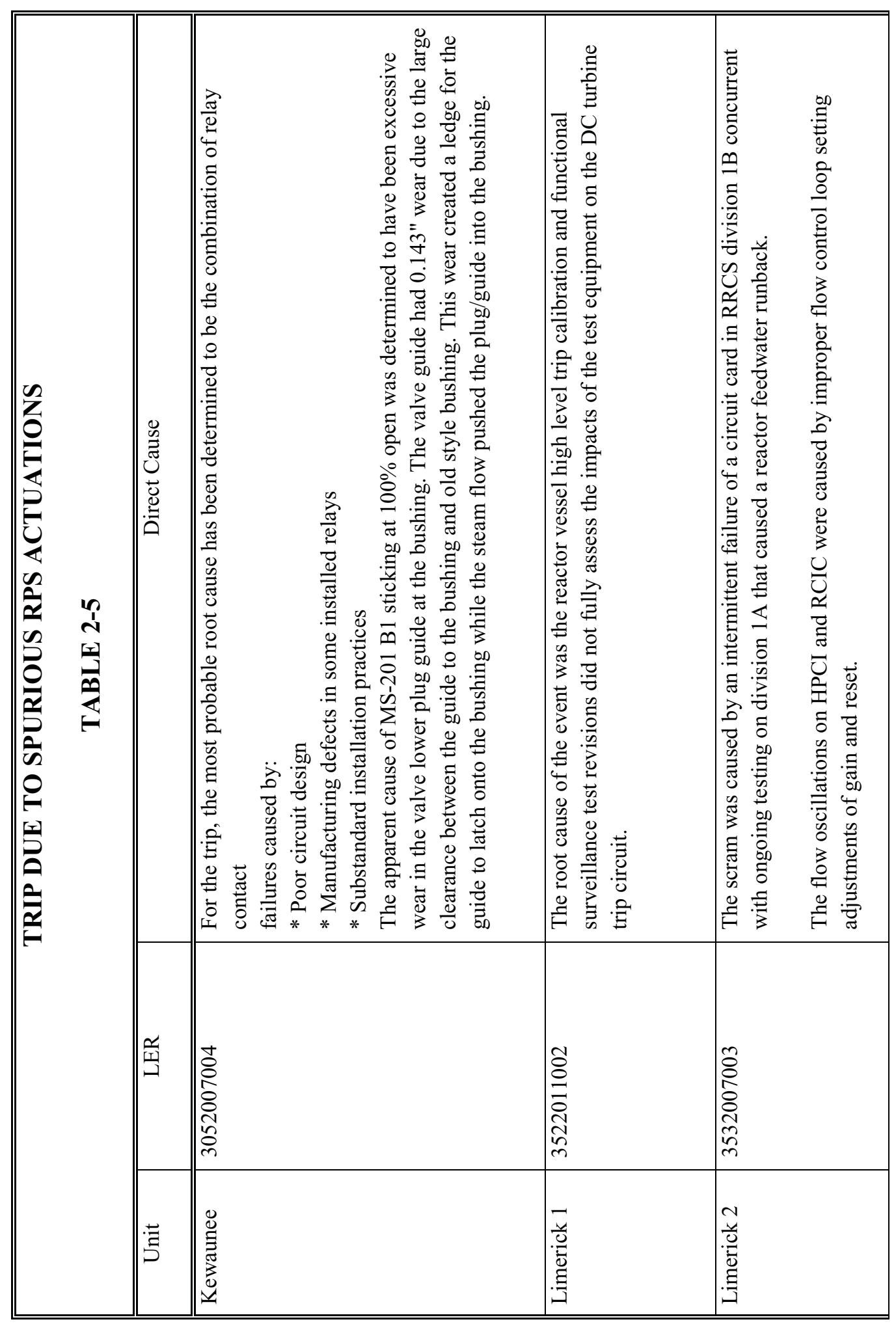




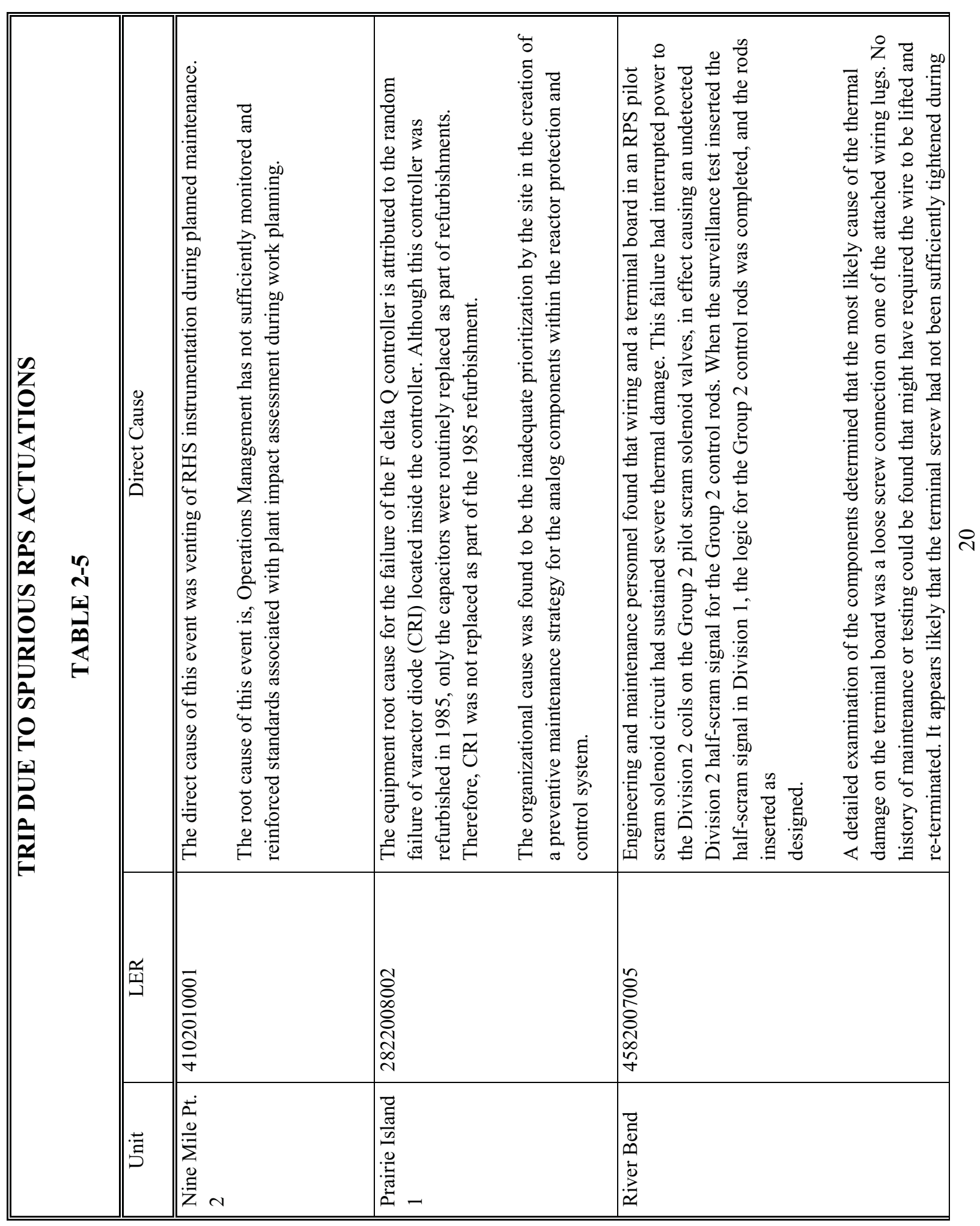




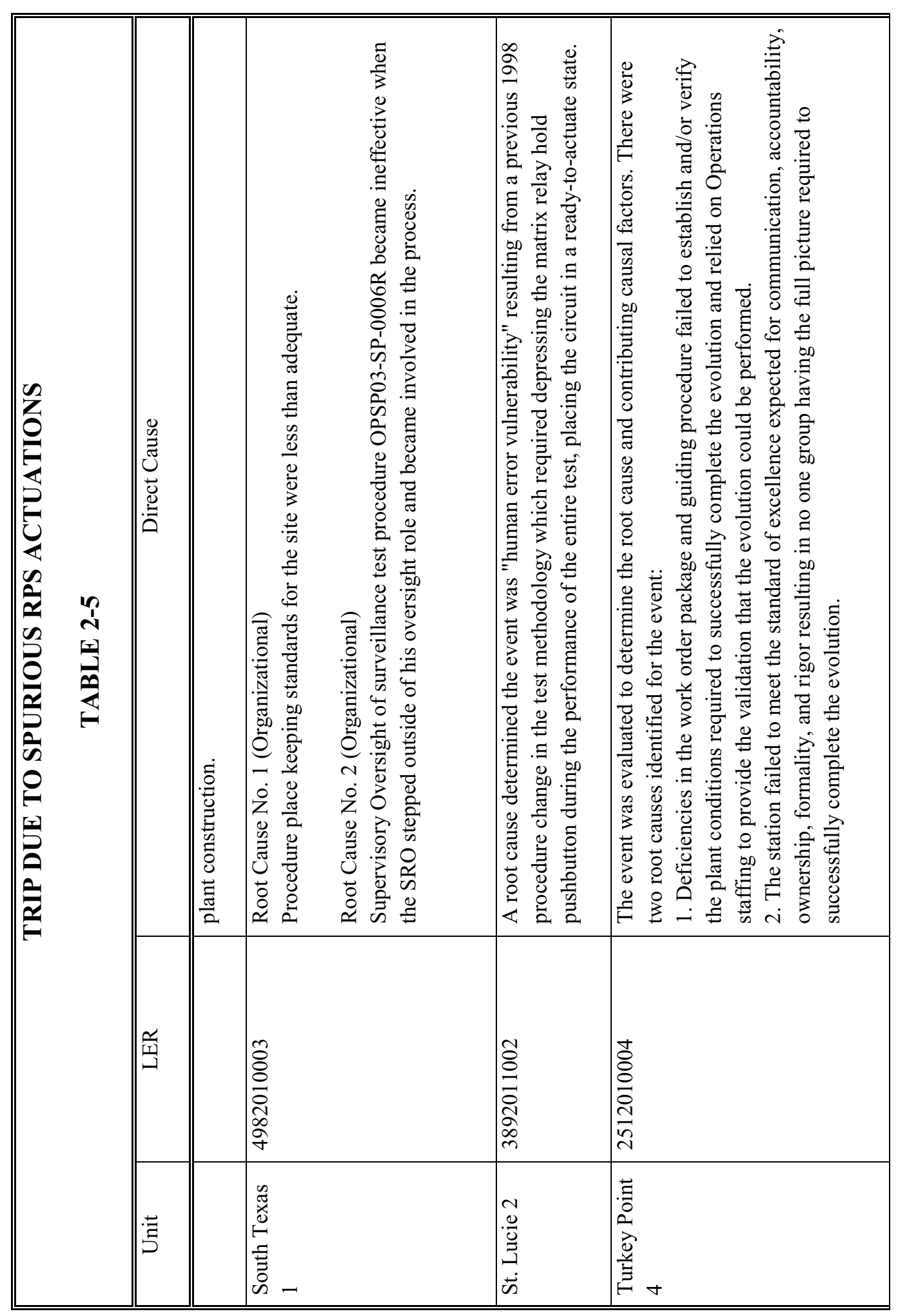




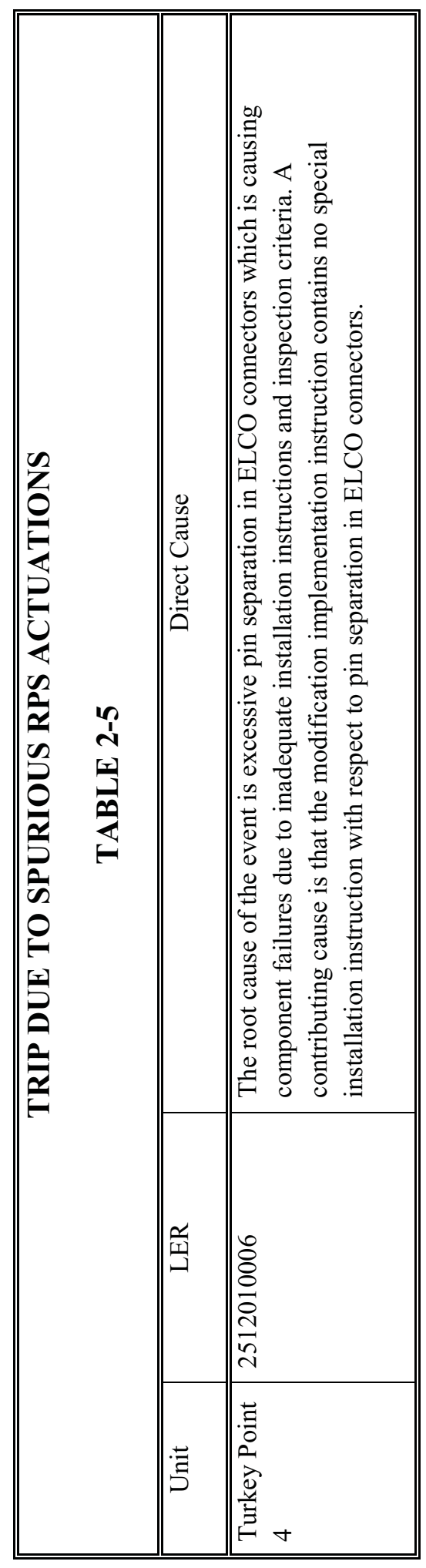

N 


\section{Advantages of Automation of Manual Actions}

In the early days of this generation of plants, a manual response was probably necessitated by the high cost of automation due to hard-wired, analog systems, which couldn't distinguish between a component failure and a sensor failure. The point of this project is to identify those situations where modern automation technology can provide a much better response to these situations.

Executing procedural actions is a slow deliberate process. Response to off-normal conditions typically begins with the response to a control room alarm. Depending on the type of alarm, it may take some time to diagnose the condition which may include dispatching an operator to conduct a local inspection of the alarming condition. Once the condition has been diagnosed the appropriate procedure needs to be referenced. All of the procedure prerequisites must be confirmed as being met. Then the procedurally described actions may be completed.

Some typical actions that may be taken in response to an off normal condition include things like swapping the controlling channel, verifying by alternate indication that a sensor has failed, putting standby equipment in service, taking manual control of pumps and valves to control flow rates, swapping to alternate sources of power, water, instrument air, etc.

Conducting manual actions in response to an off-normal condition is an error likely process. In the course of conducting the procedure, there may be steps that are missed or perhaps steps that are executed out of sequence. The procedure itself may contain latent errors that lead to adverse results. Reverting to manual control may present the operator a situation that is not often encountered. This could lead to inadequate control of the process. For example, feedwater control is not an intuitive process. A number of factors such as reactor coolant system temperature, power level, steaming rate and feedwater temperature play a role making manual control difficult. Implementing an automated process to replace manual conduct of procedural actions could improve the time efficiency and reduce errors related to accomplishing the task.

The reactor trips that were included in the review can be divided into two categories. One category is where the reactor trips with essentially no prior warning to the control room operators. This is frequently the case where a test or maintenance activity initiates the trip. A second category is where the control room operator is alerted to an off-normal condition, typically by a control room annunciator, and may attempt to take compensatory actions to avoid the reactor trip. A preliminary assessment of the LERs identified 70 of 95 trips where there was at least a small amount of time for operator response. 
Many equipment failures are not specifically addressed by procedures or the technical specifications. Table 3-1 shows the manual actions identified in the evaluated LERs that were necessary to accommodate an equipment failure. Two of the events required manual isolation of the moisture separator reheater steam supply to limit the cooldown of the primary system. Two events required manual operation of the HPCI and/or the RCIC systems due to observed flow oscillations. One event caused a momentary loss of some non-1E 120 volt loads as a result of transfer of power between transformers. The momentary loss of power caused 4 steam dump valves to not open as quickly as needed. During another event, a moisture separator reheater drain valve failed to close and had to be closed manually (its backup did close). One event involved a turbine driven auxiliary feedwater pump to trip shortly after a successful automatic start. And finally, during one event, it was necessary to manually close the main steam isolation valves to control the primary system cooldown. 


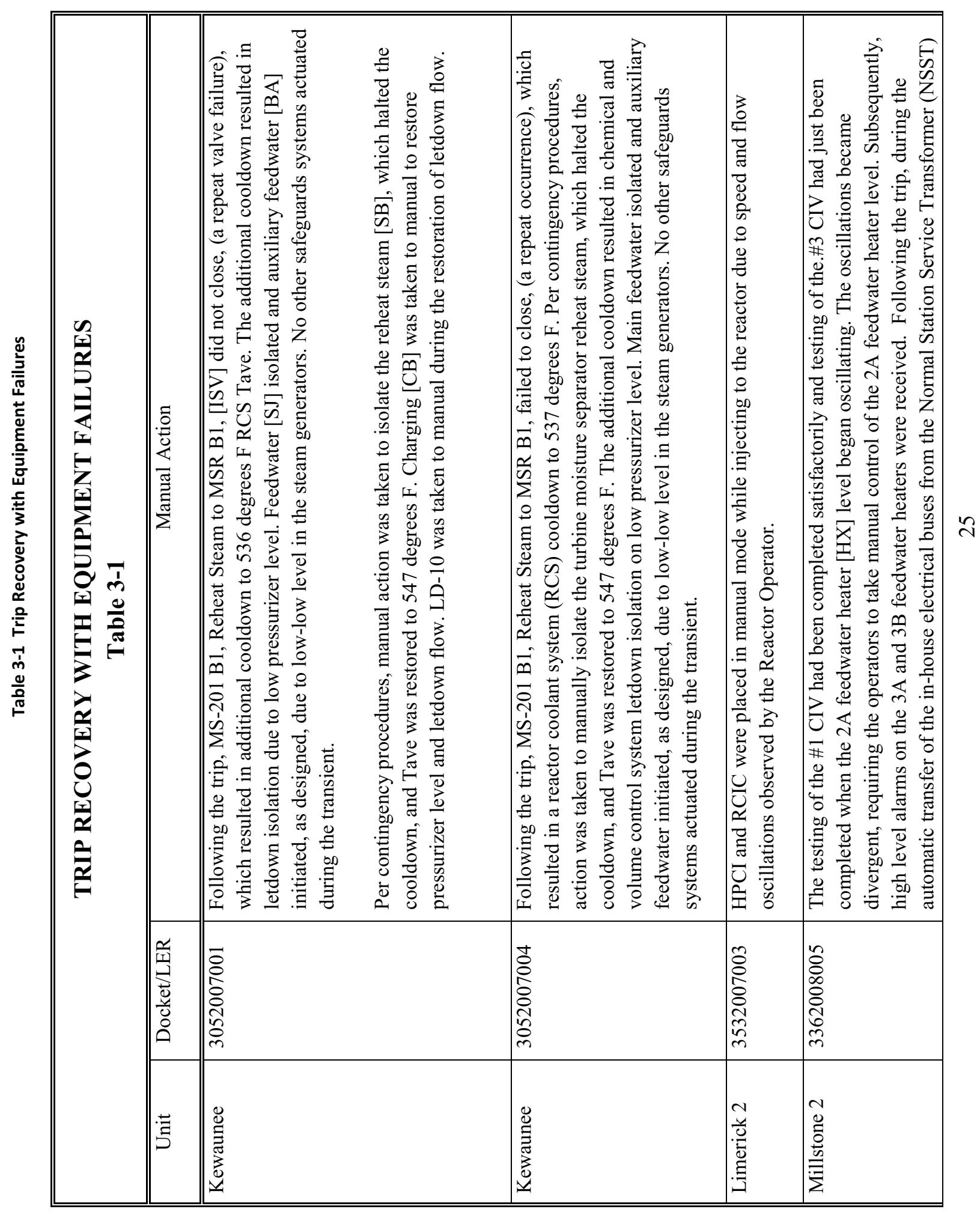




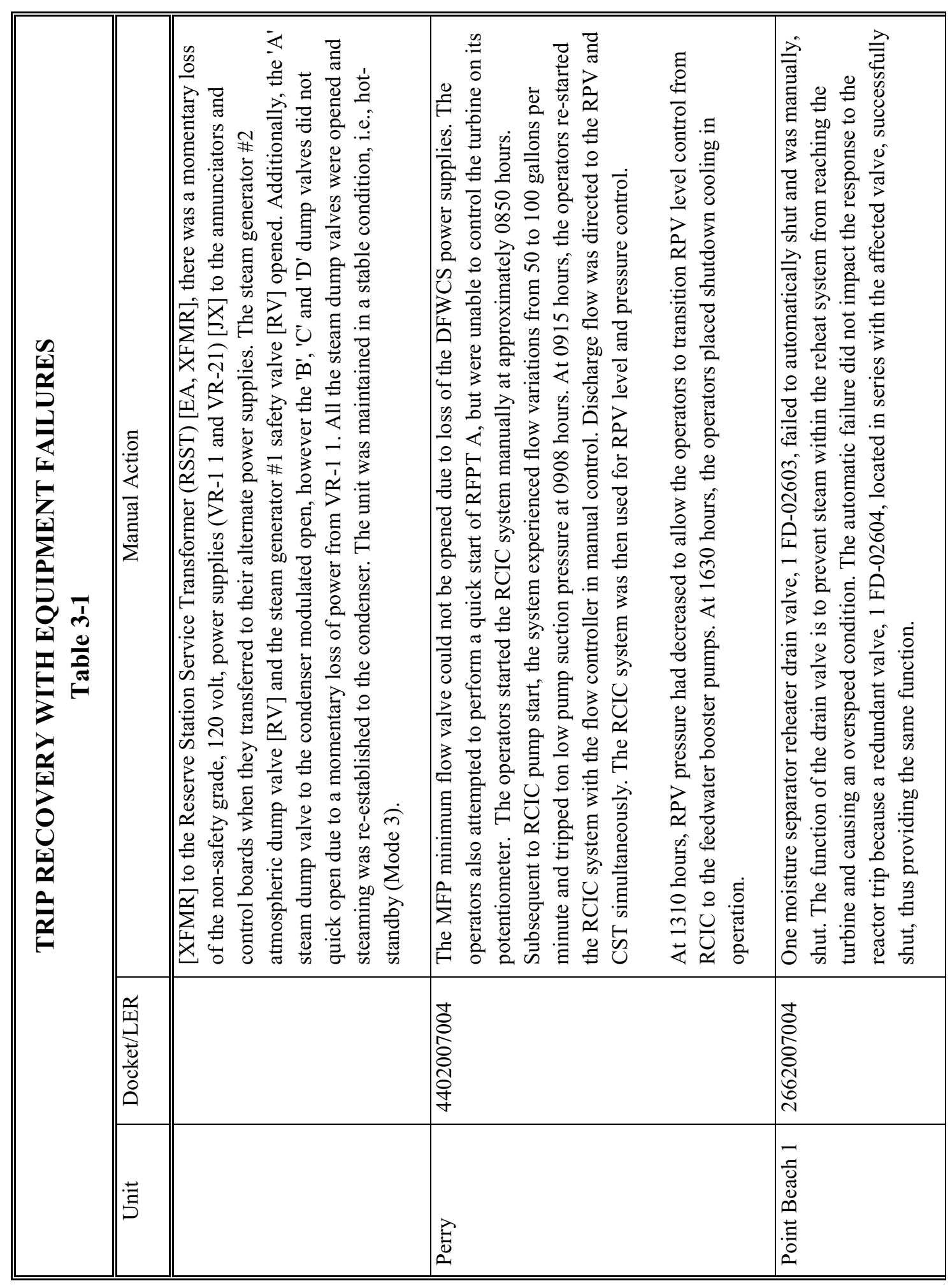

ง 


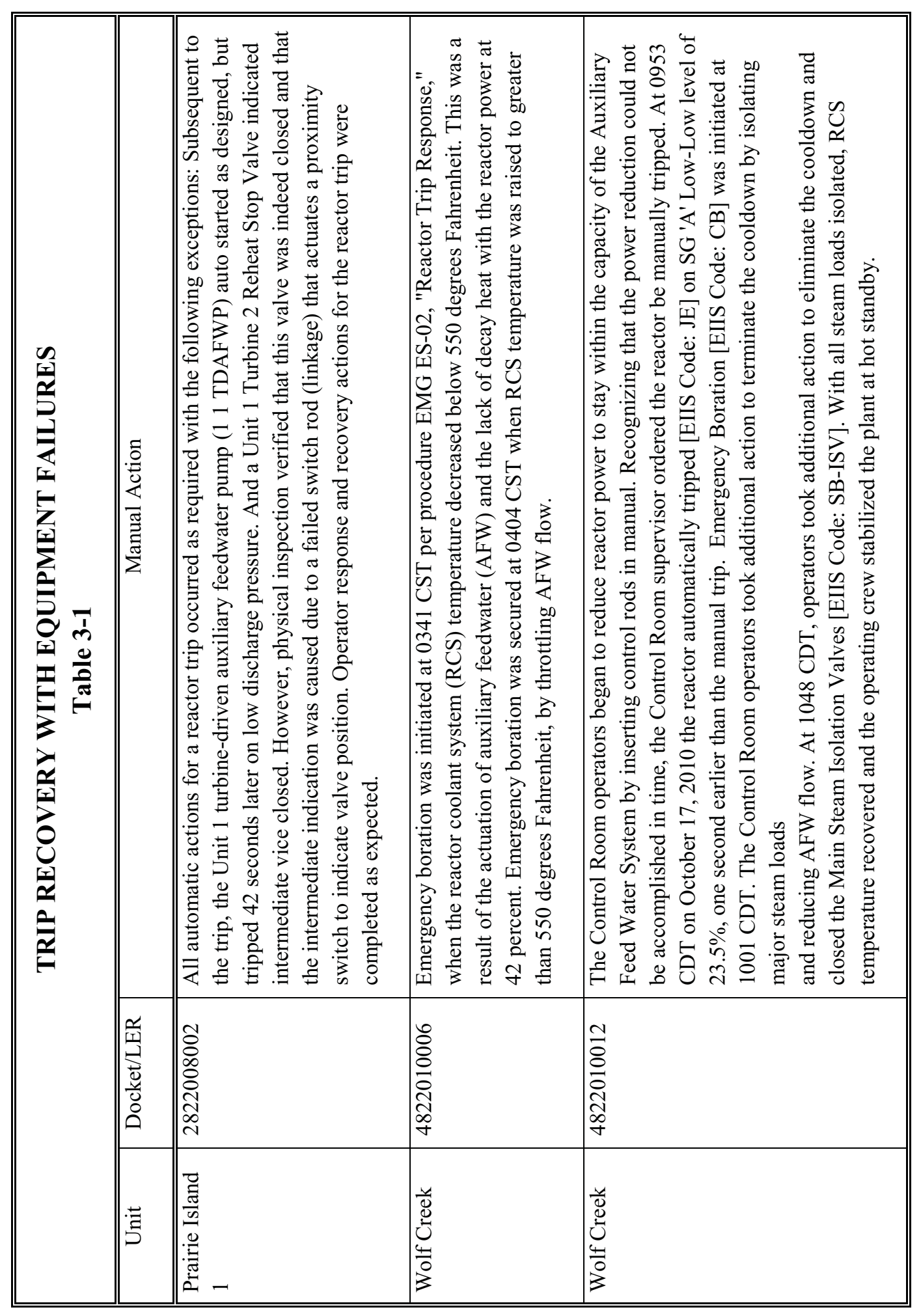

ก 


\section{How Automating Response/Recovery Would Improve Success}

Automating the response of a unit to off normal conditions could potentially improve plant reliability by avoiding some reactor trips. Those trips where there was no advance indication to the control room operator are not candidates for a recovery response since there is no time to conduct any mitigating actions. However, over $70 \%$ of the evaluated LERs provided at least a small amount of time for mitigating the event.

In addition to having some time to execute mitigating actions, the means to implementing the actions must also be available. For example, if there is a failure in the air supply or control equipment to a feed regulating valve, there is no alternative system available to take mitigating actions in the required time frame. If the time and means are available automated response to some off normal conditions could be successful in avoiding reactor trips.

Automation of the diagnosis of plant conditions could improve the accuracy of the diagnosis of adverse conditions and improve the timeliness of response to off normal conditions.

\section{Candidates for Automation to Improve Success}

There are a number of opportunities to reduce the number of reactor trips. There are a range of actions that may be taken to automate the response to an off normal condition. With current technology, the health of sensors can be diagnosed and switching to an alternate sensor can be built into the design. Likewise, alternate electrical power or air supplies can be monitored and automatic transfer can be designed in the event of an upset condition with the primary.

Focusing on the primary contributors to trips provides the best opportunity for success. From Table A-1, of the 99 identified causes of reactor trips, 56 were related to the feedwater system. Additionally, 7 were related to the condensate system where the trip occurred due to the resulting impact on the feedwater system. Of the 96 events, manual operator actions were identified in the LERs in 47 of the events. Table 5-1 lists the manual operator actions that are identified in the evaluated LERs either prior to the reactor trip and/or following the reactor trip. 
Table 5-1 Manual Operator Actions

\begin{tabular}{|c|c|}
\hline \multicolumn{2}{|l|}{$\begin{array}{l}\text { MANUAL OPERATOR ACTIONS } \\
\text { Table 5-1 }\end{array}$} \\
\hline Operator Action & Events \\
\hline "Manually controlled AFW & 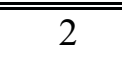 \\
\hline Manually operated charging and letdown & 2 \\
\hline Initiated emergency boration & 2 \\
\hline Tripped main turbine & 1 \\
\hline Manually secured condensate pump & 1 \\
\hline Manually initiated safety injection & 1 \\
\hline Manually operated feedwater bypass valve & 2 \\
\hline Manually operated main feedwater valve & 16 \\
\hline Manually tripped main feedwater pump & 2 \\
\hline Manually operated main feedwater pump turbine & 5 \\
\hline Manually controlled feedwater heater level & 1 \\
\hline Manually operated steam bypass system & 1 \\
\hline Manually operate high pressure coolant injection & 1 \\
\hline Manually operated MSIVs & 1 \\
\hline Manually isolated moisture separator reheater & 1 \\
\hline Manually operated nuclear instrumentation & 1 \\
\hline LER specifically stated no operator action & 2 \\
\hline LER did not specifically identify an operator action & 49 \\
\hline Manually operated reactor core isolation cooling & 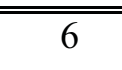 \\
\hline Manually operated reactor recirculation system & 3 \\
\hline Manually operated electromatic relief valves & 1 \\
\hline Manually started stator cooling water pump & 1 \\
\hline
\end{tabular}

Some candidate opportunities to reduce the frequency on reactor trips are redundant feedwater controls, automated response to a feedwater or condensate pump trip reducing 
power vice a reactor trip, and elimination of air operators for the feedwater control valves or providing redundant air supplies.

\section{$\underline{\text { Redundant Feedwater Control }}$}

The feedwater control system was identified as a cause of 27 reactor trips over the evaluation period. Twenty-three of those trips were due to a problem related to the electronic control system. A redundant electronic control system for each feedwater control valve offers a means for avoiding the majority (if not all) of the reactor trips from this cause. Some nuclear units have implemented redundant feedwater control.

\section{Improved Feedwater Regulating Valve Operators}

Most feedwater control valves utilize an air operator to position the valve. This requires an air supply, a pressure regulator, a current to pressure converter, and the air operator. These air components caused 8 trips over the evaluation period. A potential improvement is to replace the air components with an electric valve positioner. An electric positioner equipped with redundant power sources and electronic controls has the potential to significantly reduce trips caused by feedwater regulating valve air operator issues. Another possibility is to provide redundant air supply components with an automatic switchover when signal and air pressure do not match.

\section{Improved Feedwater Pump Turbine Control}

Similar to the opportunities to improve feedwater valve control, implementation of redundant electronic feedwater pump turbine control and/or electric governor valve positioning has the potential for reducing nuclear unit trips. From Table A-1, 4 reactor trips were caused by electronic feedwater pump turbine control and two were caused by hydraulic components in the feedwater pump turbine speed control system.

\section{Automated Response to Feedwater Pump Trip}

An alternative (or compliment) to changes to the feedwater turbine controls is to automate the response of the feedwater system to a feedwater pump trip. Most nuclear units operate with control rods fully withdrawn. A consequence of this strategy is that reactor power reduction is slow when control rods are inserted until they reach a significant amount of rod insertion. The significant obstacles to achieving the ability to reliable operate through a feedwater pump trip are to maintain steam generator level control and to control primary system temperature while bringing reactor power and the steam demand into balance. An integrated feedwater control system that can automatically lower power (turbine runback for PWRs, recirculation pump runback for BWRs) could prevent the a number of scrams from this group. 


\section{$\underline{\text { Reduction of Spurious Reactor Protection System Trips }}$}

After feedwater events, trips of the reactor protection system account for the most reactor trips over the evaluation period. Since reactor protection systems are not control systems, automation is not a prime option to reduce trips. The overwhelming majority of the RPS trips occurred during maintenance or testing. There are several potential changes that would likely be effective in reducing the number of spurious RPS trips. Some plants are conducting analyses necessary to extend the surveillance interval for the reactor protection system periodic testing. Utilizing probabilistic risk assessment tools, it may be possible to significantly increase the required surveillance test intervals for reactor protection systems.

Of the 16 trips associated with reactor protection systems, 5 occurred due to a pre-existing unknown half trip condition. It may be possible to install an automatic indication of a half trip condition so that the failed component could be repaired prior to performing a trip test on an alternate channel. 


\section{6. $\quad$ Task 2: Identify Issues and Approaches Associated with Runback to House Load on Loss-of-Load}

This task explores the issues and possible approaches for improving the capability of the current operating nuclear fleet to successfully run back to house load following a loss-of-load or load rejection event. A successful runback avoids tripping the reactor subsequent down-time of approximately two days before the unit can be back in service and providing power to the grid. It is desired for the unit to be reconnected to the grid rapidly following the runback to prevent minor grid disturbances from expanding into major grid disturbances like the grid collapse of 2003.

The current operating nuclear fleet has varying capabilities to successfully run back to house loads following load rejection events. Some designs are already fully capable, and other designs would require significant designs changes to reach an equivalent capability. The design features that enhance or limit that capability are identified, and the opportunities to modify the plant designs to achieve the desired load rejection capability are discussed. A primary issue is to determine any impact on nuclear safety, which involves performing analyses to evaluate the impact of any proposed design changes on the regulatory requirements established by the NRC. The cost of designing and installing the design changes, performing the required analyses, and obtaining NRC approval, would then need to be evaluated against the benefit of the increased capability to handle a load rejection and avoid contributing to major grid disturbances.

\section{Loss-of-Load Transients}

\subsection{Types of Loss-of-Load Scenarios}

The scenarios categorized as loss-of-load transients include all those initiating events, along with consequential responses of plant components that result in the separation of the electrical output of the main electrical generator from the offsite grid. This includes loss of the offsite electrical grid itself, commonly referred to as a loss-of-offsite-power (LOOP), as well as failures of components in the plant switchyard (transformers, busses, switchgear, etc), and failures resulting in opening of the main generator breakers. These loss-of-load transients may occur at full power or at partial power, and with different switchyard configurations. Because the most probable initial condition for these events is full power with the normal plant configuration, that scenario is the main focus of this study. 


\subsection{Advantages of Successful Runback}

The capability for a plant to successfully run back to house load following a load rejection has many advantages:

- Nuclear safety will be enhanced

- Avoids potential consequences that begin with a reactor trip initiating event

- The probability risk assessment (PRA) will not be adversely affected

- Fewer challenges to plant safety systems

- Loss of generation will be minimized

- The time lost to recover from a reactor trip will be avoided

- Reduced regulatory requirements and interactions

- No event investigation and review

- Grid stability will be enhanced with less time required to reconnect a unit to the grid that has run back to house loads

- Capacity factors are increased if generation remains on-line

\subsection{PWR Design Basis Loss-of-Load Safety Analysis}

The PWR loss-of-load event is an anticipated operational occurrence (AOO) as defined in Appendix A to Part 50, "General Design Criteria for Nuclear Power Plants". The NRC guidance for performing the safety analysis for the loss-of-load event is provided in the Standard Review Plan (NUREG-0800), Section 15.2.1, "Loss of External Load". For AOOs the following acceptance criteria are specified:

- The specified acceptable fuel design limits (SAFDLs) are not exceeded

- The centerline fuel melting (CFM) temperature is not exceeded

- The minimum departure-from-nucleate boiling ratio (DNBR) is not exceeded

- The cladding strain limit is not exceeded

- The peak primary system pressure does not exceed $110 \%$ of the design limit

- The peak secondary system pressure does not exceed $110 \%$ of the design limit

The safety analysis is performed by simulating the plant response to all loss-of-load scenarios with a system thermal-hydraulic analysis code, and is presented in UFSAR Chapter 15. In these simulations conservative assumptions are used for the plant initial conditions and the response of plant systems and components so that an overall conservative result is assured. No credit for non-safety grade plant control systems is allowed, so the safety analysis is not typical of the actual expected plant response to a loss-of-load event. The main purpose of the safety analysis is 
to demonstrate that the fuel and pressure boundaries are protected by the safety-grade equipment, which typically consists of the following:

- The Reactor Protection System (prevents fuel failure by dropping all control rods / prevents over pressurization by limiting the heat source)

- The Reactor Power Cutback System (prevents fuel failure by dropping select control rods / prevents over pressurization by limiting the heat source - only installed in some CE plants)

- The pressurizer code safety valves (prevents primary system over pressurization)

- The secondary code safety valves (prevents secondary system over pressurization)

- The Auxiliary Feedwater System (prevents fuel failure and primary system over pressurization by providing decay heat removal)

For the loss-of-load event the Reactor Protection System trip functions that protect the fuel and the pressure boundaries can include the following depending on the specific plant design:

- A reactor trip on loss-of-load or due to a turbine trip caused by the loss-of-load. This type of trip function is typically enabled above a reactor power level for which the plant design cannot survive a loss-of-load without some other reactor trip occurring subsequently. For example, a plant with a steam dump capacity of $50 \%$ cannot handle a loss-of-load greater than 50\% (or above an initial power level of 50\%), and so an immediate reactor trip will occur on this trip function for those events.

- A reactor trip on high primary system pressure (i.e. pressurizer or hot leg pressure). This trip function is necessary to protect the primary and secondary pressure boundaries.

- A reactor trip on over-temperature $\Delta \mathrm{T}$ or over-power $\Delta \mathrm{T}$ (for Westinghouse PWRs). These trip functions protect the fuel from centerline fuel melt (CFM) and departurefrom-nucleate-boiling (DNB), which are the two main safety concerns for protecting the fuel cladding during AOOs. Should CFM occur the cladding will potentially fail from excessive thermal expansion of the fuel pellet, which overstresses the cladding causing it to crack open. Should DNB occur the cladding temperature will potentially fail from overheating, due to the heat transfer from the cladding surface degrading as it transitions from efficient nucleate boiling to inefficient film boiling. DNB can occur from an adverse combination of heat flux, temperature, flow, and pressure.

- Other reactor trip functions designed to protect the fuel from failure due to exceeding the CFM and the DNBR limits (CE design plants with and without the Core Protection Calculator (CPC) digital trip functions). 


\subsection{BWR Design Basis Loss-of-Load Safety Analysis}

The NRC guidance for performing the safety analysis for the loss-of-load event is provided in the Standard Review Plan (NUREG-0800), Section 15.2.1, "Loss of External Load", and 15.2.6 "Loss of Nonemergency AC Power to the Station Auxiliaries". For AOOs the following acceptance criteria are specified:

- The specified acceptable fuel design limits are not exceeded

- The centerline fuel melting (CFM) temperature is not exceeded

- The critical power ratio (CPR) is not exceeded

- The cladding strain limit is not exceeded

- The peak primary system pressure does not exceed $110 \%$ of the design limit

As with the PWRs, the safety analysis is performed by simulating the plant response to all lossof-load scenarios with a system thermal-hydraulic analysis code, and is presented in UFSAR Chapter 15. Conservative assumptions regarding initial conditions, trip set points and delays and single failures and no credit is taken for non-safety grade plant control systems. These analyses demonstrate that the transients do not violate the NUREG- 800 acceptance criteria.

NUREG-0800, Section 15.2.1 describes a loss-of-load event caused by an electrical disturbance that can cause a significant drop in load demand. For this transient, AC power remains available to operate plant equipment and components. Emergency diesel power is no not needed.

NUREG-0800, Section 15.2.6 describes a complete loss of load due to the loss of AC power. The loss of AC power triggers a reactor trip.

\section{Pressurized Water Reactors}

\subsection{Desired PWR Plant Response}

The desired plant response following a loss-of-load is for the unit to initiate a plant runback to house electrical loads with the turbine on-line (in the range of $10-15 \%$ power), while avoiding exceeding any of the reactor or turbine trip set points. A plant runback consists of a reactor runback - an automatic insertion of control rods to reduce the thermal energy source, and a turbine runback - an automatic closure of the main turbine control valves to reduce the steam flow to the turbine so that the house electrical load is attained. Steam relief to the main condenser and to the atmosphere is used to balance the energy transfer. Pressurizer spray and PORV actuation limits the primary pressure and improves the capability to avoid the high pressure reactor trip setpoint. In addition, both the primary and the secondary systems 
temporarily function as heat sinks until the energy transfer can be balanced. The imbalance of the energy transfer is what causes the reactor and turbine trip set points to be approached. Many plant systems and components must respond as designed in a coordinated manner for the plant to successfully run back and handle the loss-of-load events. The load rejection capability of the operating fleet varies due to differing designs and margins, with all designs capable of withstanding partial load rejections, and some designs including full load rejection capability. The safety analysis of the plant response to a load rejection must demonstrate that the primary and secondary peak pressure limits are not exceeded, and that the DNBR limit is not exceeded. Load rejection capability has not been a focus of the industry. Reactor power uprates, which are a focus of the industry, reduce the load-rejection capability.

\subsection{Overview of Loss-of-Load Transient for Various Plant Designs}

The typical response of a pressurized water reactor to a loss-of-load initiating event would consist of the following sequence of events. (Note that for some designs and above certain power levels a loss-of-load may result in an immediate reactor trip and the following sequence of events is not applicable):

- The load rejection event is detected by various sensors

- The load rejection mitigation circuitry is actuated, and plant alarms actuate

- The main generator output is transferred to provide house loads

- The loss of electrical energy transfer from the main generator causes the turbine speed to increase (mechanical energy stored in turbine/generator)

- The turbine control (governor) valves close (turbine runback) to maintain turbine speed at setpoint (e.g. $1800 \mathrm{rpm}$ )

- The steam generator pressure increases due to the turbine control valve closure (thermal energy stored in the secondary system)

- The control rods insert (reactor runback) to reduce reactor power (reduce thermal energy input to primary system)

- The primary system temperature and pressure increases (thermal energy stored in primary system). Pressurizer spray and PORVs actuate to mitigate the pressure increase.

- The secondary steam relief systems actuate due to increasing main steam pressure and/or increasing primary temperature (reduce thermal energy stored in secondary system). These systems include

- Steam dump to the main condenser (turbine bypass)

- Steam dump to atmosphere 
Main feedwater pump speed and control valves are adjusted to match demand

- Control systems (main turbine control, feedwater control, steam dump control, reactor control, and primary pressure control) continue to respond by balancing heat sources and heat sinks to stabilize the unit at house electrical load.

- Some operator actions may occur to optimize control of the plant and to respond to off-normal situations

- The operator can respond to identified system and component malfunctions by taking manual control

- Training experience on the control room simulator and associated procedure revisions for loss-of-load events can include specific manual actions to enhance unit continuity and stability (e.g. manual control of main feedwater system and steam dump system; manual control of main turbine; manual insertion of control rods; manual actuation of pressurizer PORVs)

The typical response of a pressurized water reactor as described above is discussed further based on the major design differences within the fleet for the following six plant design categories:

\section{Westinghouse 4-Loop Design}

The Westinghouse 4-loop plant was designed with the intent of providing a $100 \%$ load rejection capability provided that sufficient secondary steam relief capacity exists. For some plants this capability does not exist and a loss-of-load above a specific power level will result in an immediate turbine and reactor trip. The initial power level for which a high pressure reactor trip would occur is the basis for the turbine and reactor trip on loss-of-load. The design includes a secondary steam relief capacity that combines steam dump to the main condenser, steam dump to atmosphere for the express purpose of enhancing load rejection capability, and steam dump to the atmosphere through the steam line PORVs. The main steam code safety relief valves are not expected to actuate for a load rejection event. The steam dump valves are actuated in a staggered manner based on a primary temperature deviation signal. The control rods are inserted with a variable insertion speed based on a temperature deviation signal. The pressurizer PORVs (two or three) are actuated based on a pressure setpoint or a temperature deviation signal, and provide a significant pressure relief capacity to prevent reaching the high pressure reactor trip setpoint. The over-temperature $\Delta \mathrm{T}$ and over-power $\Delta \mathrm{T}$ reactor trip functions are expected to be the trip functions that limit the operating continuity of the plant following a load rejection event. In addition, there are reactor trip set points on low voltage and low frequency on the $6900 \mathrm{~V}$ supplies to the reactor coolant pump motors. If a loss of load causes a decrease in voltage or frequency below the trip set points the reactor will trip. The objective is for the runback to successfully stabilize the plant at house electrical loads with the turbine on-line (10-15\% power). 


\section{Westinghouse 3-Loop Design}

The Westinghouse 3-loop plant was designed with the intent of providing a $100 \%$ load rejection capability provided that sufficient secondary steam relief capacity exists. For some plants this capability does not exist and a loss-of-load above a specific power level will result in an immediate turbine and reactor trip. In addition, the time-in-cycle has a strong influence on the capability to handle a load rejection due to the negative reactivity resulting from the moderator temperature coefficient (MTC). Later in cycle the MTC is more negative and the load rejection capability is enhanced. The negative MTC assists with the reactor runback by adding negative reactivity due to the coolant temperature in the reactor increasing following the load rejection. The turbine runback rate is $\sim 10 \% / \mathrm{min}$. The design includes a secondary steam relief capacity that combines steam dump to the main condenser $(\sim 50 \%)$, steam dump to atmosphere for the express purpose of enhancing load rejection capability $(\sim 20 \%)$, and steam dump to the atmosphere through the steam line PORVs $(\sim 20 \%)$. The main steam code safety relief valves are not expected to actuate for a load rejection event. The steam dump valves are actuated in a staggered manner based on a primary temperature deviation signal. The control rods are inserted with a variable insertion speed based on a temperature deviation signal. The reactor runback rate is $\sim 5 \% / \mathrm{min}$. The pressurizer PORVs (two or three) are actuated based on a pressure setpoint or a temperature deviation signal, and provide a significant pressure relief capacity to prevent reaching the high pressure reactor trip setpoint. The over-temperature $\Delta \mathrm{T}$ and over-power $\Delta \mathrm{T}$ reactor trip functions are expected to be the trip functions that limit operating continuity following a load rejection event. The design process for these two set points allows the margin to be allocated on a plant-specific basis, and so either trip may be the limiting trip. In addition, there are reactor trip set points on low voltage and low frequency on the $6900 \mathrm{~V}$ supplies to the reactor coolant pump motors. The low frequency trip function protects the fuel against a reduction in core flow (and the potential for fuel failure caused by DNB) due to the reactor coolant pump motors slowing down as frequency decreases. If a loss of load causes a decrease in voltage or frequency below the trip set points the reactor will trip. The objective is for the runback to successfully stabilize the plant at house electrical loads with the turbine on-line (10$15 \%$ power).

\section{Westinghouse 2-Loop Design}

The Westinghouse 2-loop plant is designed with the intent of providing a 50\% load rejection capability. An automatic reactor trip will result for load rejections larger than 50\%. The high pressure, over-temperature $\Delta \mathrm{T}$, and over-power $\Delta \mathrm{T}$ reactor trip functions are the trip functions that limit the operating continuity following a load rejection event. In addition, there are reactor trip set points on low voltage and low frequency on the $6900 \mathrm{~V}$ supplies to the reactor coolant pump motors. If a loss of load causes a decrease in voltage or frequency below the trip set points the reactor will trip. 


\section{Combustion Engineering Design With RPCS}

The Combustion Engineering plant design has full load rejection capability using the Reactor Power Cutback System (RPCS). The RPCS senses a load rejection and drops one or more preselected control rod groups into the reactor (i.e. partial reactor trip) to effect a step reduction in reactor power level. The turbine initiates a runback and excess steam is dumped to the main condenser and to the atmosphere, with a total steam dump capacity of approximately $80 \%$ of full steam flow. The secondary safety valves do not open for a load rejection when the steam dump system functions correctly. The objective of the design following a load rejection is to stabilize the plant at $60 \%$ reactor power with steam dump to the condenser. The reactor is protected by the high pressure trip and the DNBR trip, but these should not actuate. There is also a reactor trip on low reactor coolant pump speed with a setpoint of $95 \%$ of nominal speed. Note that this design has pressurizer spray but does not include PORVs.

\section{Combustion Engineering Design Without RPCS}

The Combustion Engineering Design without RPCS will experience an automatic reactor trip if the load rejection exceeds the steam dump capacity. Therefore, this design cannot survive a full load rejection as the steam dump capacity is typically 50\%. The other design features are similar to the with RPCS design.

\section{Babcock \& Wilcox Design}

The Babcock \& Wilcox (B\&W) plant was originally designed with significant load rejection capability due to the fast-responding Integrated Control System (ICS). A plant runback at $20 \% / \mathrm{min}$ is initiated following a load rejection. The secondary steam dump to condenser capacity is nominally $25 \%$ of full main steam flow, with additional secondary ADVs/PORVs installed at some plants. Following the accident at TMI-2 the NRC mandated a design change that has essentially defeated load rejection capability. The high pressure reactor trip setpoint was lowered, and the pressurizer PORV actuation setpoint was raised, such that a load rejection above $40-55 \%$ power will now cause a high pressure reactor trip, and the PORV open setpoint will not be challenged. There is also a reactor trip on low power to the reactor coolant pump motors. 


\subsection{Limitations in Current Designs}

Westinghouse 4-Loop Design

The Westinghouse 4-loop design has a reactor trip based on turbine trip above a certain power level, and a turbine trip will occur on a load rejection that exceeds its steam dump capacity. Therefore, the steam dump capacity is limiting for 4-loop plants. Also, the reactor runback rate is limiting.

\section{Westinghouse 3-Loop Design}

The Westinghouse 3-loop design is limited by the reactor runback rate during the earlier part of the fuel cycle when the MTC is not sufficiently negative.

\section{Westinghouse 2-Loop Design}

The Westinghouse 2-loop design is limited by the steam dump capacity.

\section{Combustion Engineering Design With RPCS}

The Combustion Engineering design with RPCS does not have any limitations and has the capability to survive large load rejections without a reactor trip. However, it is necessary to manually down power the unit to allow the main turbine to be re-synchronized properly before reconnecting to the grid.

\section{Combustion Engineering Design Without RPCS}

The Combustion Engineering design without RPCS is limited by the steam dump capacity, in addition to the absence of the RPCS.

\section{Babcock \& Wilcox Design}

The B\&W plants were required by NRC to lower the high pressure reactor trip setpoint, and raise the pressurizer PORV setpoint following the TMI-2 accident. This design change has restricted the loss-of-load capability to a range of $40-55 \%$ initial power, or a partial load rejection of approximately $50 \%$. The NRC would need to agree to delete this requirement for any improvement in load rejection capability for the $\mathrm{B} \& \mathrm{~W}$ design. Obtaining NRC agreement is expected to be difficult due to the impact of increasing challenges to the PORV and the associated impact on the PRA. 


\subsection{Discussion of Probability of Success in Runback to House Loads}

For the current plant designs only the large CE plants with the power cutback system, and the Westinghouse plants with large steam dump capacity, have a capability to handle a large load rejection. Other designs can only handle partial load rejections.

\section{Complications of Concurrent Equipment Failures}

The three control functions that must perform correctly for a plant to handle a load rejection are the rod control system (or the RPCS for those CE design that have installed it), the steam dump system, and the pressurizer pressure control systems. As stated above, only certain plants can survive a full load rejection. Concurrent equipment failures in any of these three control functions would likely result reactor trip following a large load rejection.

\section{Possible Control Changes That Would Improve Success}

The RPCS (partial reactor trip) design employed in the CE design would significantly improve the capability to survive load rejections in the other designs, provided that sufficient steam dump capacity exists. Without the power cutback feature a design change to increase the reactivity insertion rate (faster rod insertion speed and/or higher differential control rod worth) would improve the plant response to load rejections. A faster rod insertion speed may or may not be possible with the existing control rod drive mechanisms. A higher differential control rod worth may be possible by grouping the control rods differently so that more rods or higher worth rods are in the control bank that is inserted when a load rejection is detected.

Optimization of the steam dump system may also be possible, such as designing an anticipatory strategy focused on load rejection capacity rather than simple secondary pressure control or simple primary temperature control.

Optimization of the feedwater control system may be possible, such that feedwater pump speed and control valve position, and the resulting steam generator inventory, would be better matched to the reactor heat generation during the reactor runback. This would assist in preventing a reactor trip on high pressure, and would also prevent a reactor trip on the trip functions that protect the fuel from DNB.

For the Westinghouse plants the turbine/reactor trip setpoint on loss of load could be optimized based on the time-in-cycle (by incorporating the MTC variation into the design), and with consideration for the end-of-cycle T-ave reduction (or reduced T-ave operation). Other optimizations of the over-power $\Delta \mathrm{T}$ and over-temperature $\Delta \mathrm{T}$ trip set points may be possible for Westinghouse plants. These trip functions set points can be set in various combinations to 
provide margin for various purposes, such as to avoid turbine runback on high $\Delta \mathrm{T}$ caused by hot leg temperature spiking. The potential benefit of a certain combination of $\Delta \mathrm{T}$ set points to enhance load rejection capacity can be studied. However, any change will cause a loss of margin that may affect safety analyses for other Chapter 15 transients. Reanalysis of the Chapter 15 events that credit the $\Delta \mathrm{T}$ set points will be a significant engineering and licensing effort, with associated cost.

Also, refinements in the analysis inputs related to control systems may also provide an opportunity to justify optimizing the set points to enable handling large load rejections. As an example, analysis inputs may allow for a wider band of primary temperature control than is actually used at the plant, and narrowing the control band would have a beneficial impact on load rejection capacity. Other examples would be reducing overly conservative assumptions for steam generator tube plugging or primary coolant flow.

It is noted that the above control system changes that are non-safety-grade cannot be credited in the UFSAR Chapter 15 safety analyses of the loss-of-load event.

\section{Possible Mechanical System Changes That Would Improve Success}

Additional steam dump capacity would improve the capability to handle load rejections for all designs (except for those with 100\% capacity). Additional pressurizer spray or PORV capacity would also be an improvement for designs that are limited by the high reactor pressure trip. Refinements in the analysis inputs related to mechanical systems may also provide an opportunity to justify optimizing the set points to enable allow large load rejections. These refinements would include actual plant performance parameters for SSCs such as steam dump valve capacity and valve stroke times.

It is noted that the above mechanical system changes that are non-safety-grade cannot be credited in the UFSAR Chapter 15 safety analyses of the loss-of-load event. 
The Table 8-1 summarizes the key design considerations for PWRs and also includes the number of units in each of the six PWR plant categories:

Table 8-1 Candidate Design Changes for PWR Plant Categories

\begin{tabular}{|c|c|c|c|}
\hline \multicolumn{4}{|c|}{$\begin{array}{c}\text { Candidate Design Changes for PWR Plant Categories } \\
\text { Table 8-1 }\end{array}$} \\
\hline Plant Category & $\begin{array}{l}\text { Number of } \\
\text { Units in U.S. }\end{array}$ & Current Design Limitations & Candidate Design Changes \\
\hline Westinghouse 4-Loop & 29 & $\begin{array}{l}\text { Steam dump capacity, small } \\
\text { margin to reactor trip }\end{array}$ & $\begin{array}{l}\text { RPCS } \underline{\text { OR optimized controls and }} \\
\text { increased steam dump capacity }\end{array}$ \\
\hline Westinghouse 3-Loop & 13 & $\begin{array}{l}\text { Steam dump capacity, small } \\
\text { margin to reactor trip }\end{array}$ & $\begin{array}{l}\text { RPCS } \underline{\text { OR optimized controls and }} \\
\text { increased steam dump capacity }\end{array}$ \\
\hline Westinghouse 2-Loop & 6 & $\begin{array}{l}\text { Steam dump capacity, small } \\
\text { margin to reactor trip }\end{array}$ & $\begin{array}{l}\text { RPCS OR optimized controls and } \\
\text { increased steam dump capacity }\end{array}$ \\
\hline CE with RPCS & 4 & None & $\mathrm{N} / \mathrm{A}$ \\
\hline CE without RPCS & 10 & Steam dump capacity & RPCS \\
\hline Babcock \& Wilcox & 7 & $\begin{array}{l}\text { Post-TMI-2 imposed design } \\
\text { changes }\end{array}$ & $\begin{array}{l}\text { RPCS } \underline{\text { AND }} \text { reverse imposed } \\
\text { design changes }\end{array}$ \\
\hline
\end{tabular}




\section{Boiling Water Reactors}

\subsection{Desired BWR Plant Response}

The older BWR design plant response to a loss-of-load transient results in a fast reactor vessel pressurization. The steam line safety valves prevent the vessel pressure from exceeding $110 \%$ of the design pressure.

The reactor power at nominal conditions is controlled by the amount of core voiding (regulated by recirculation pump flow control). When the RPV pressure increases, it collapses a substantial amount of the voids in the core which increases neutron moderation, the reactivity increases and a power excursion will occur if the reactor is not scrammed. Consequently, preventing a power excursion is the focus of many plant control systems. Thus, a reactor trip occurs as a result of a turbine control or main steam isolation valve closure.

For PWRs a loss of load has an indirect impact on the reactor coolant system and tends to decrease the reactor power as the RCS heats up due to less efficient steam generator cooling. The BWR loss-of-load transient can have an immediate effect of rapidly increasing reactor power unless control actions are taken. Because of the potential power excursions, domestic BWRs are not designed to handle (not inserting scram control rods) a loss-of-load transient. For a load rejection at low power $(<33 \%)$ the reactor does not automatically scram as a result of the turbine control valve closure since the steam bypass valve is sized to bypass an adequate amount of steam to the condenser. However, with several recent significant BWR power uprates, the bypass flow capacity has not changed with the power. Thus, it seems reasonable the ability to handle a loss-of-load event has been further diminished.

The advanced boiling water reactor (ABWR) design is able to handle a loss-of-load transient from full power because of recirculation flow control, vessel pressure control systems and a large steam bypass capacity designed specifically for that purpose. These systems are:

- a large steam bypass capacity ( $110 \%$ nominal steam flow)

- a recirculation flow control system (RFCS) that either trips the reactor internal pumps or rapidly decreases the pump speed to the minimum rate, and

- a steam bypass and pressure control system (SBPCS) that adjusts the turbine control valve and steam bypass valve to mitigate vessel pressure rise.

Upon a loss-of-load, the pressure rise is minimized by the SBPCS and the reactor power is decreases due to decreasing core flow which increases the core voiding due to RFCS actions. 
Four ABWRs units are operational in Japan and two in Taiwan.

\subsection{Overview of Loss-of-Load Transient for Various BWR Plant Designs}

Since the operating domestic BWRs are a General Electric design, there is not the variety of systems that exists in PWRs.

There are five BWR designs currently operating. The basic reactor vessels designs are similar. Major differences include recirculation loops, power density, and containment. The designs are:

- BWR2 - Forced external recirculation with five loops, Mark I containment

- BWR3 - Two external recirculation loops that drive jet pumps in the reactor vessel, Mark I containment

- BWR4 - Same as a BWR3 with increased power density with either a Mark I or II containment

- BWR5 - Same a BWR4 with a revised recirculation flow control, Mark II containment

- BWR6 - Increased power density from the BWR5, Mark III containment

- ABWR - Numerous changes and improvements from the older BWR designs. Internal pumps replace the recirculation loops and jet pumps. Analog reactor protections system and control systems are replaced with digital systems. The containment design has also been significantly improved.

For the purposes of this discussion, the BWR2 through BWR6 are referred to as BWR. BWRs have limited ability to handle a loss-of-load event due to insufficient bypass valve capacity (approximately $1 / 3$ of nominal steam flow) and lack of vessel pressure control systems the minimize the pressure excursion

The BWR reactor protection system causes a reactor trip if any of the signals below occur.

- Turbine stop-valve or turbine control-valve closure (for power $>$ than $33 \%$ )

- High neutron flux

- High reactor vessel pressure

- Main steamline isolation valve closure

- Loss of offsite-site AC power

- Low vessel water level

- High vessel water level (BWR6)

- High drywell pressure

- Low RPV pressure

- Seismic events 
The main BWR control systems include:

- Control rods control

- Recirculation flow control

- Reactor pressure control

- Reactor water level control

- Turbine power control

- Turbine steam bypass system

- Reactor Protection system

Typically, the power is controlled by the control rod controller for less than $65 \%$ nominal power. Above $65 \%$, recirculation flow rate controller maintains the desired power level.

The pressure control maintains the reactor vessel pressure at a desired setpoint. The pressure regulator maintains pressure by opening and closing the turbine governor control valve and the steam bypass valve. Under normal operating conditions, the turbine power control system regulates the turbine steam flow to meet the target load and target turbine inlet pressure by controlling the opening of the turbine governor valve. Should a load rejection occur, the turbine governor valve will close terminating flow to the turbine. The turbine steam bypass valve is controlled by the pressure regulator during normal operation. For a load rejection, an automatic steam bypass system is provided to dump steam to the condenser based on predetermined pressure setpoint. The steam bypass capacity was originally capable of maintaining vessel pressure and preventing a reactor trip at reactor power levels less than $30 \%$ to $33 \%$.

ABWRs are designed to handle a loss-of-load at full power and reduce the power to house load. The bypass flow capacity is $110 \%$ of the nominal steam flow. The power is reduced by quickly reducing the core flow by the recirculation flow control system The recirculation flow control system quickly reduces core flow and reactor power and the vessel pressure rise is minimized through the actions of steam bypass and pressure control system.

\subsection{Limitations in Current BWR and ABWR Designs}

Because of the need to prevent the power surge during loss-of-load events, the reactor protection system and control designs are quite inflexible. Only at low power level, is it possible to have a load rejection without a reactor trip.

One of the following BWR reactor trip signals will actuate during this event to prevent a power excursion.

- Turbine stop-valve or turbine control-valve closure

- High neutron flux 
- High reactor vessel pressure

- Main steamline isolation valve closure

- Loss of offsite-site AC power

ABWRs are designed to prevent a reactor trip during a loss-of-load event. Thus, there are no design limitations.

\subsection{Discussion of Probability of Success in BWR Runback to House Loads}

Successful BWR runback from nominal to house loads is less probable than most PWRs since a turbine trip triggers a reactor trip to prevent a power excursion. If the reactor were not tripped on a turbine control valve closure, the power could raise to three to six time nominal which would cause a reactor trip on high neutron flux. These reactor protection actions are required to prevent fuel damage. Current BWR designs would require modifications to the bypass flow capacity, the recirculation flow controller and vessel pressure controller to handle a loss-of-load event.

Fast acting ABWRs flow and pressure control systems minimize vessel pressure increase and prevent power excursions. The existing ABWR design can reduce power to house load during a loss-of-load event with no modifications.

\section{BWR Complications of Concurrent Equipment Failures}

The steam line safety valves must perform as designed to mitigate a high pressure trip. The bypass must function normally. The recirculation flow controller must decrease the core flow as quickly as possible to increase core voiding to offset the power excursion. As an example, if is the recirculation pumps are tripped, the core power can be reduced to approximately $30 \%$ of nominal.

\section{Possible BWR Control Changes That Would Improve Success}

Possible control actions would need to focus on increasing core voiding for a loss-of-load event. This could include immediately tripping the recirculation pumps and closing the feedwater control valves.

The control rod control controller is not active at full power. This controller could be modified to participate in a vessel pressurization event such as the loss of load to immediately lower the power to the bypass capacity.

The pressure control system could be modified to rapidly control the turbine valve and bypass valve to minimize the vessel pressure increase. 
Note that the power excursion following turbine trip is very rapid, and reactor trip typically occurs in only a few seconds. This time-span gives perspective to the rapidity required of any control changes.

Possible BWR Mechanical System Changes That Would Improve Success

Increased bypass flow capacity with the possible control changes would help the system handle this event. 


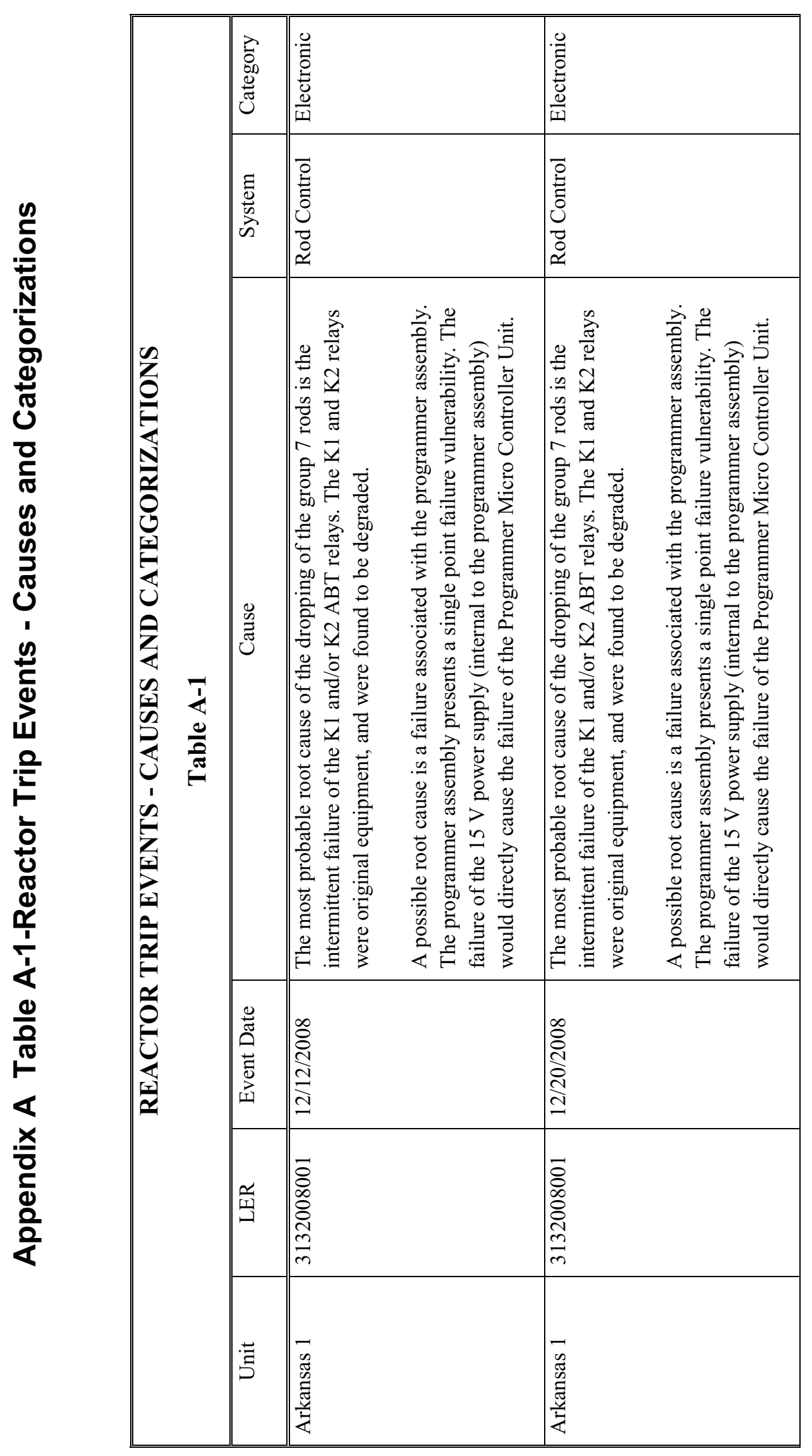




\begin{tabular}{|c|c|c|c|c|}
\hline \multirow{6}{*}{ 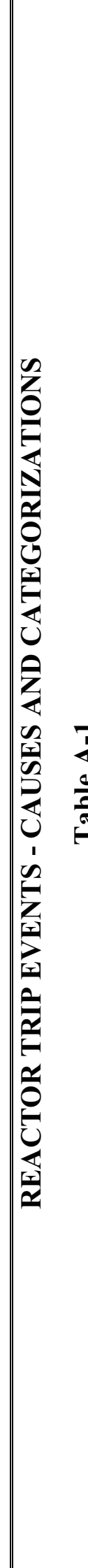 } & 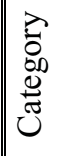 & 妾 & 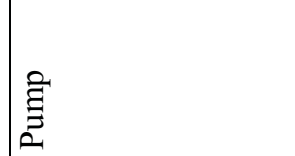 & 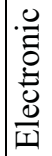 \\
\hline & 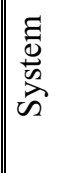 & $\overrightarrow{\underline{x}}$ & $\sum_{I=1}^{n}$ & $\frac{\tilde{a}}{2}$ \\
\hline & 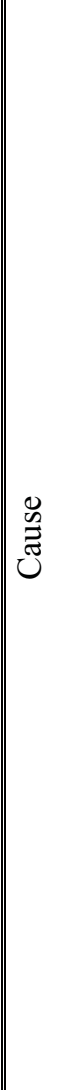 & 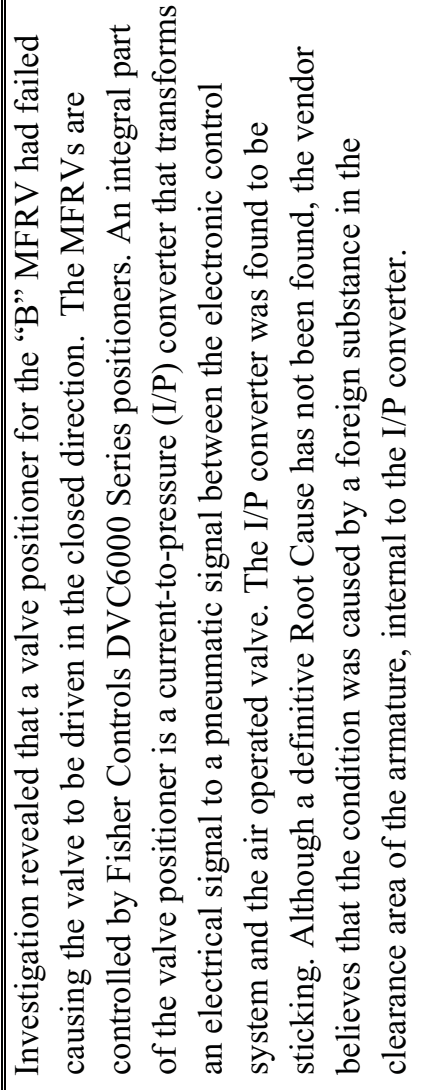 & 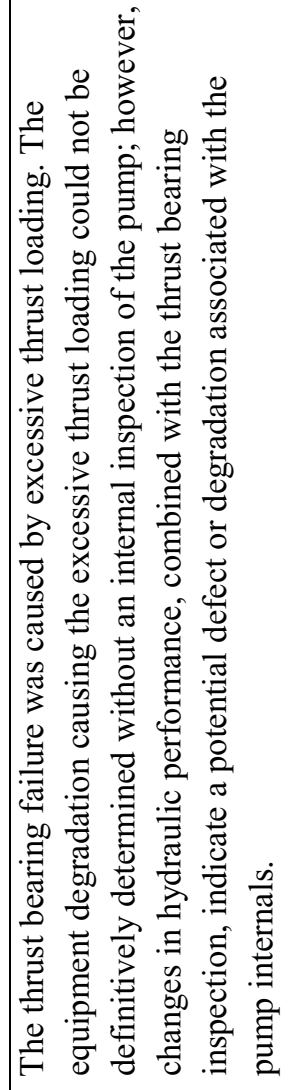 & \\
\hline & 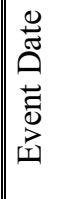 & 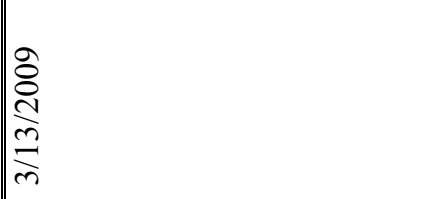 & 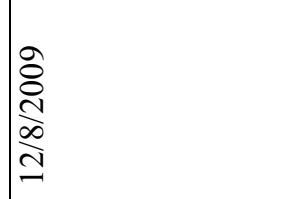 & 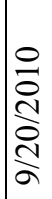 \\
\hline & 镥 & 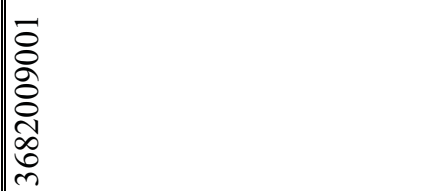 & 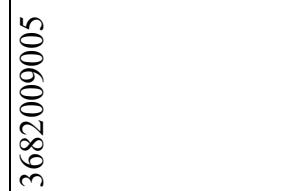 & 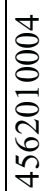 \\
\hline & $\| \bar{s}$ & 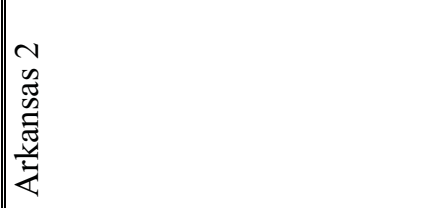 & 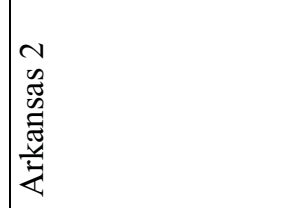 & 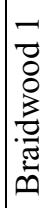 \\
\hline
\end{tabular}




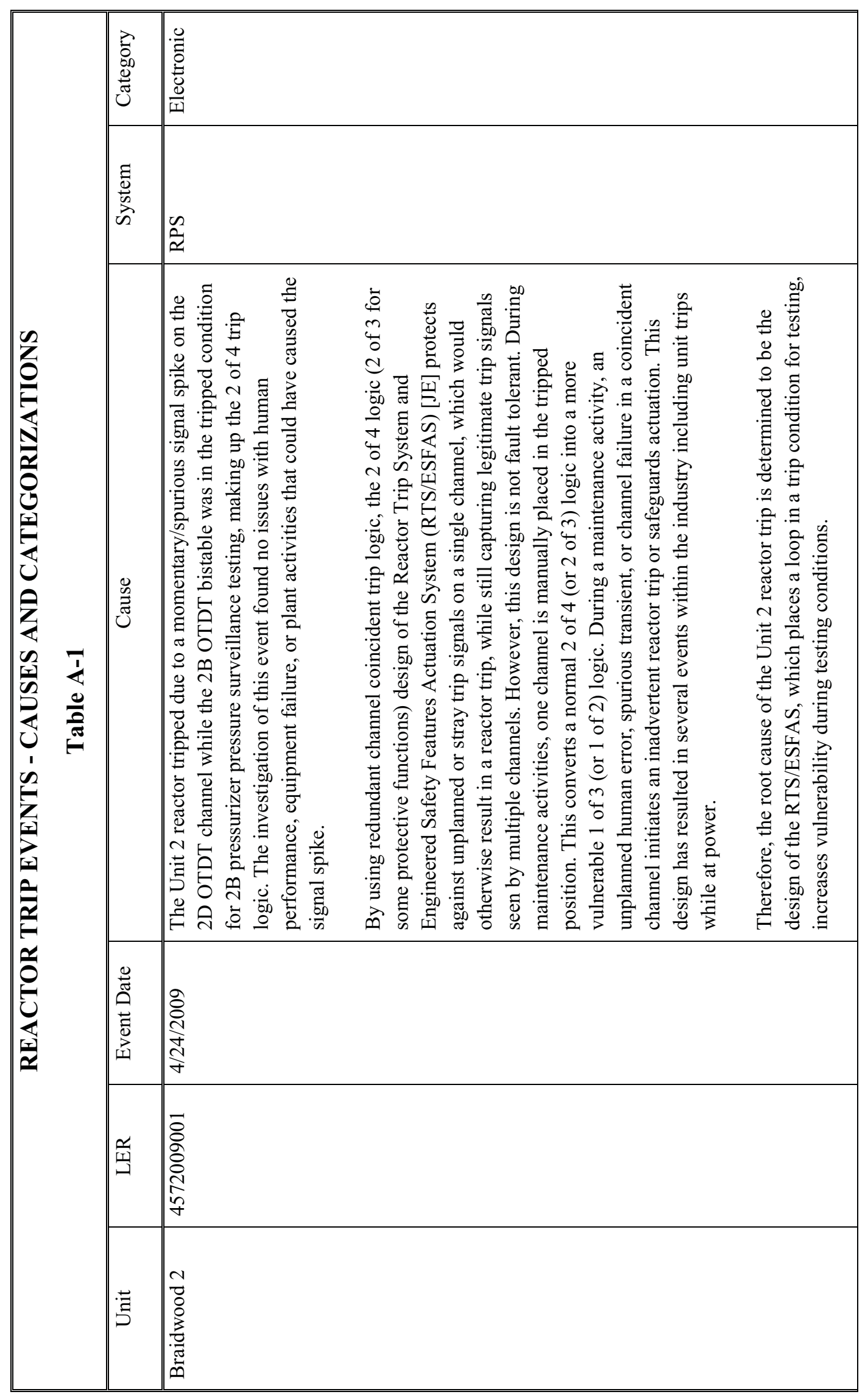




\begin{tabular}{|c|c|c|c|c|c|}
\hline \multirow{6}{*}{ 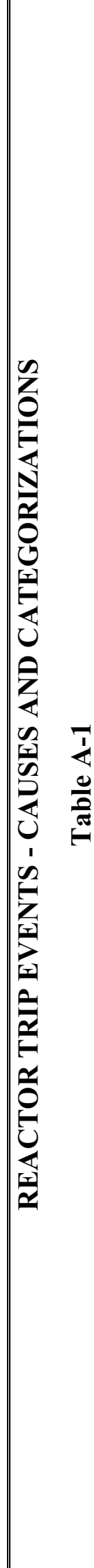 } & 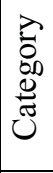 & \multicolumn{2}{|l|}{ 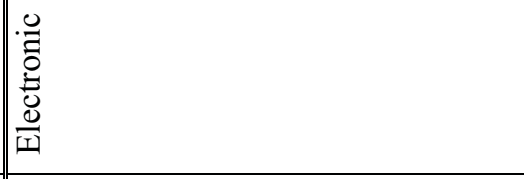 } & \multicolumn{2}{|l|}{ 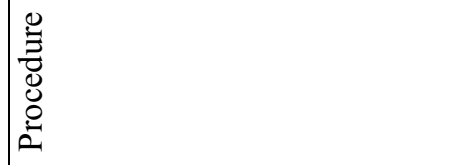 } \\
\hline & 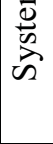 & 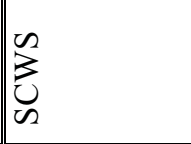 & & 产 & \\
\hline & 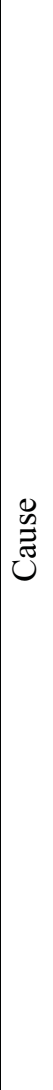 & 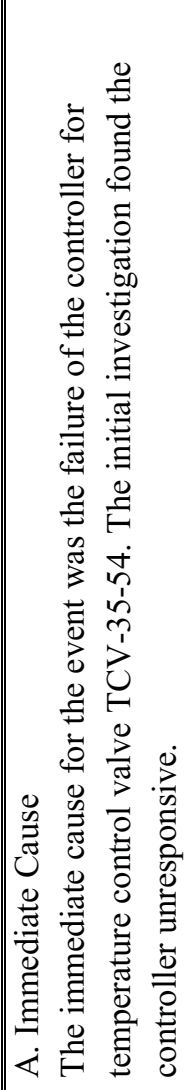 & 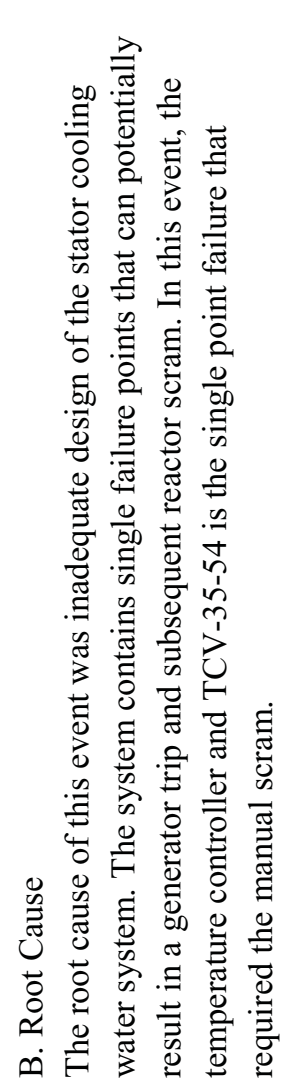 & 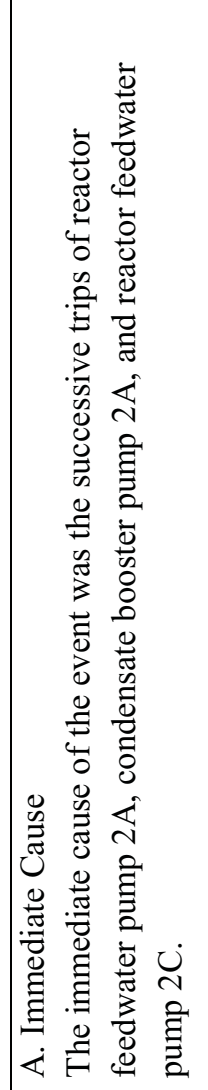 & 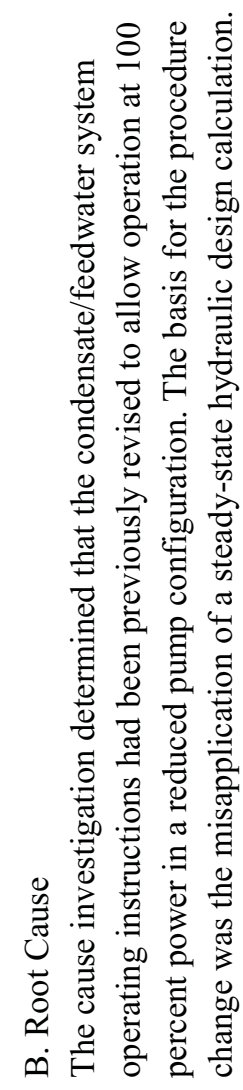 \\
\hline & 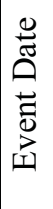 & 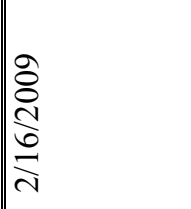 & & 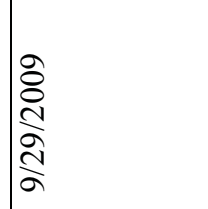 & \\
\hline & 畄 & 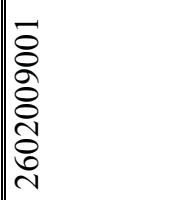 & & 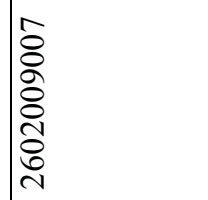 & \\
\hline & 5 & 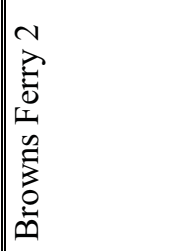 & & 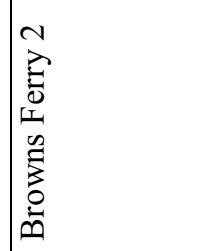 & \\
\hline
\end{tabular}




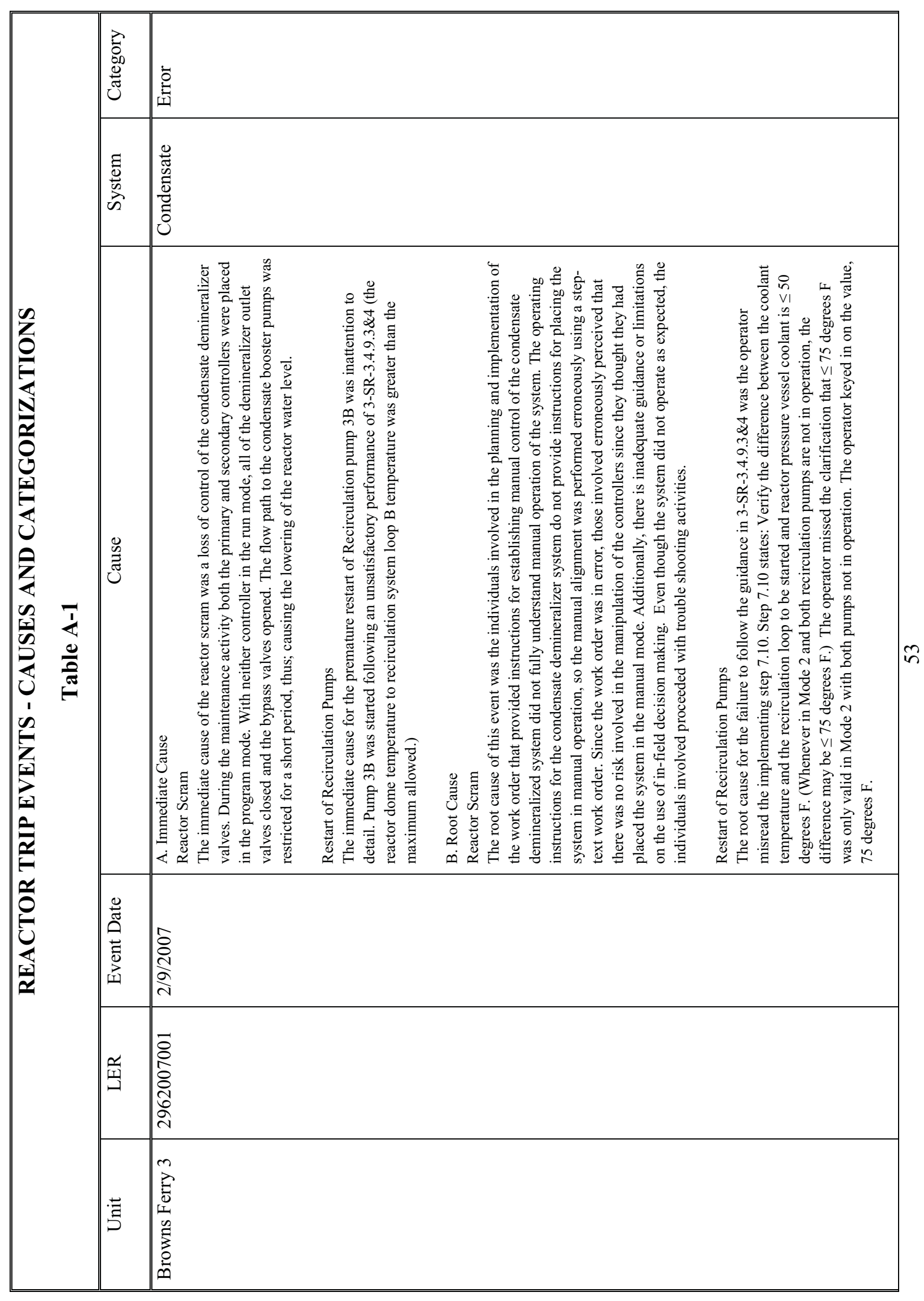




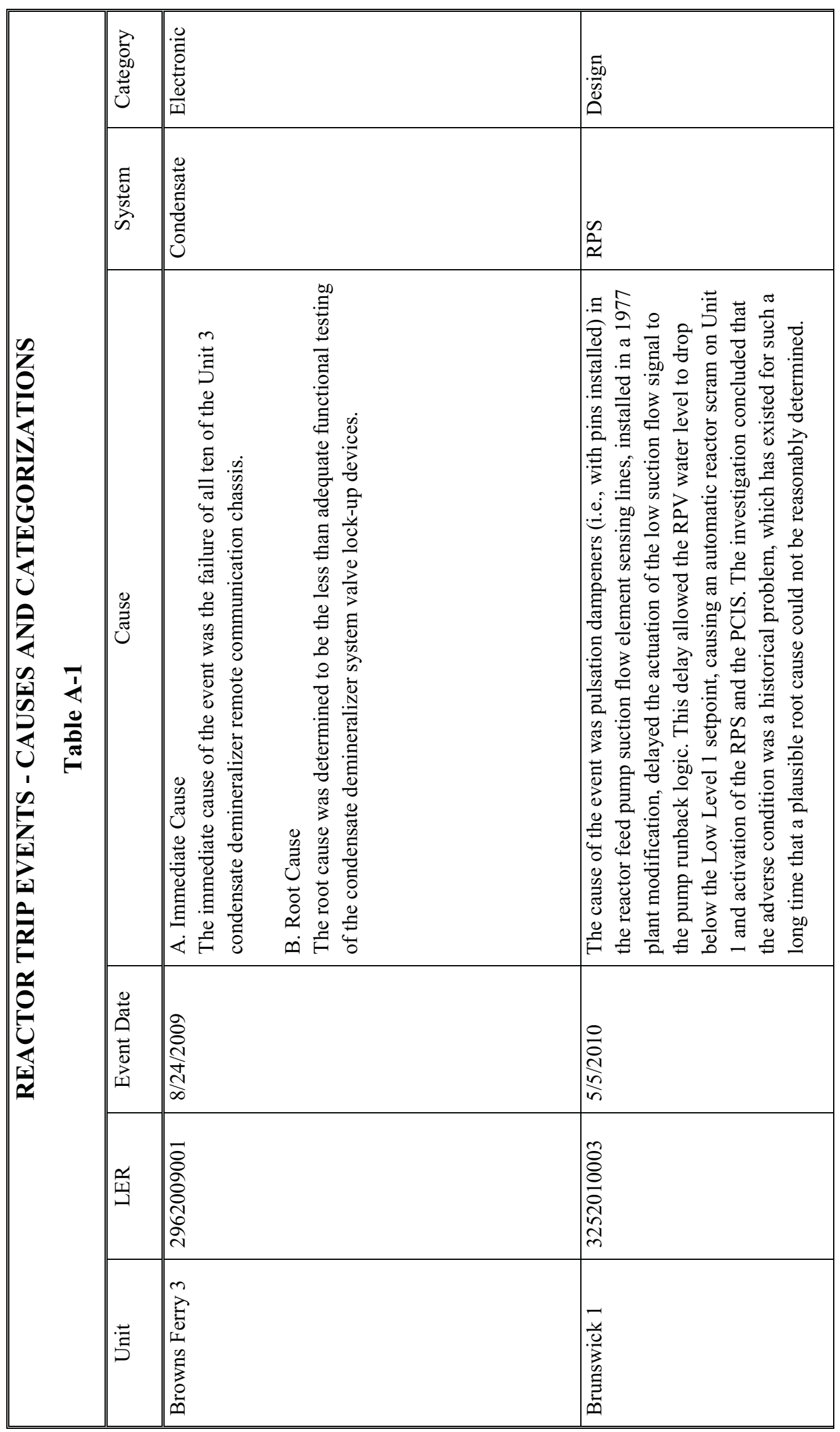




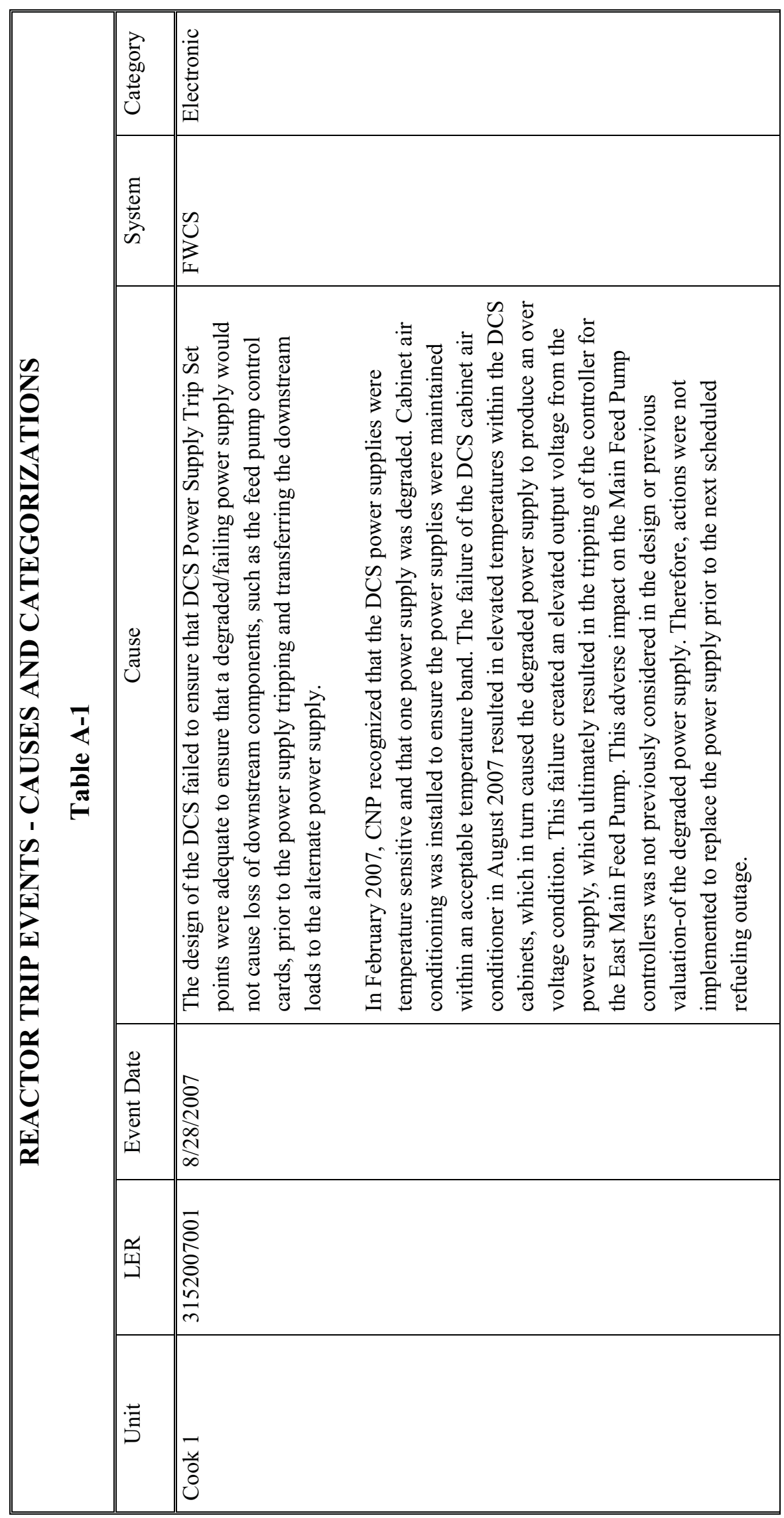




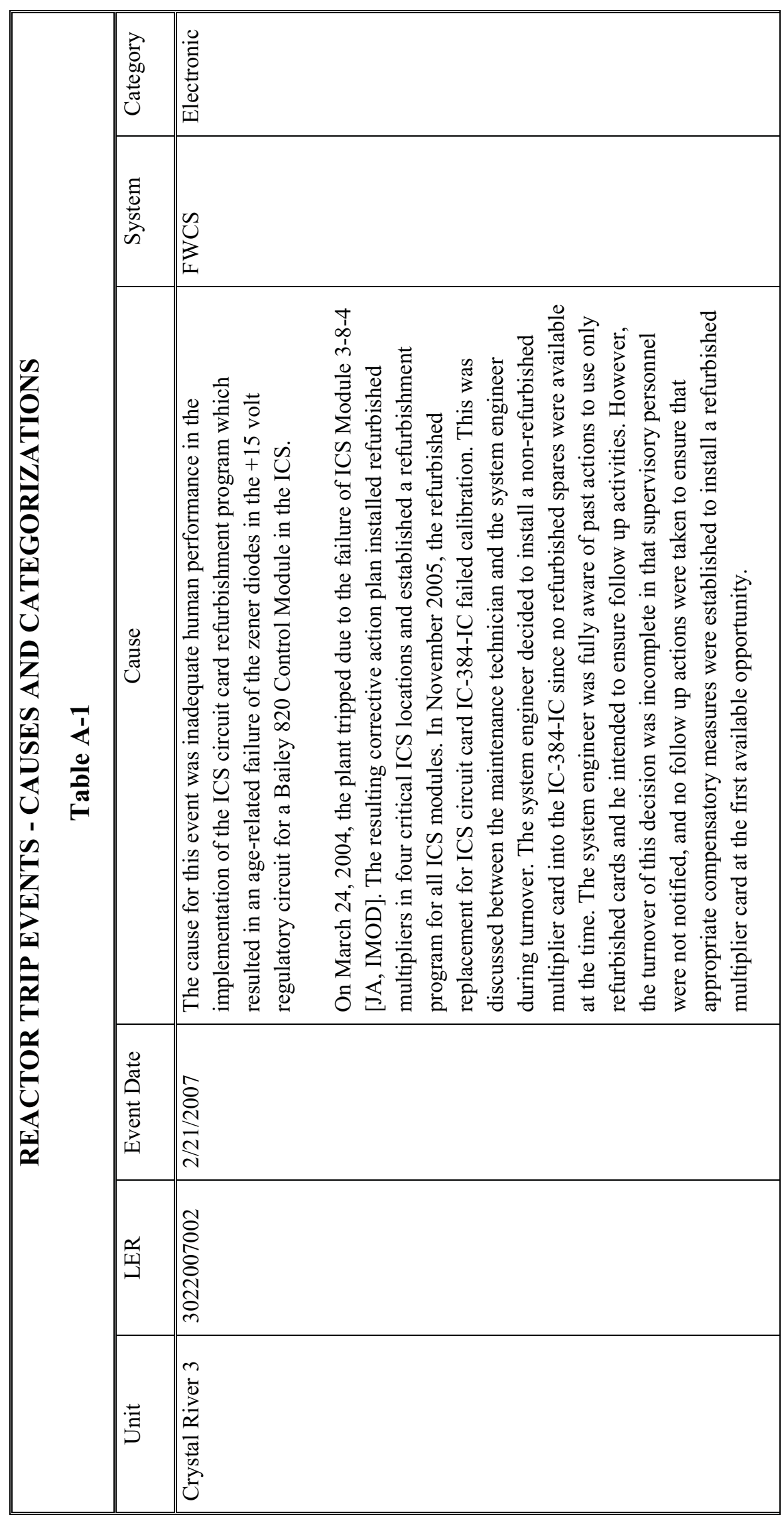




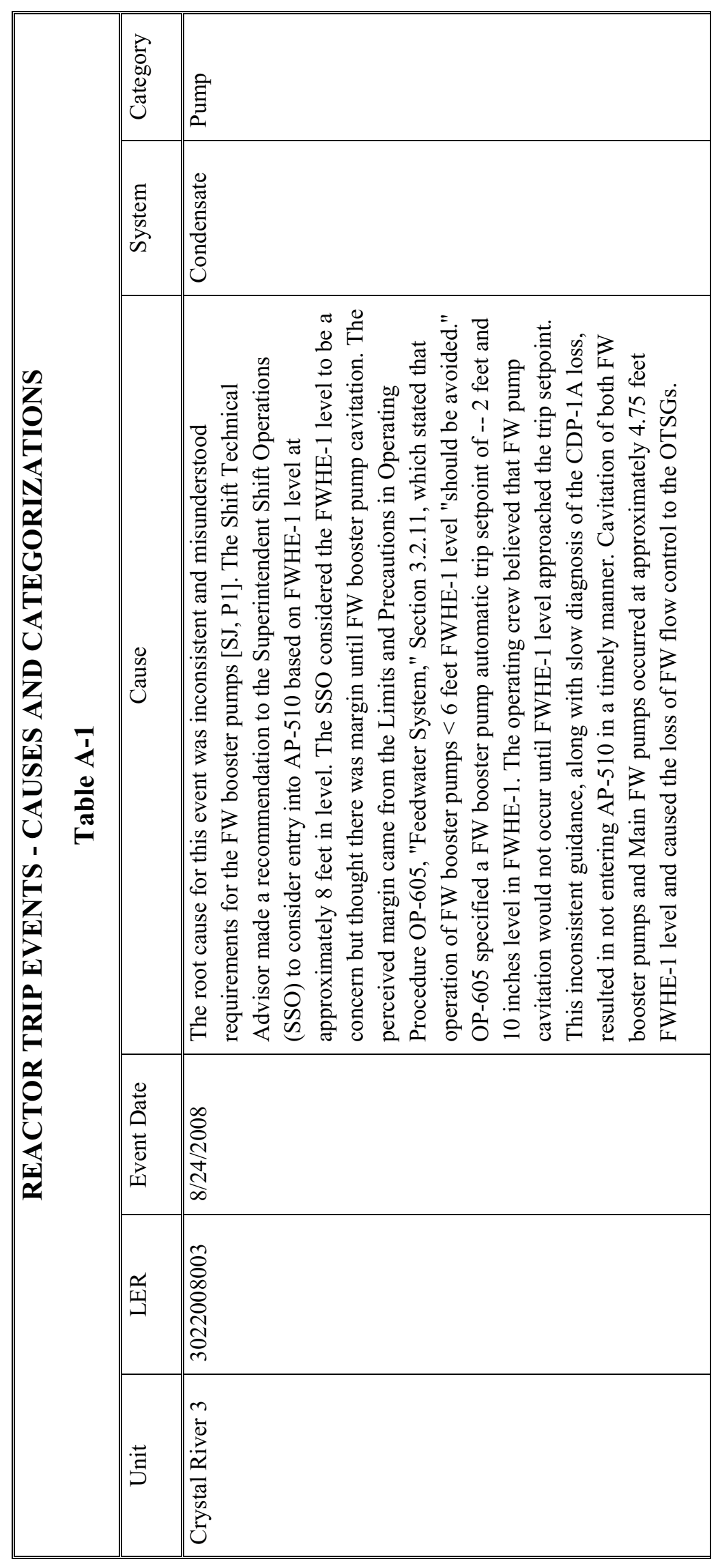

in 


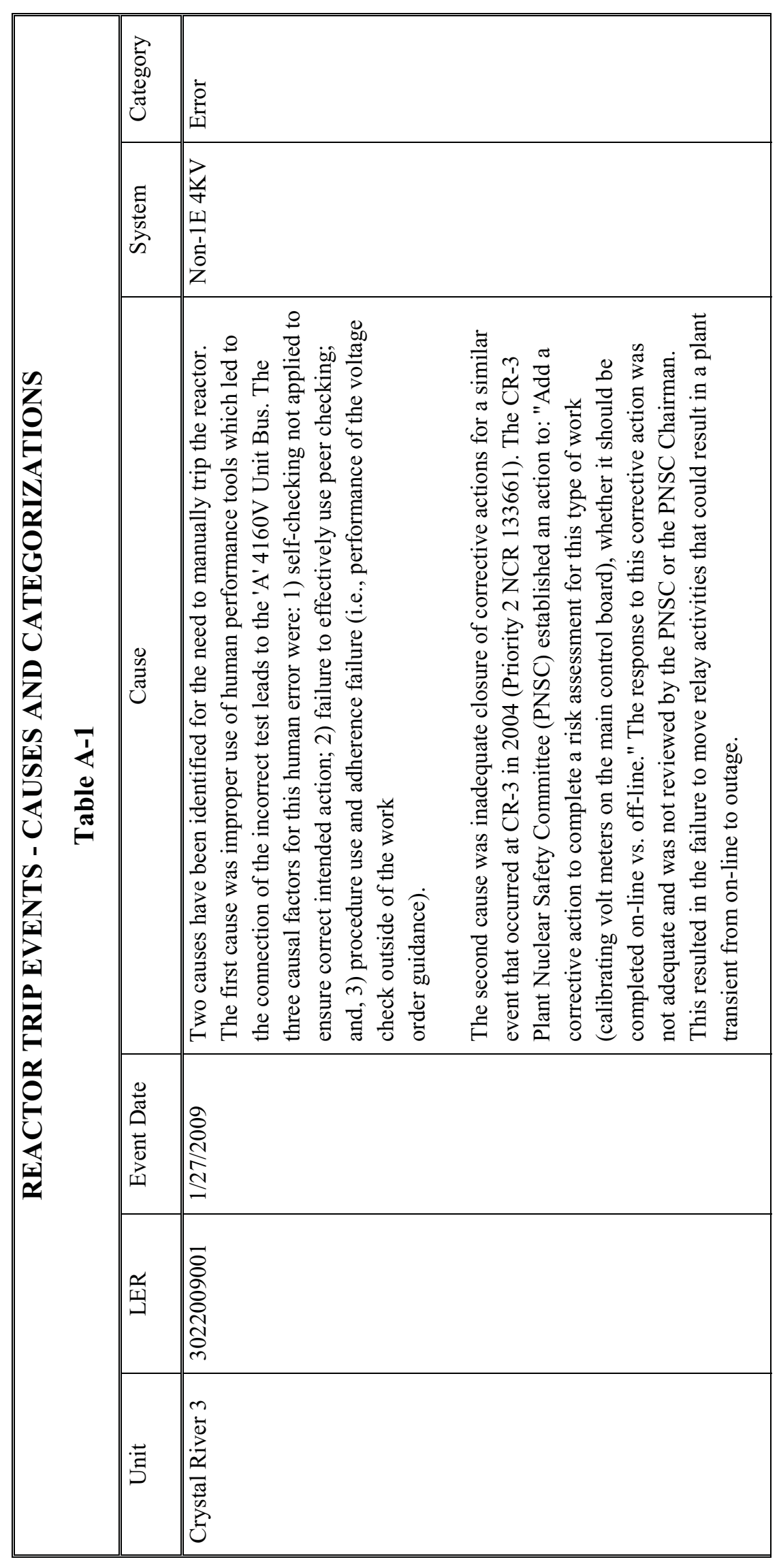




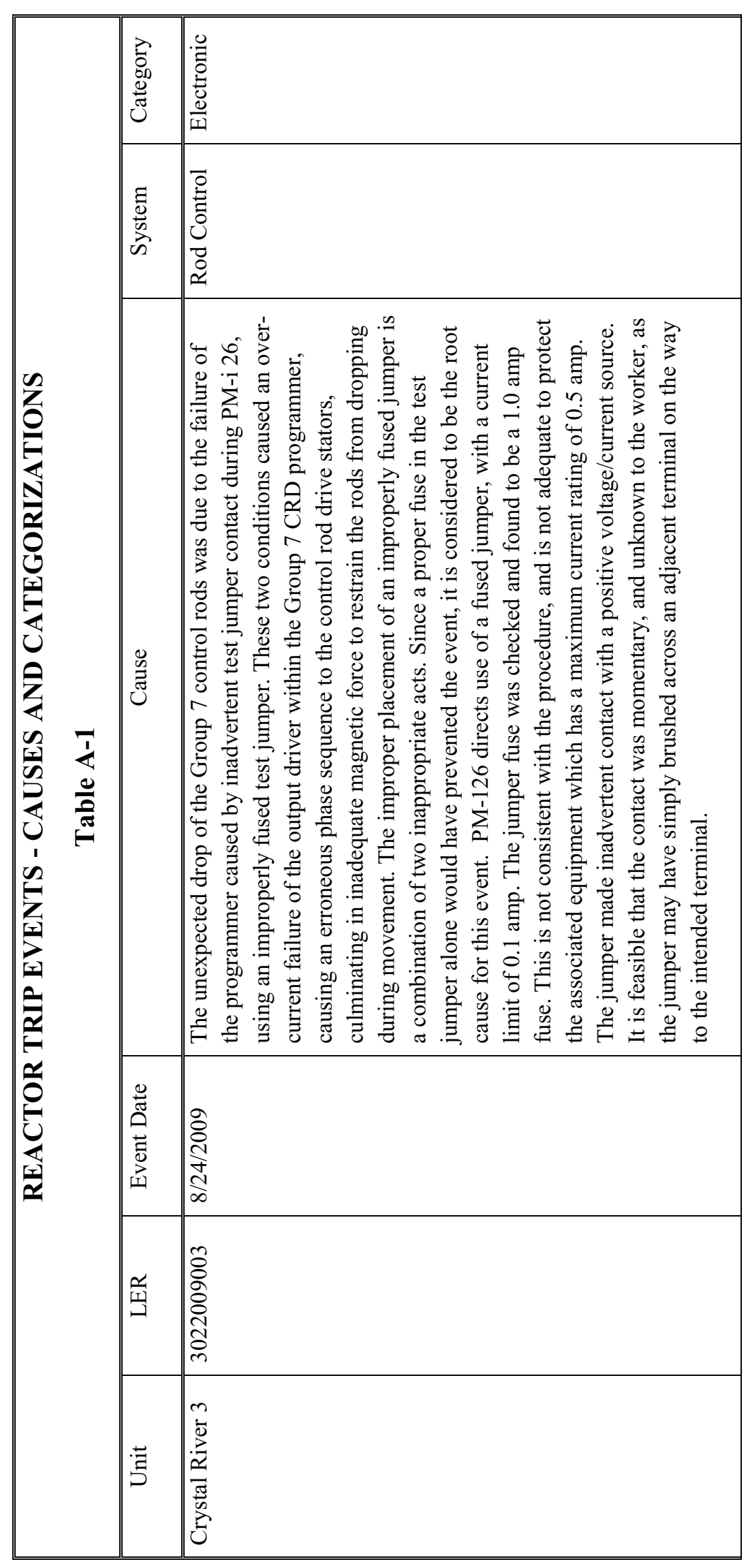




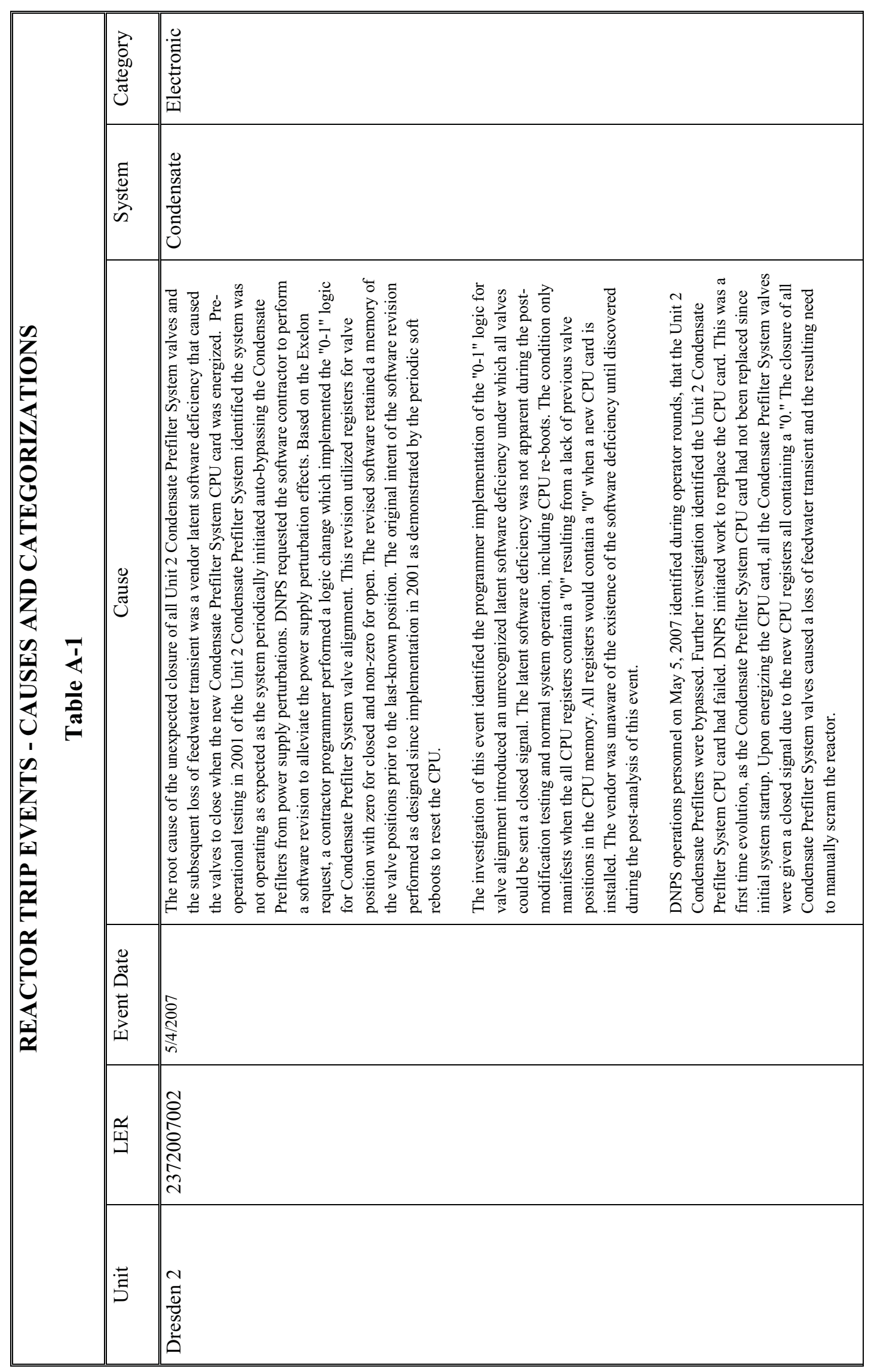

8 


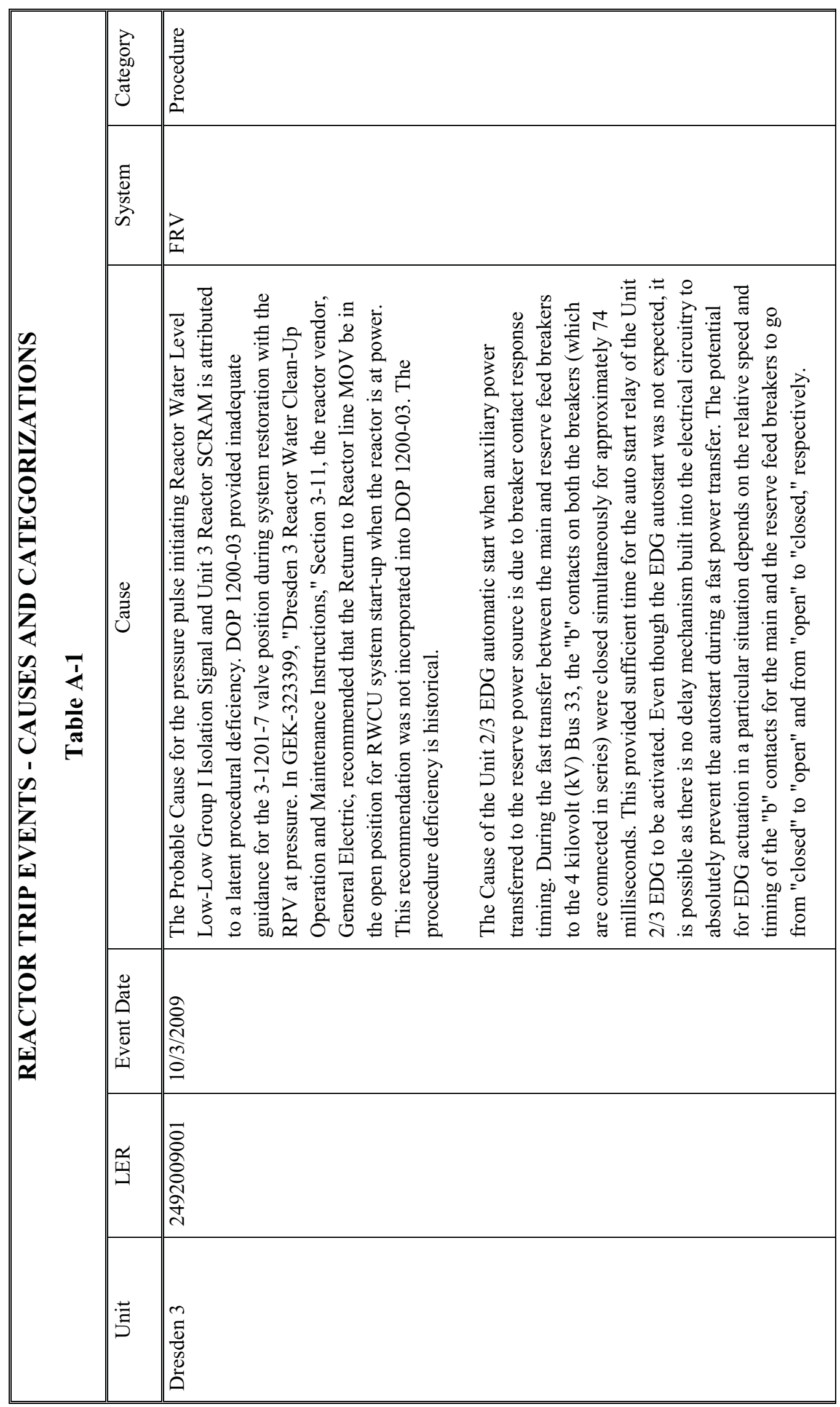




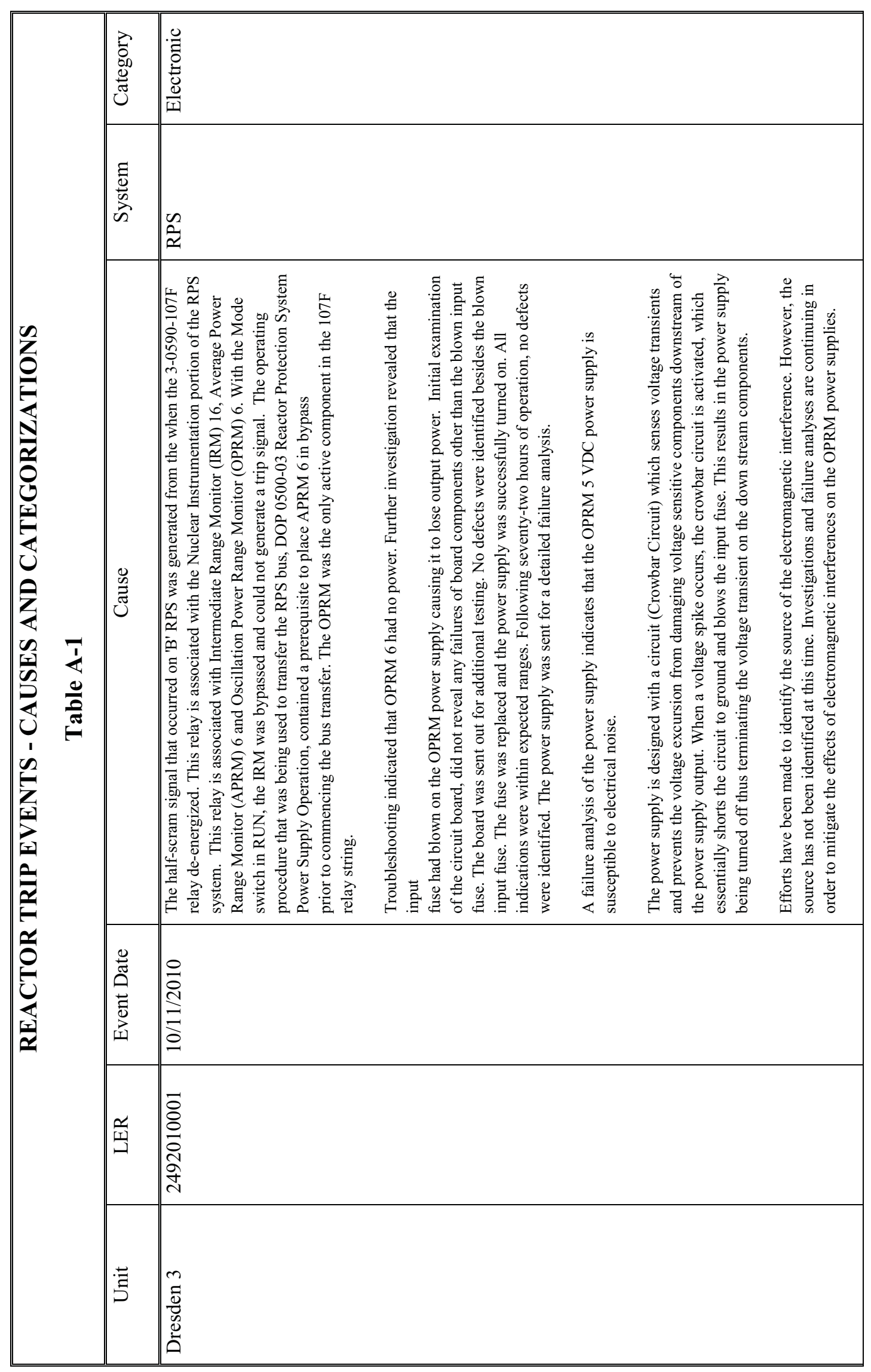




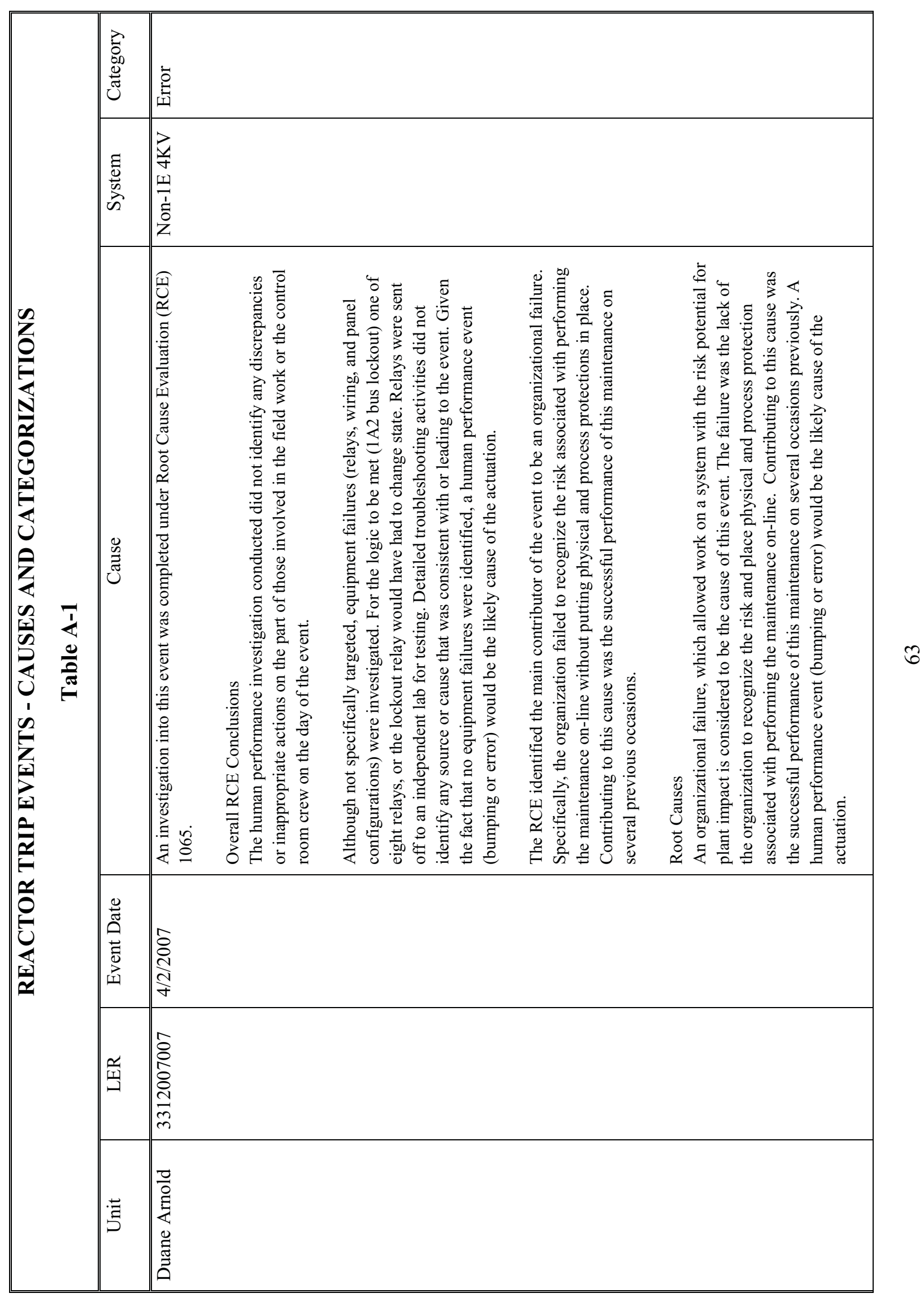




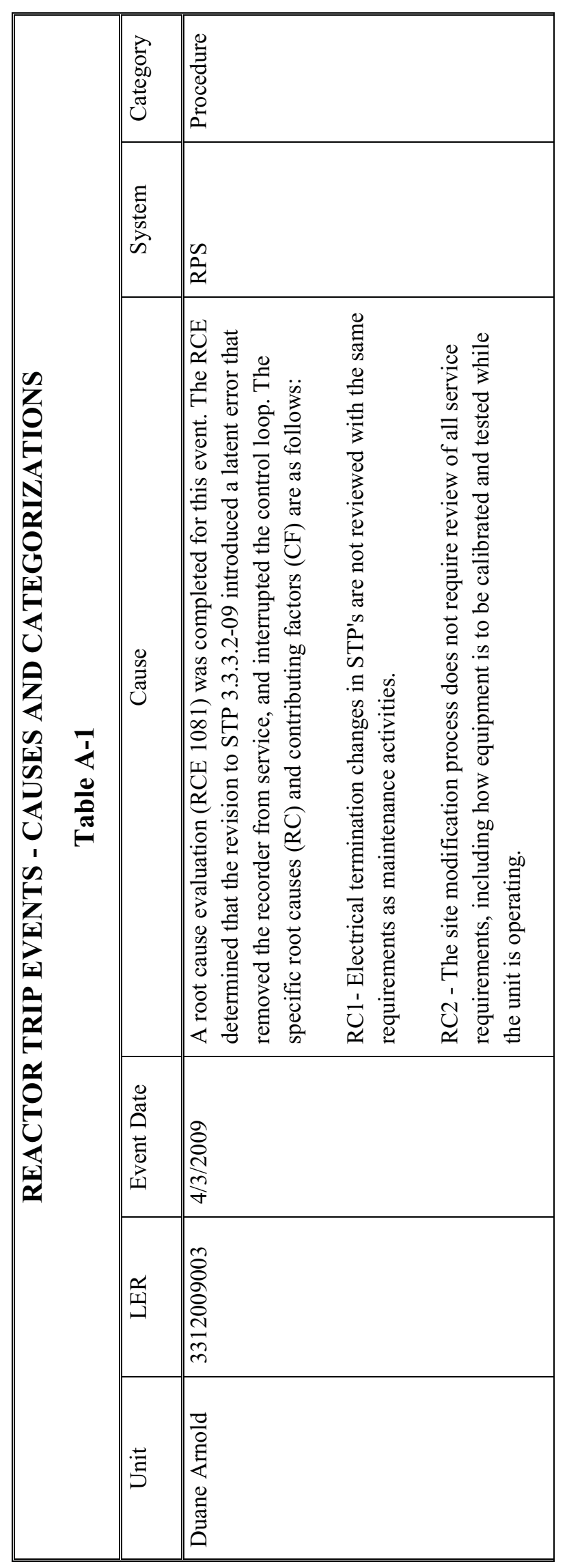




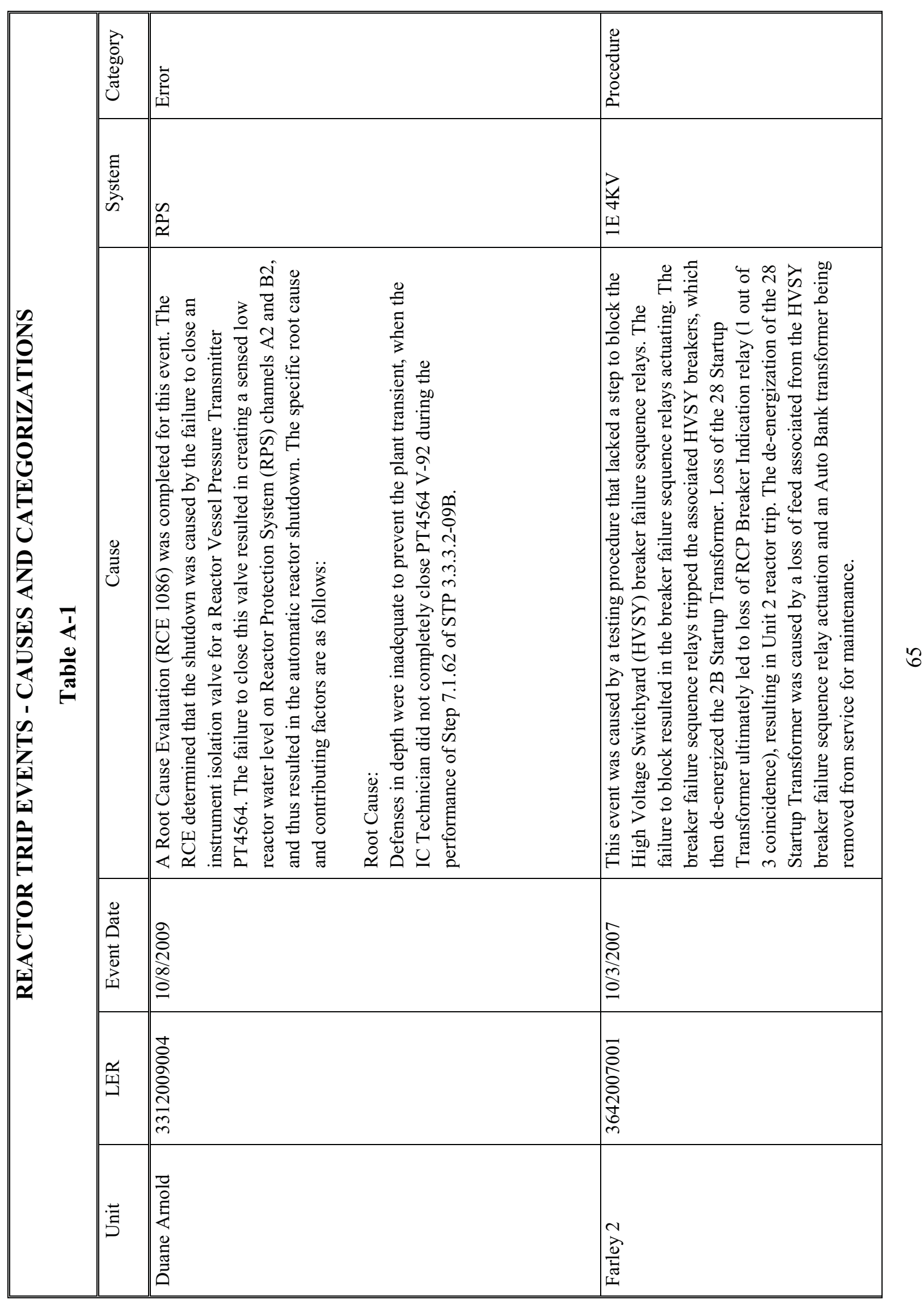




\begin{tabular}{|c|c|c|c|c|c|}
\hline \multirow{6}{*}{ 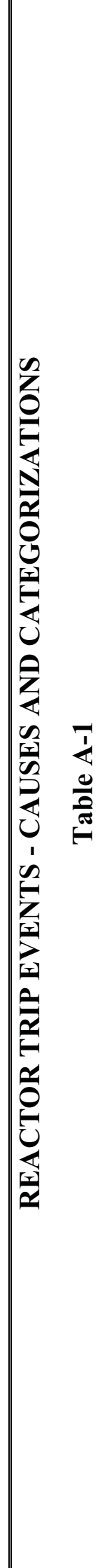 } & 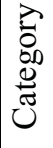 & 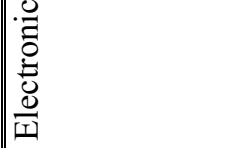 & & 蟼 & 窎 \\
\hline & 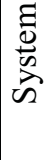 & $\int_{i}^{0}$ & & $\sum_{I=1}^{-5}$ & $\sum_{\vec{I}}$ \\
\hline & 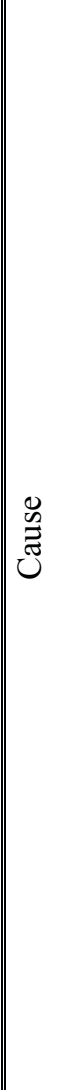 & 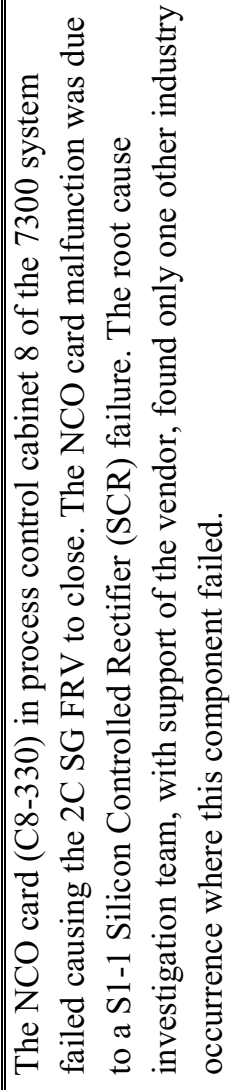 & 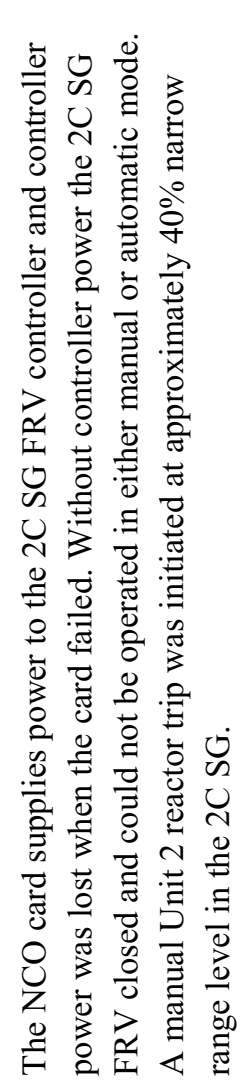 & 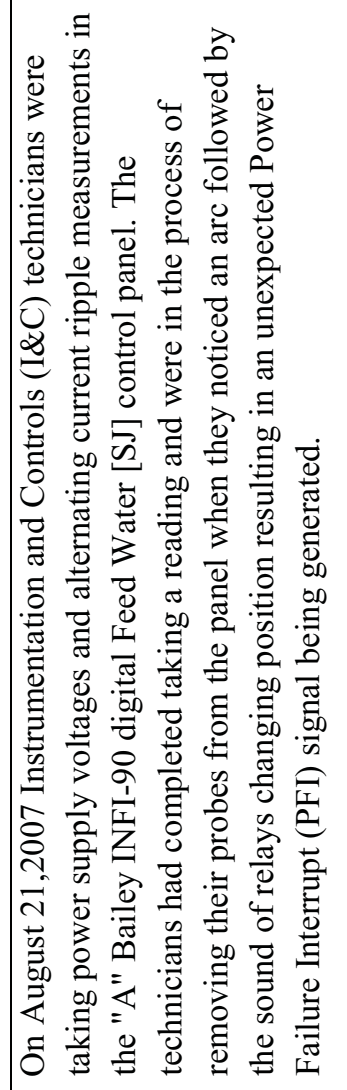 & 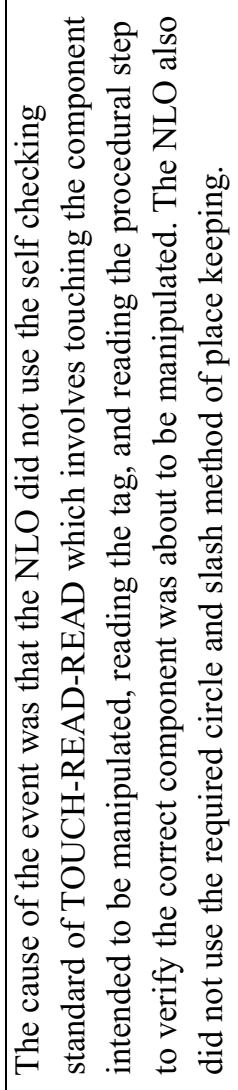 \\
\hline & 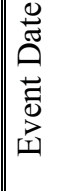 & 离 & & 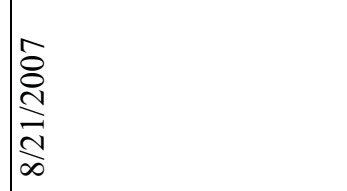 & 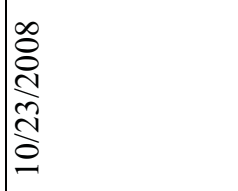 \\
\hline & 舀 & 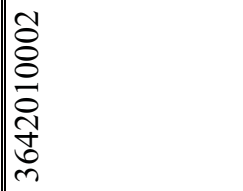 & & 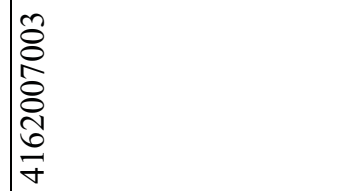 & 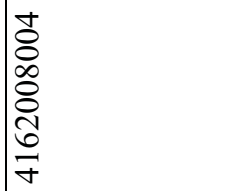 \\
\hline & $\overline{5}$ & 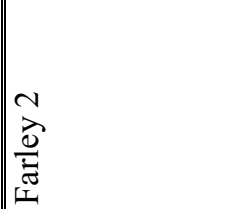 & & 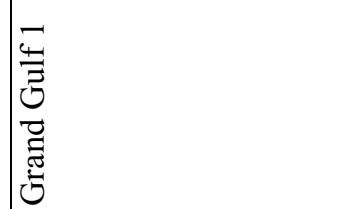 & 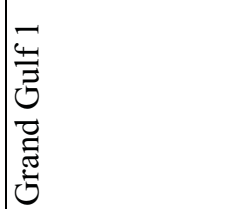 \\
\hline
\end{tabular}




\begin{tabular}{|c|c|c|c|c|}
\hline \multirow{6}{*}{ 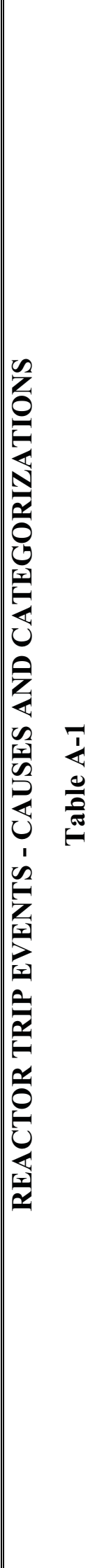 } & 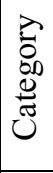 & $\frac{.}{0}$ & & 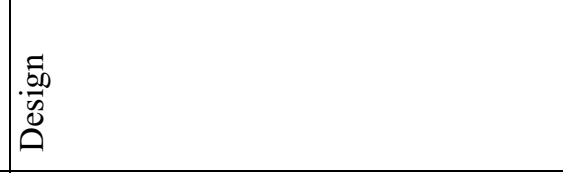 \\
\hline & & $\sum_{i=1}^{i}$ & & $\mathbb{T}_{|=|}^{0}$ \\
\hline & 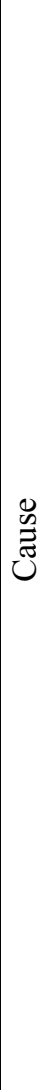 & 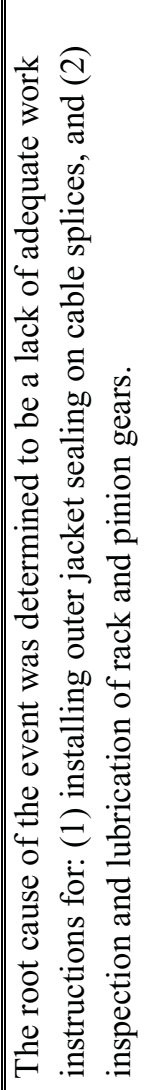 & 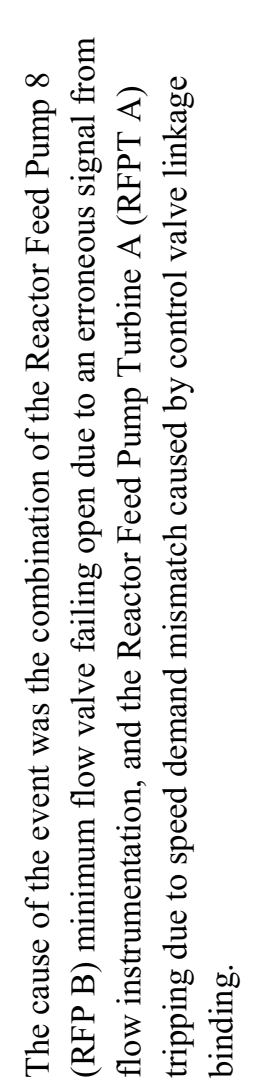 & 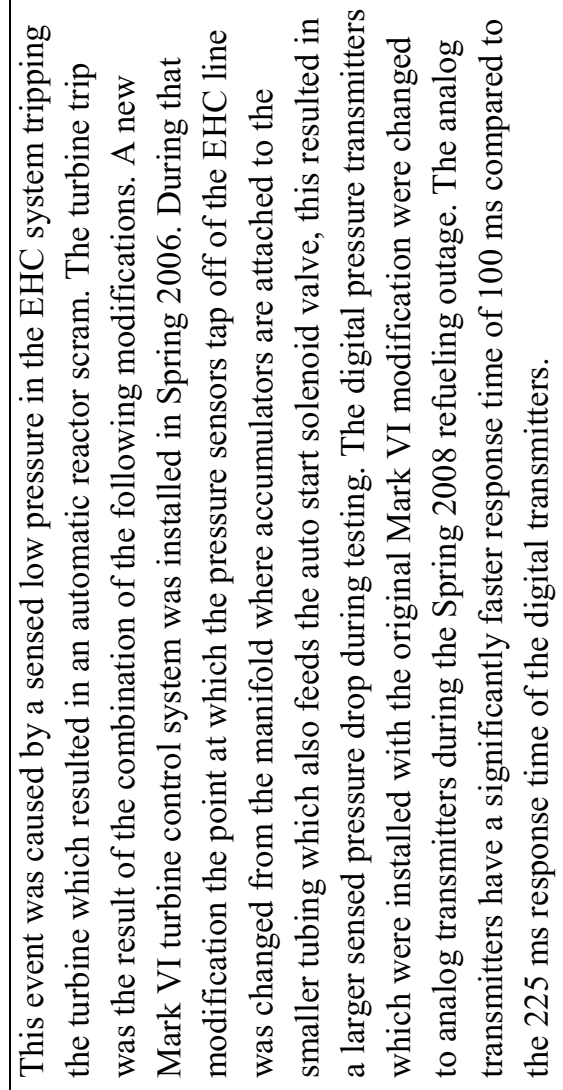 \\
\hline & 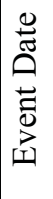 & $\mid \begin{array}{l}0 \\
\stackrel{0}{1} \\
\frac{\infty}{\infty} \\
\frac{\infty}{m}\end{array}$ & & 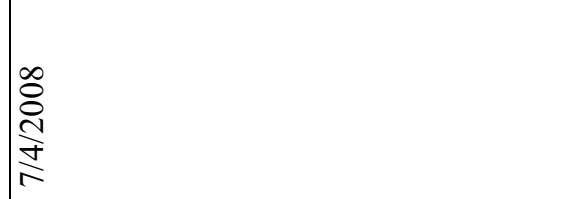 \\
\hline & 舀 & 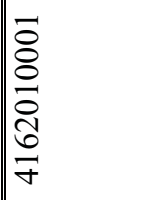 & & 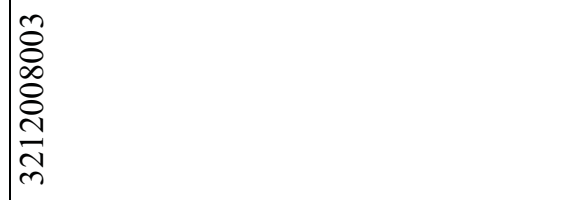 \\
\hline & $\bar{\xi}$ & 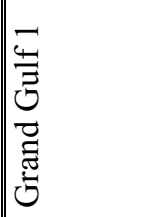 & & 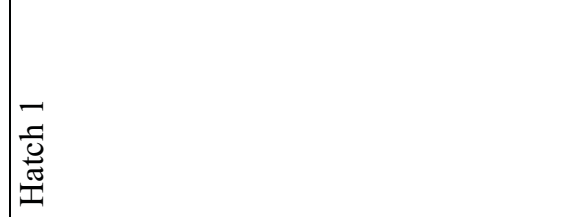 \\
\hline
\end{tabular}




\begin{tabular}{|c|c|c|c|c|c|}
\hline \multirow{6}{*}{ 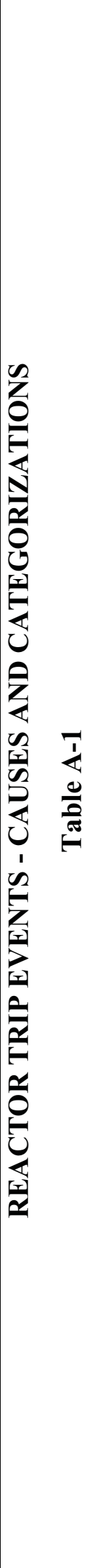 } & 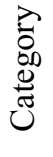 & $\frac{\vec{\pi}}{\stackrel{a}{a}}$ & 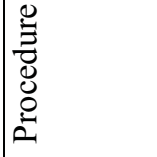 & & \\
\hline & 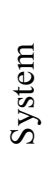 & $\begin{array}{l}\vec{y} \\
y \\
y \\
\frac{1}{1} \\
\dot{0} \\
z \\
z\end{array}$ & $\mid \begin{array}{l}\vec{y} \\
\frac{y}{4} \\
\frac{1}{y} \\
\frac{1}{1} \\
\tilde{0} \\
z\end{array}$ & & \\
\hline & $\begin{array}{l}\text { D } \\
\text { 岕 } \\
\tilde{J}\end{array}$ & 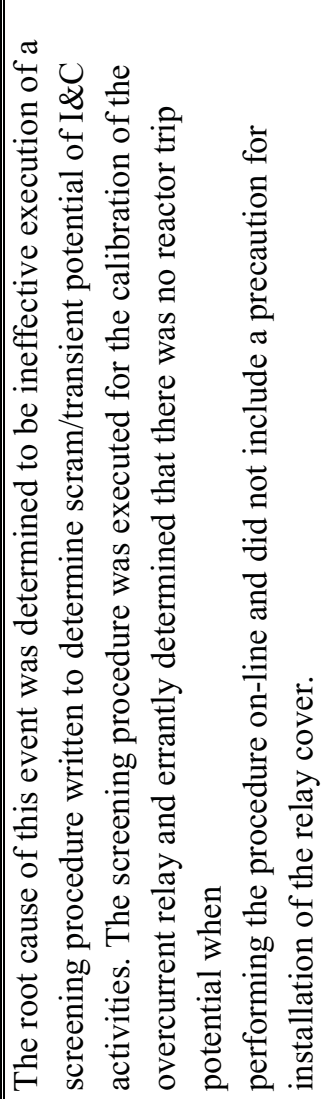 & 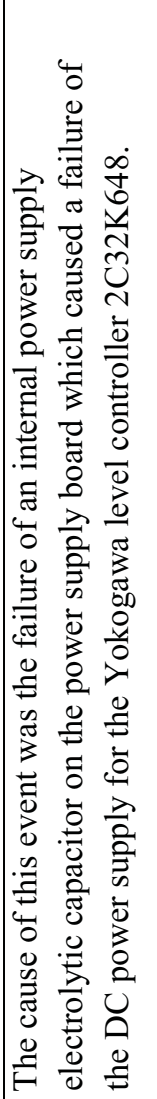 & 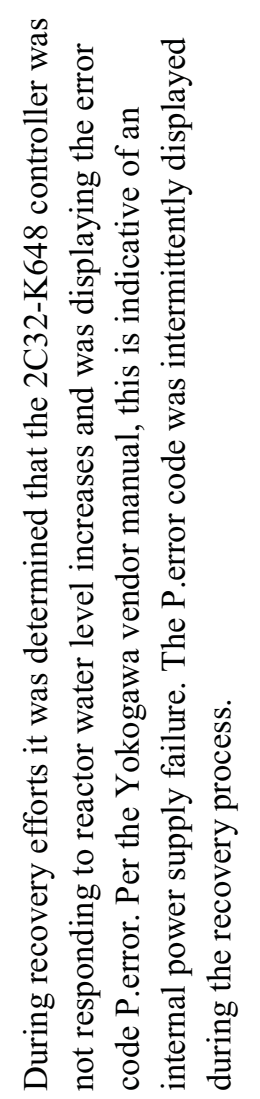 & 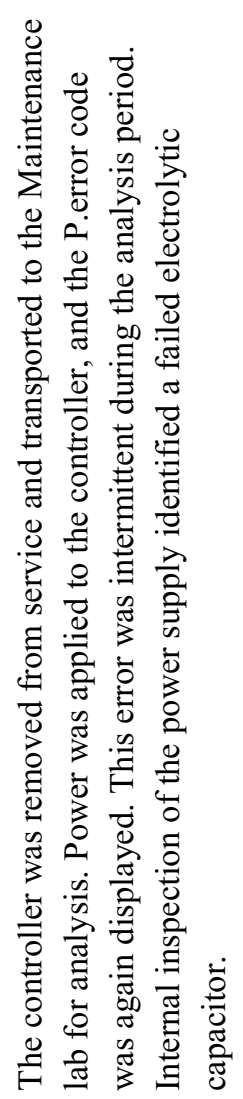 \\
\hline & 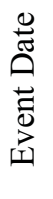 & 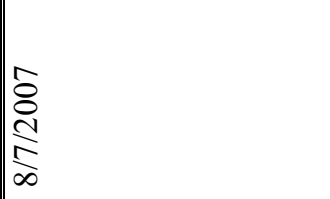 & 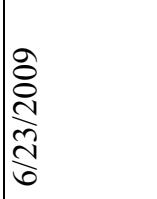 & & \\
\hline & 舀 & $\begin{array}{l}\infty \\
0 \\
0 \\
0 \\
0 \\
0 \\
0 \\
0 \\
0 \\
0\end{array}$ & 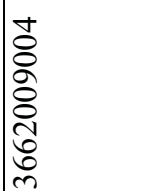 & & \\
\hline & 扬 & 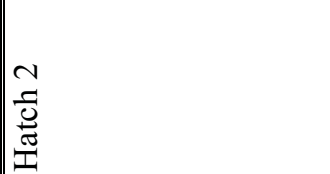 & $\mid \begin{array}{l}\frac{2}{2} \\
\frac{0}{0} \\
\frac{5}{4}\end{array}$ & & \\
\hline
\end{tabular}




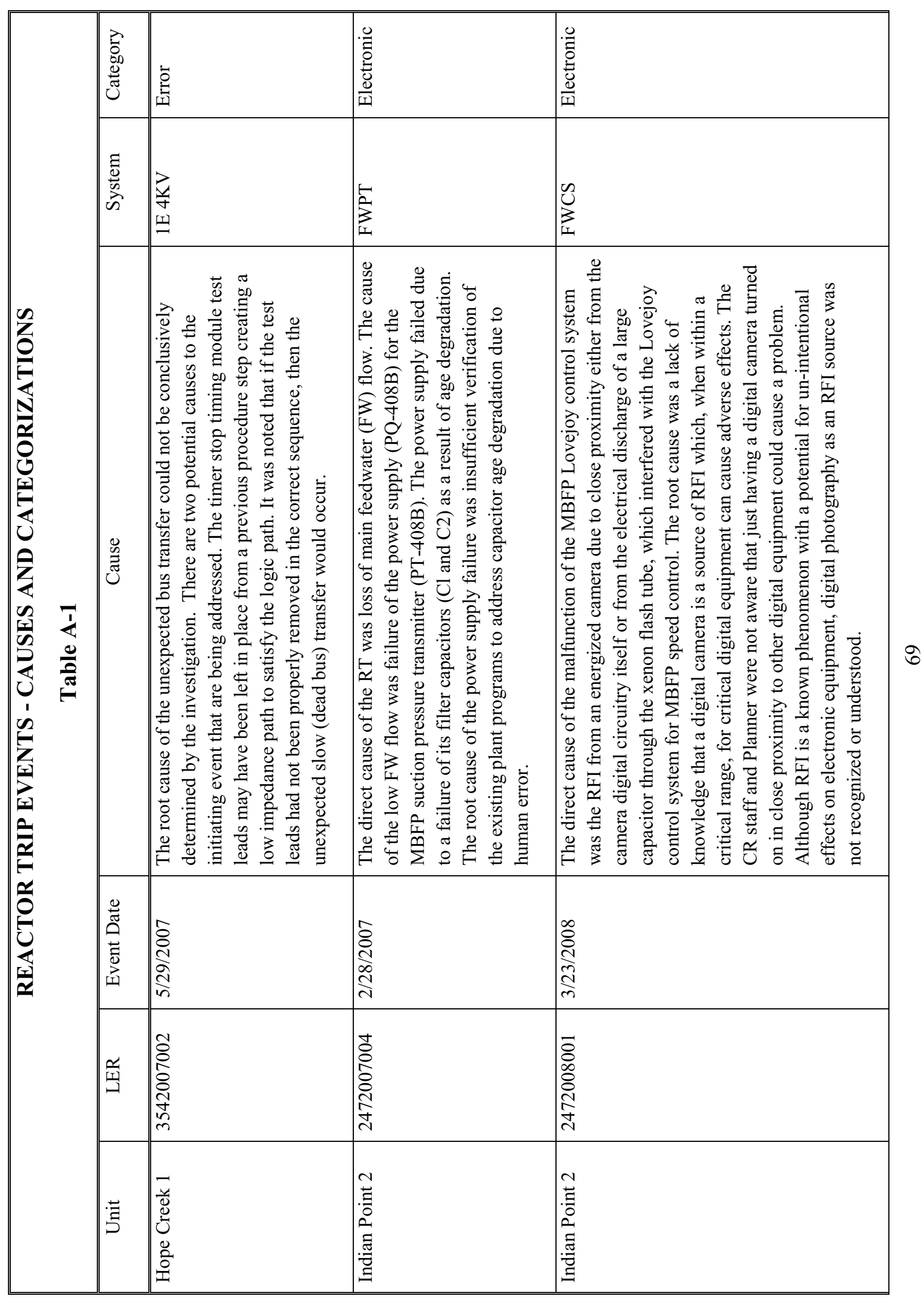




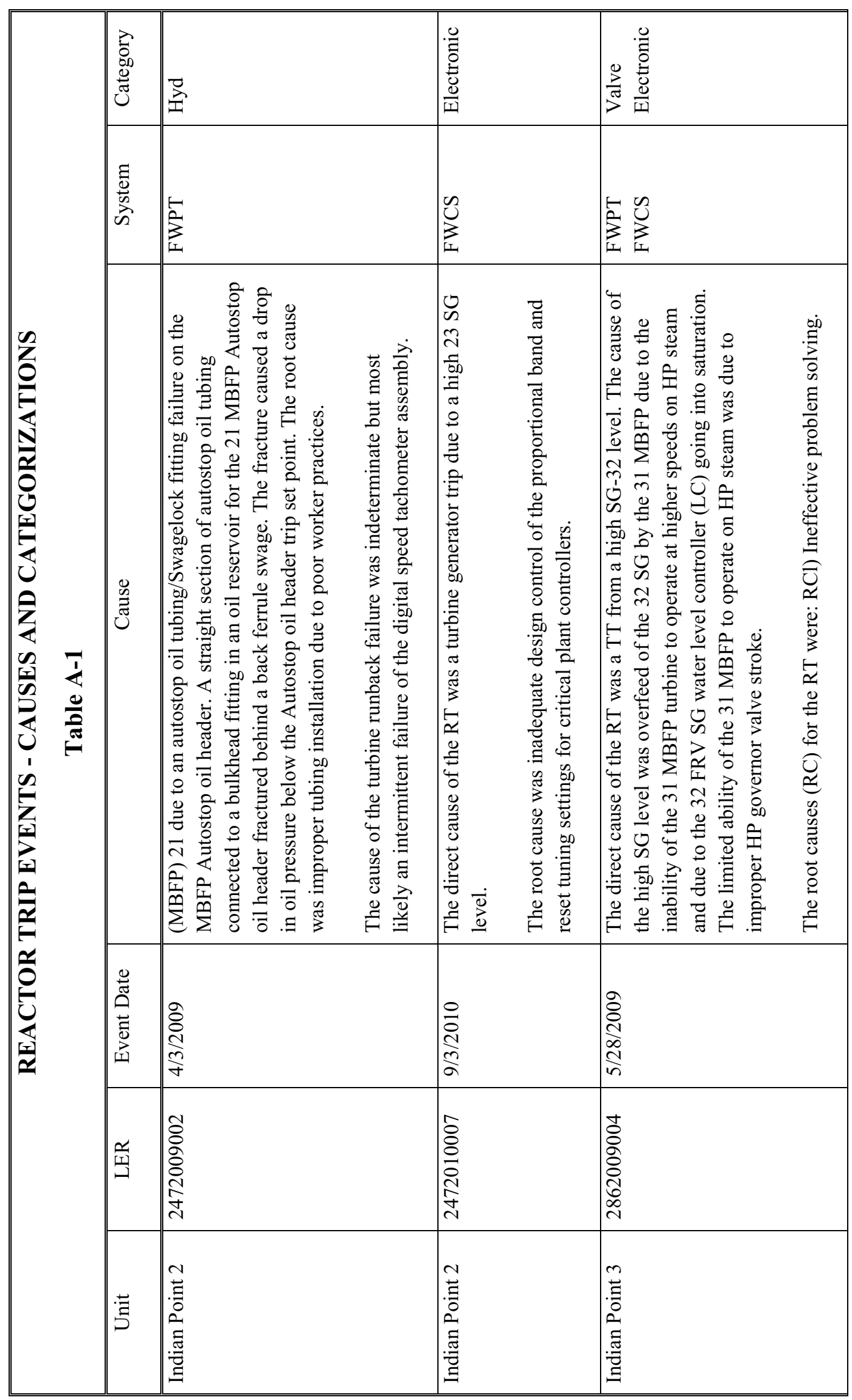




\begin{tabular}{|c|c|c|c|c|c|}
\hline \multirow{6}{*}{ 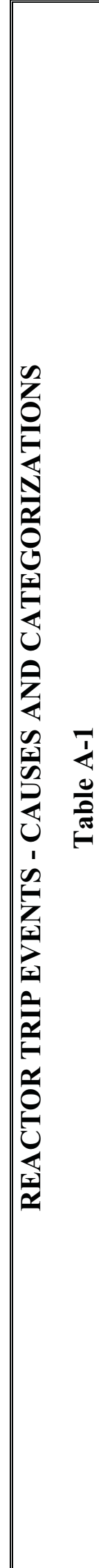 } & 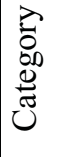 & 离 & 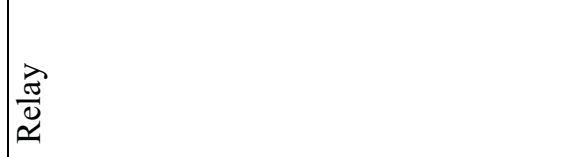 & 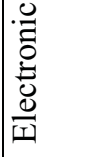 & \\
\hline & a & $\prod_{\tilde{I}}^{0}$ & $\hat{\varkappa}$ & 兽 & \\
\hline & 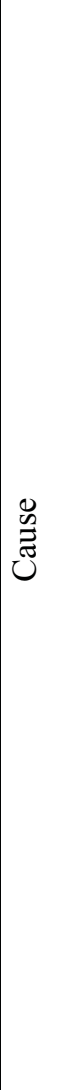 & 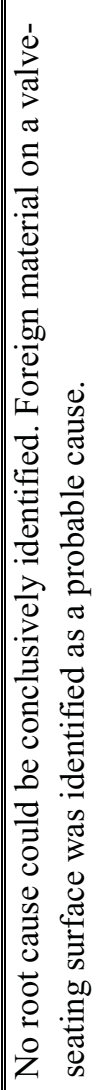 & 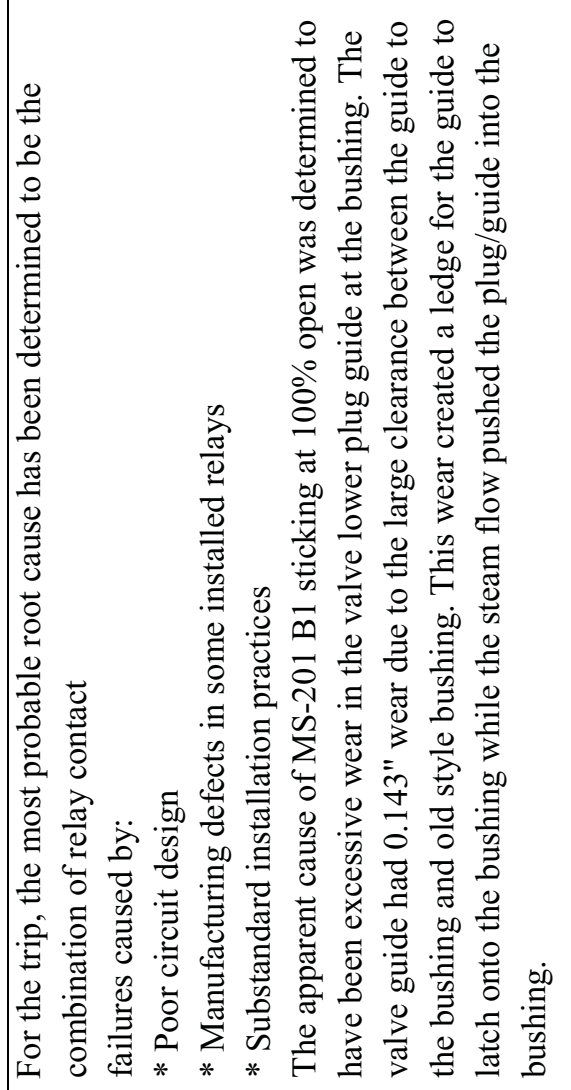 & 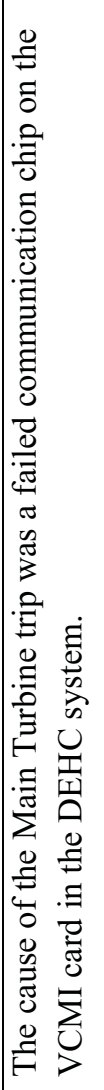 & 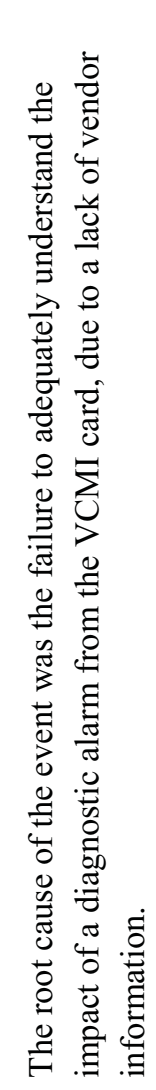 \\
\hline & 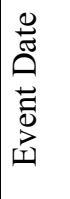 & 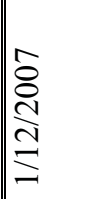 & $\mid$ & 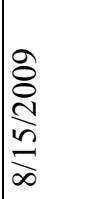 & \\
\hline & $\frac{\widetilde{r}}{\underline{y}}$ & $\begin{array}{l}\vec{b} \\
0 \\
0 \\
0 \\
0 \\
i ̂ n \\
0 \\
0 \\
0\end{array}$ & 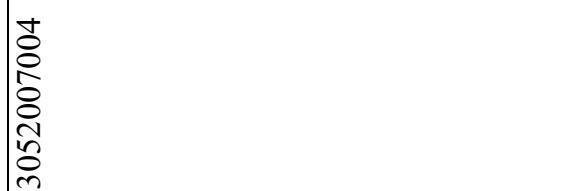 & 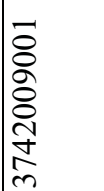 & \\
\hline & 考 & 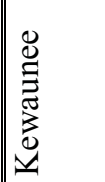 & 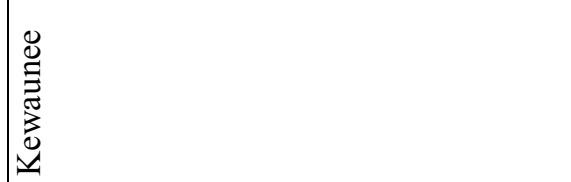 & 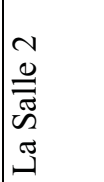 & \\
\hline
\end{tabular}




\begin{tabular}{|c|c|c|c|c|c|c|c|}
\hline \multirow{6}{*}{ 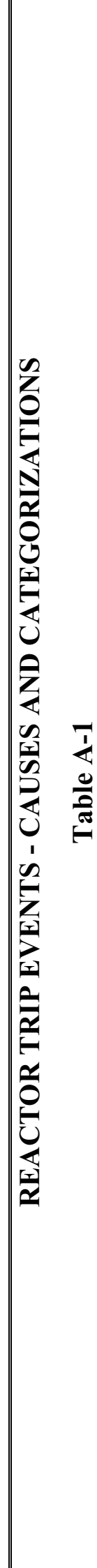 } & 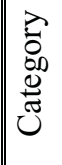 & $\mid$ & 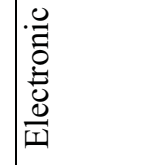 & & 蛋 & 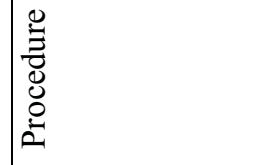 & $\frac{\frac{\partial}{\pi}}{\pi}$ \\
\hline & 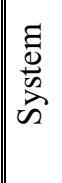 & $\frac{\infty}{\approx}$ & జ̂ & & 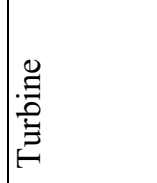 & 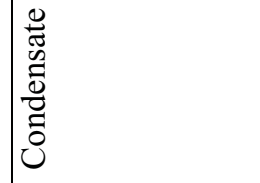 & 岂 \\
\hline & $\mid \begin{array}{l}0 \\
0 \\
\tilde{z} \\
\tilde{J}\end{array}$ & 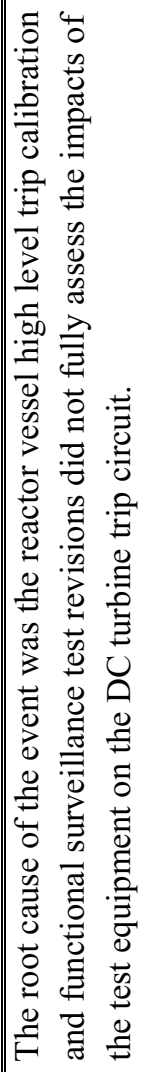 & 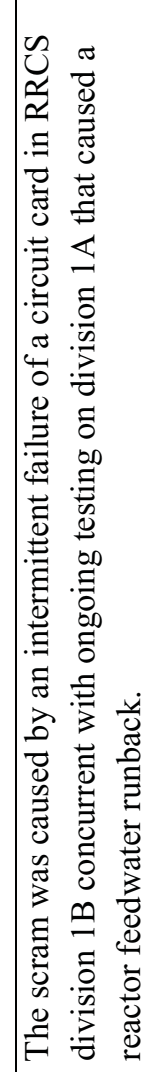 & 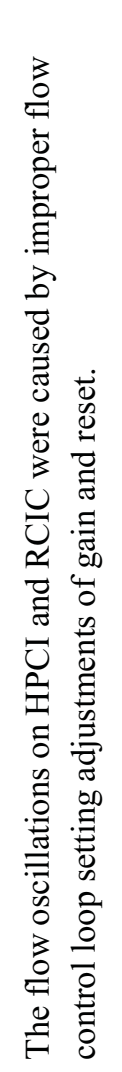 & 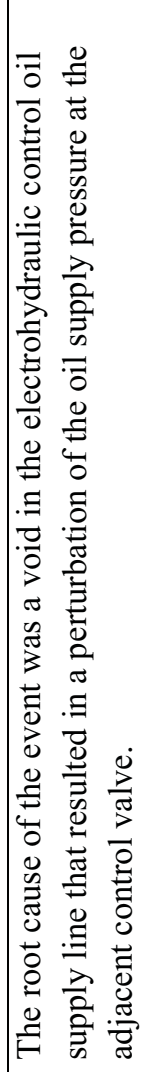 & 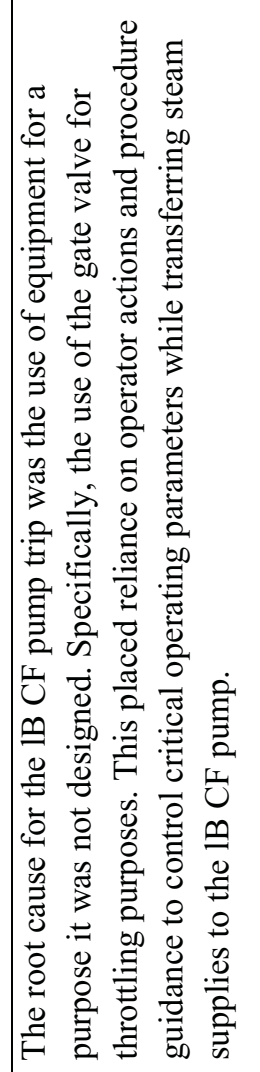 & 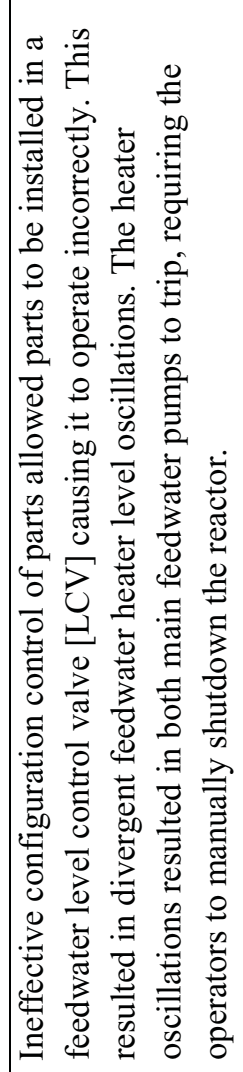 \\
\hline & 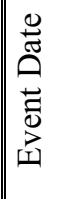 & $\frac{\overrightarrow{\vec{n}}}{\frac{\vec{N}}{6}}$ & 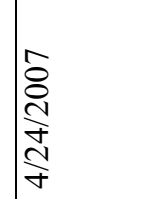 & & $\begin{array}{l}\overrightarrow{\tilde{N}} \\
\bar{N} \\
\bar{N} \\
\text { in }\end{array}$ & 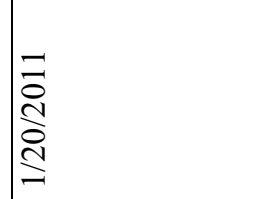 & 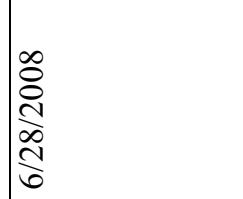 \\
\hline & 童 & 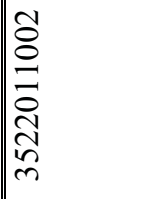 & 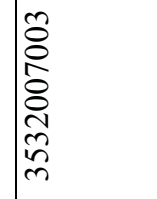 & & 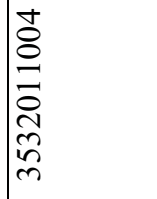 & 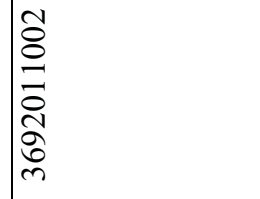 & 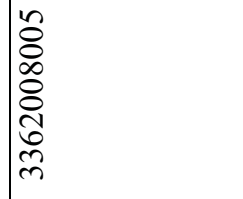 \\
\hline & $b \cdot \vec{b}$ & 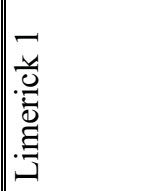 & 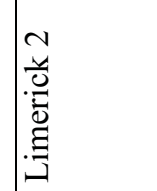 & & 童 & 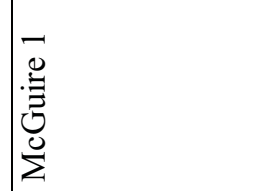 & 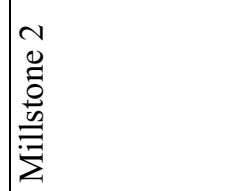 \\
\hline
\end{tabular}




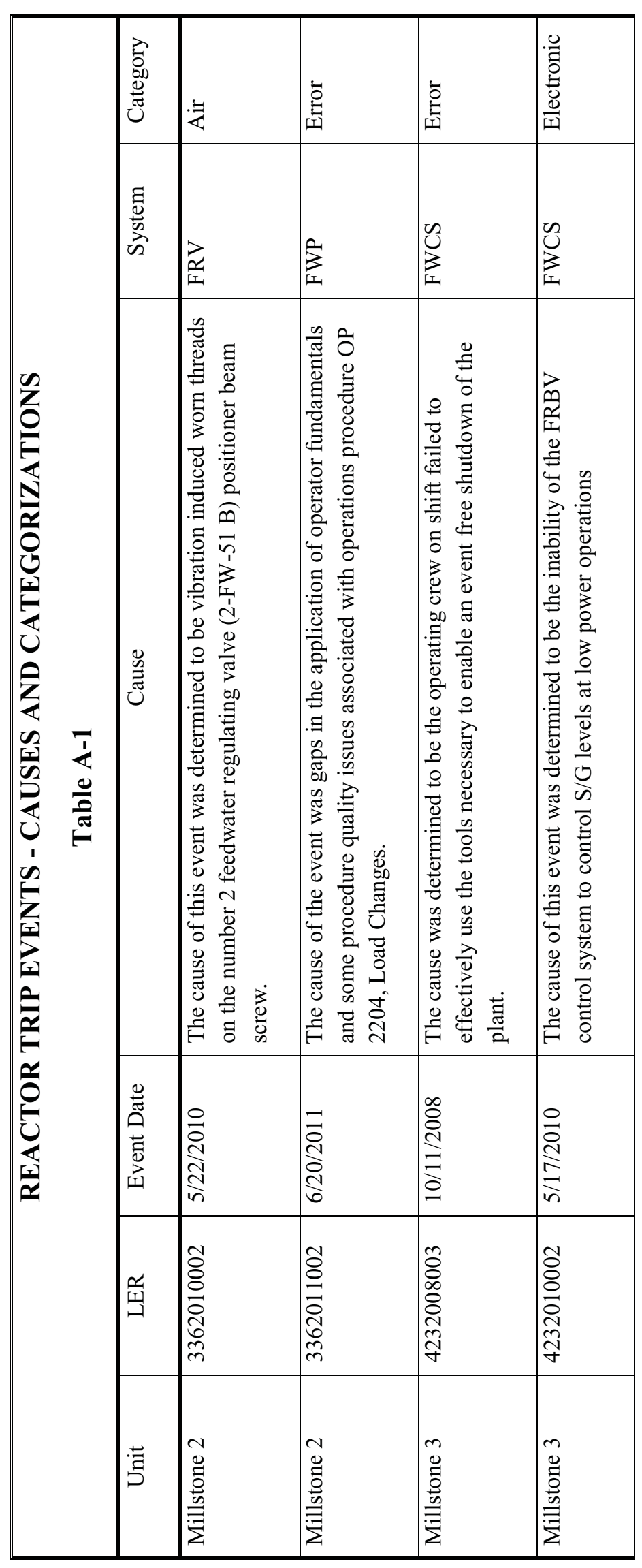




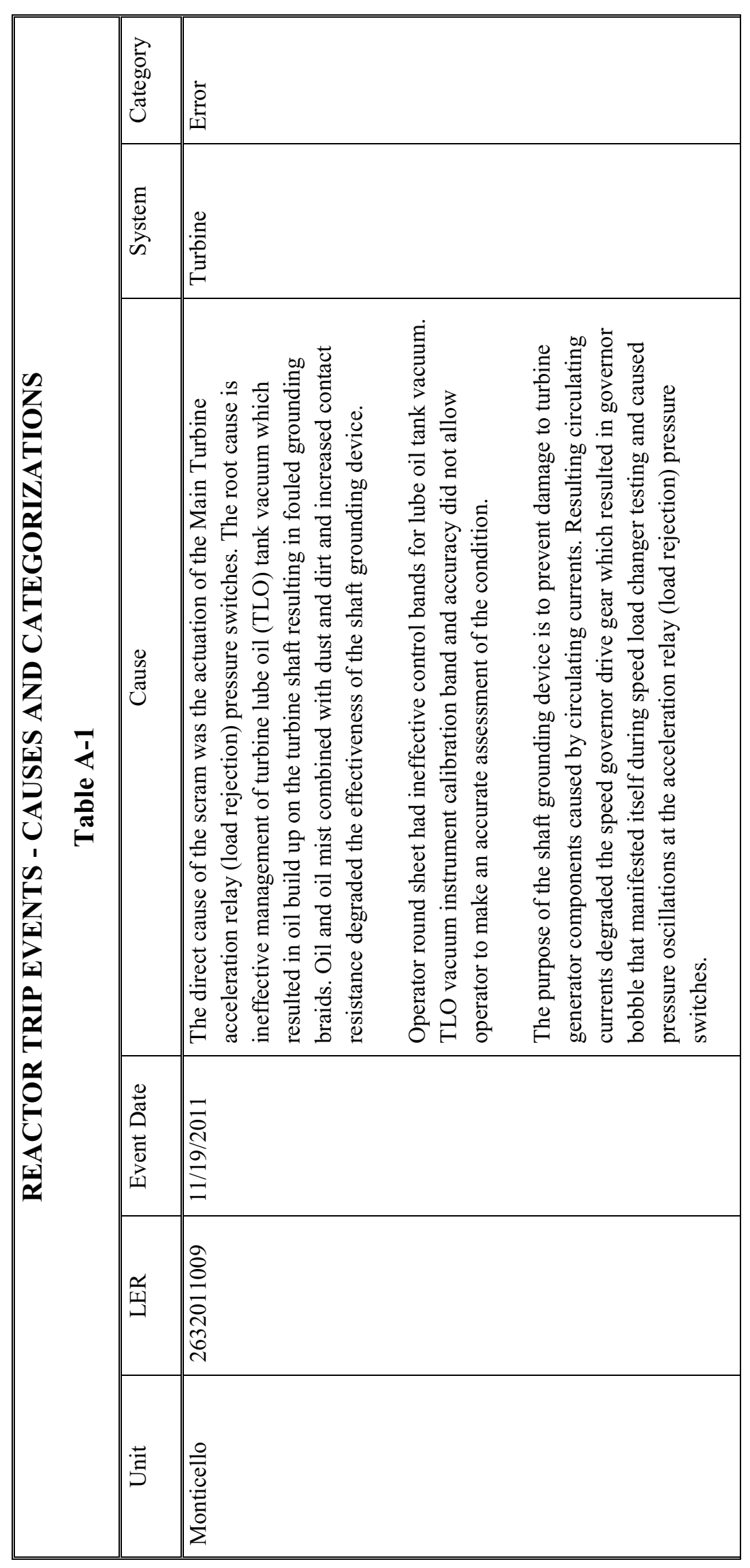




\begin{tabular}{|c|c|c|c|c|}
\hline \multirow{6}{*}{ 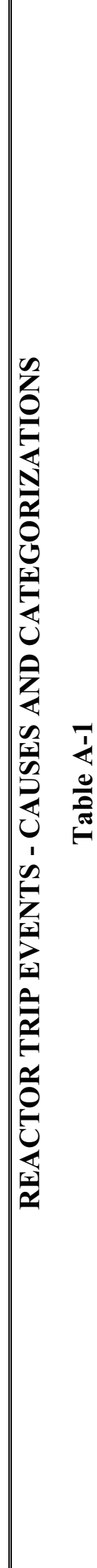 } & 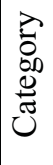 & 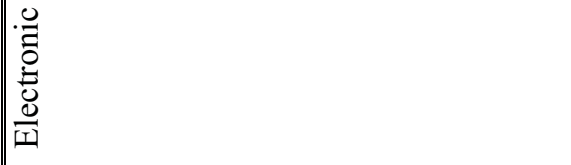 & 兽 & \\
\hline & & 垈 & 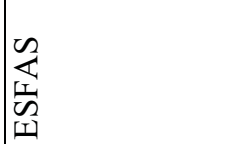 & \\
\hline & 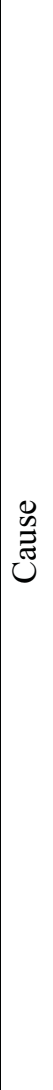 & 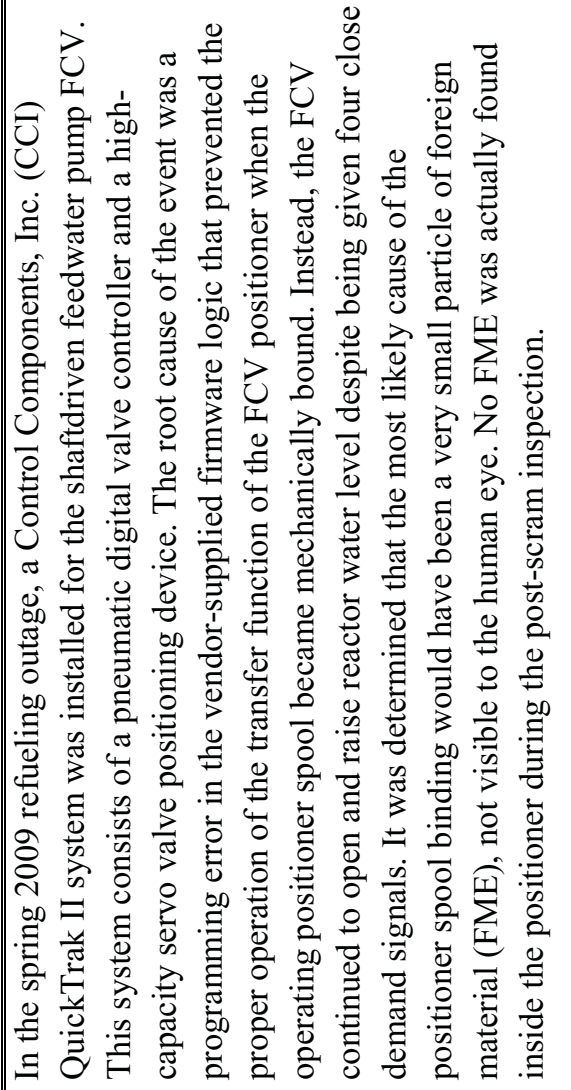 & 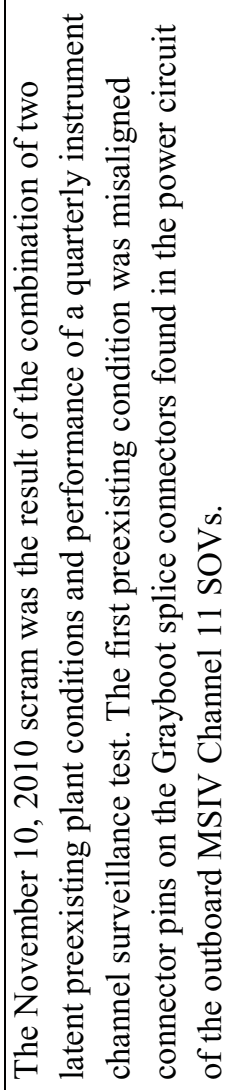 & 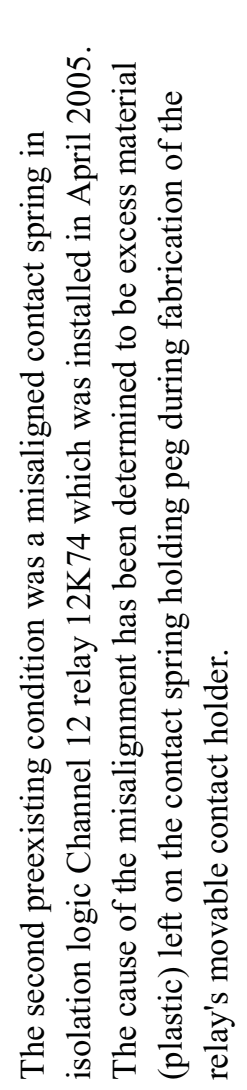 \\
\hline & 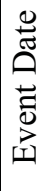 & 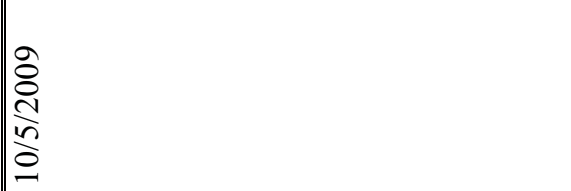 & 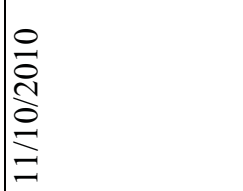 & \\
\hline & 㽣 & 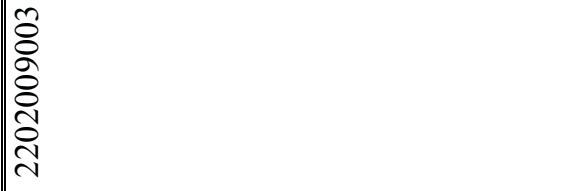 & 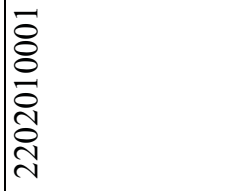 & \\
\hline & $\overline{5}$ & 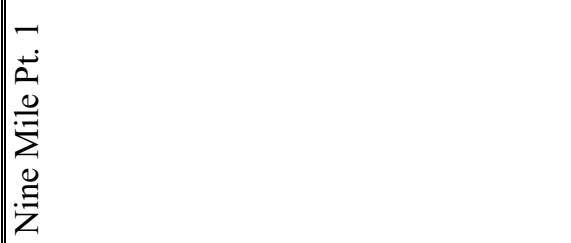 & 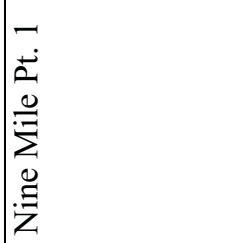 & \\
\hline
\end{tabular}




\begin{tabular}{|c|c|c|c|c|c|c|c|}
\hline \multirow{6}{*}{ 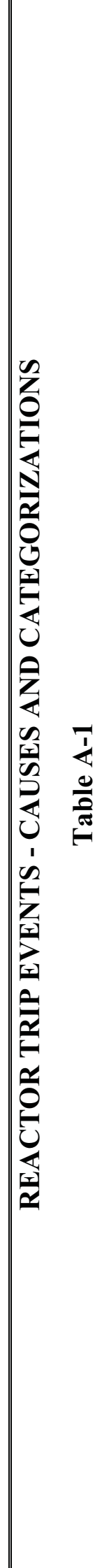 } & 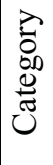 & | & & 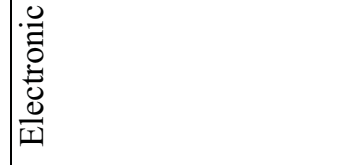 & & $\frac{\overrightarrow{0}}{\sum^{0}}$ & 总 \\
\hline & 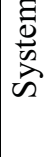 & $\frac{\tilde{a}}{\tilde{a}}$ & & $\begin{array}{l}\tilde{\nu} \\
3 \\
\end{array}$ & & $\mid \begin{array}{l}\tilde{z} \\
\end{array}$ & 虎 \\
\hline & 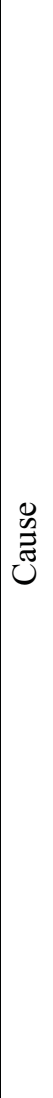 & 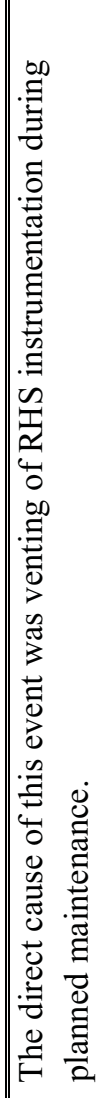 & 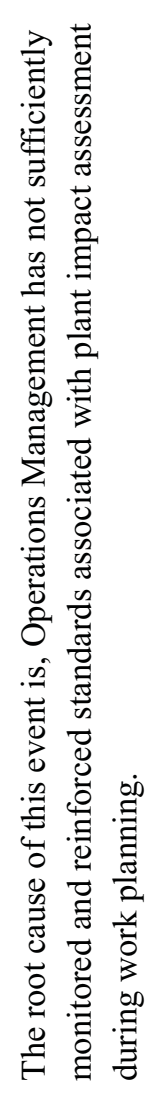 & 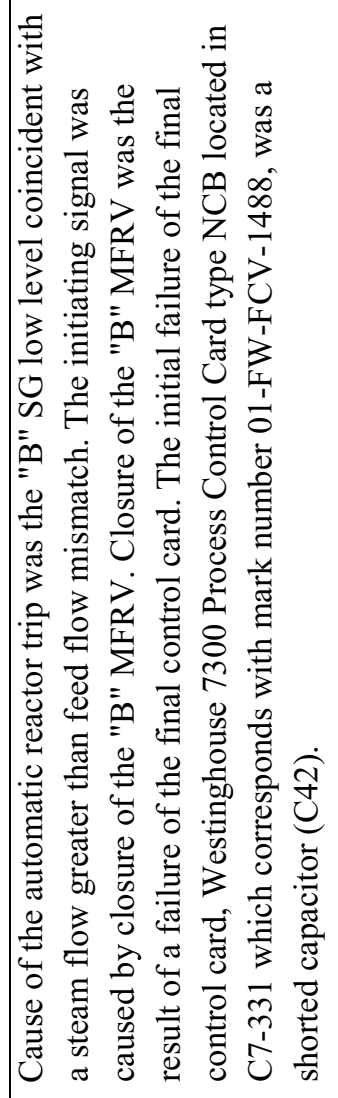 & 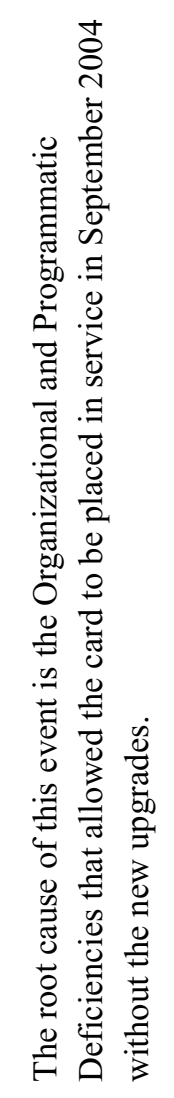 & 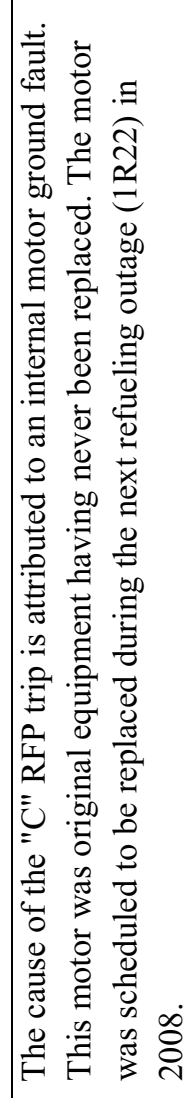 & 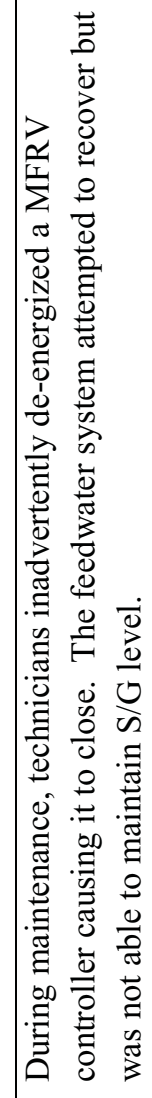 \\
\hline & 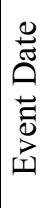 & 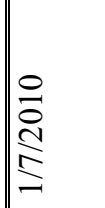 & & 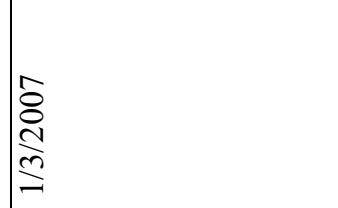 & & 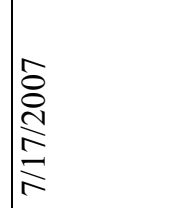 & 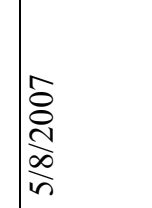 \\
\hline & 畄 & 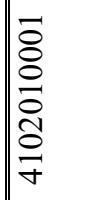 & & $\begin{array}{l}\bar{\delta} \\
\stackrel{8}{0} \\
\stackrel{0}{0} \\
\infty \\
\text { m }\end{array}$ & & 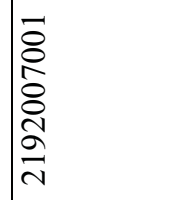 & 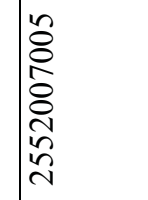 \\
\hline & 5 & $\frac{N}{\stackrel{N}{D}}$ & & 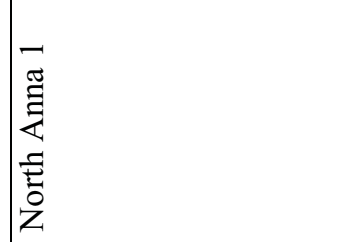 & & 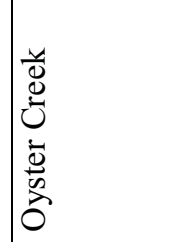 & 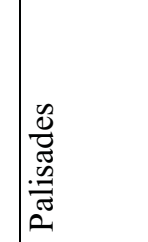 \\
\hline
\end{tabular}




\begin{tabular}{|c|c|c|c|c|c|}
\hline \multirow{6}{*}{ 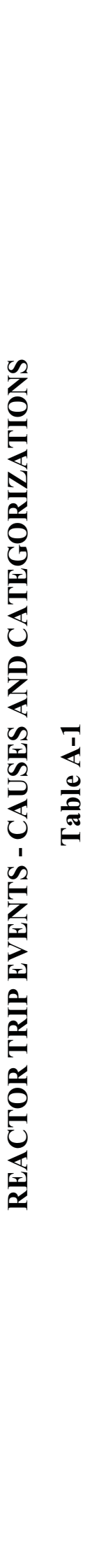 } & 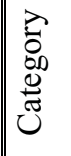 & 言 & 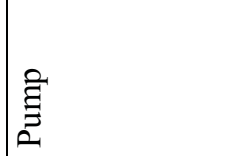 & 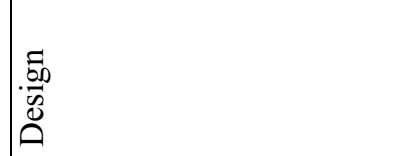 & 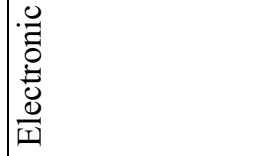 \\
\hline & 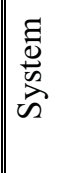 & 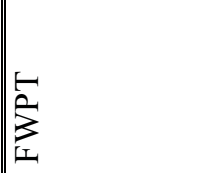 & 疍 & $\begin{array}{l}\tilde{y} \\
3 \\
z\end{array}$ & $\begin{array}{l}\tilde{u} \\
z_{I}\end{array}$ \\
\hline & 竞 & 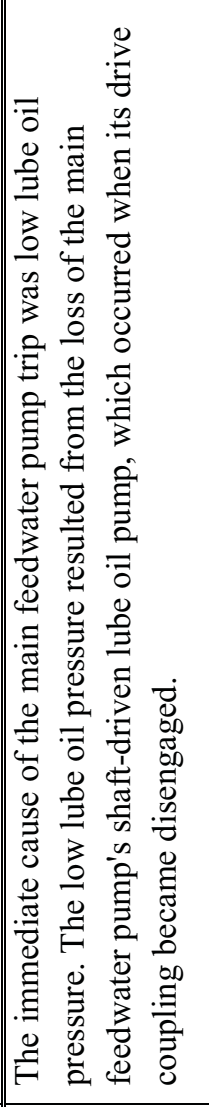 & 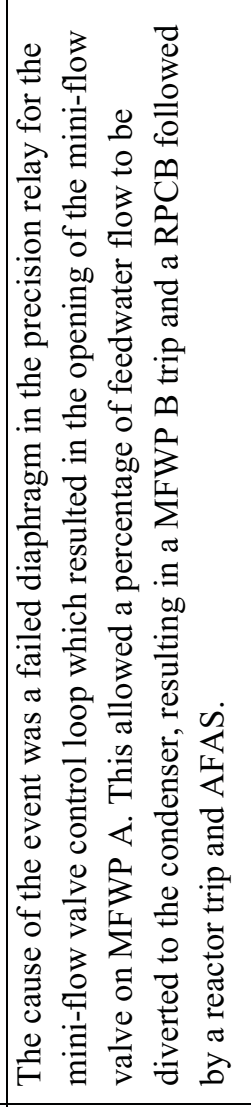 & 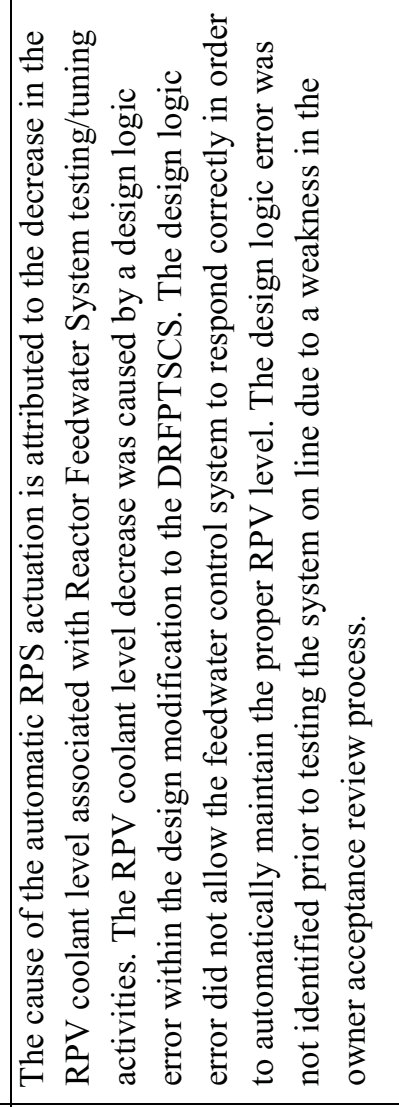 & 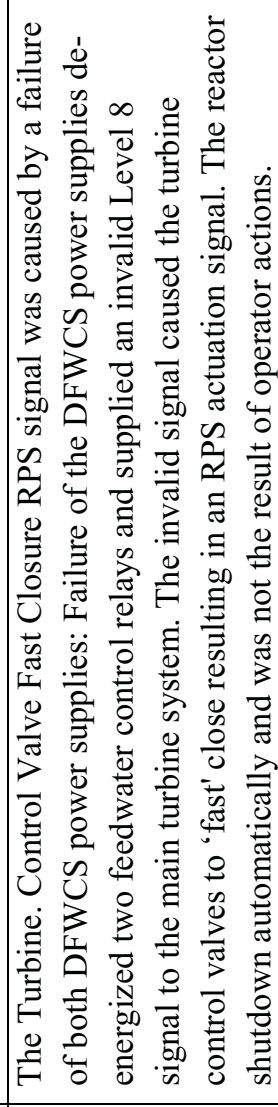 \\
\hline & 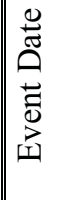 & 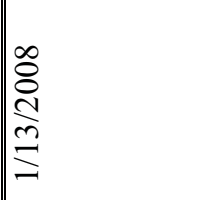 & 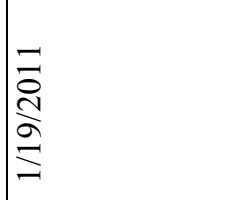 & 离 & 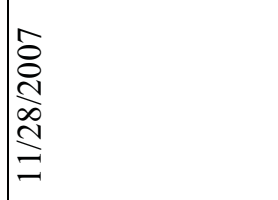 \\
\hline & 举 & 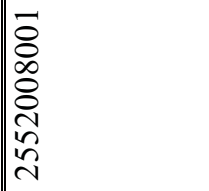 & 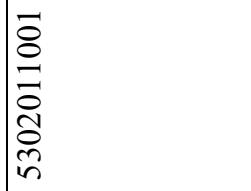 & 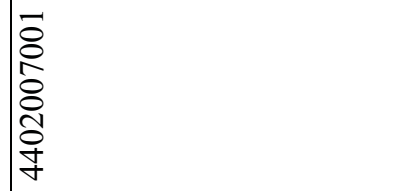 & 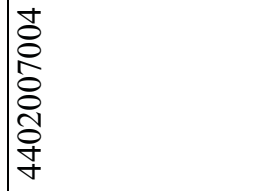 \\
\hline & $\dot{\xi}$ & 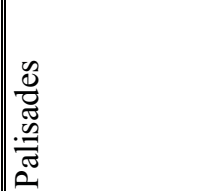 & 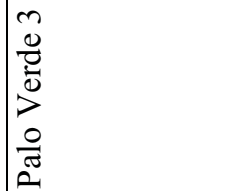 & D. & D. \\
\hline
\end{tabular}

 


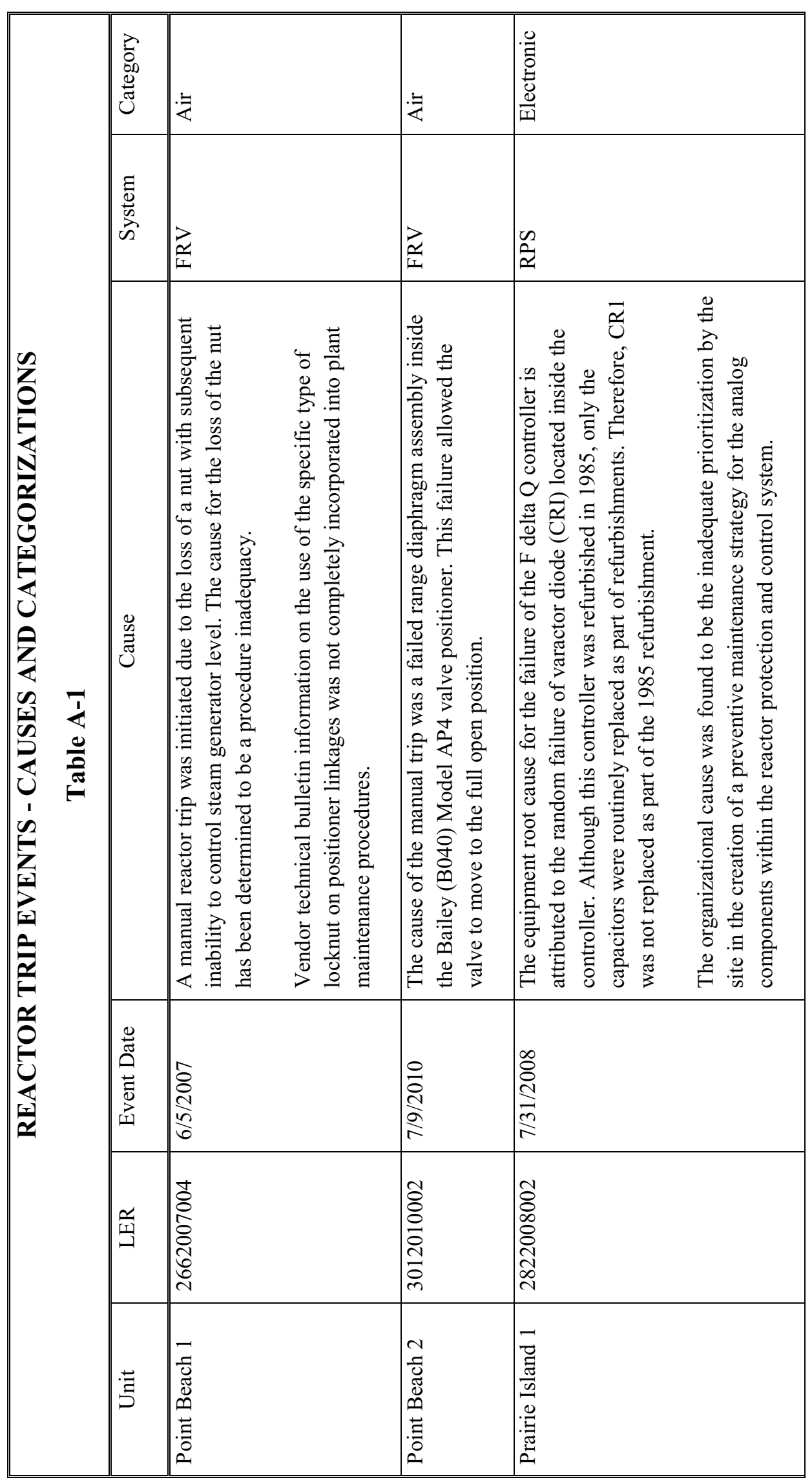




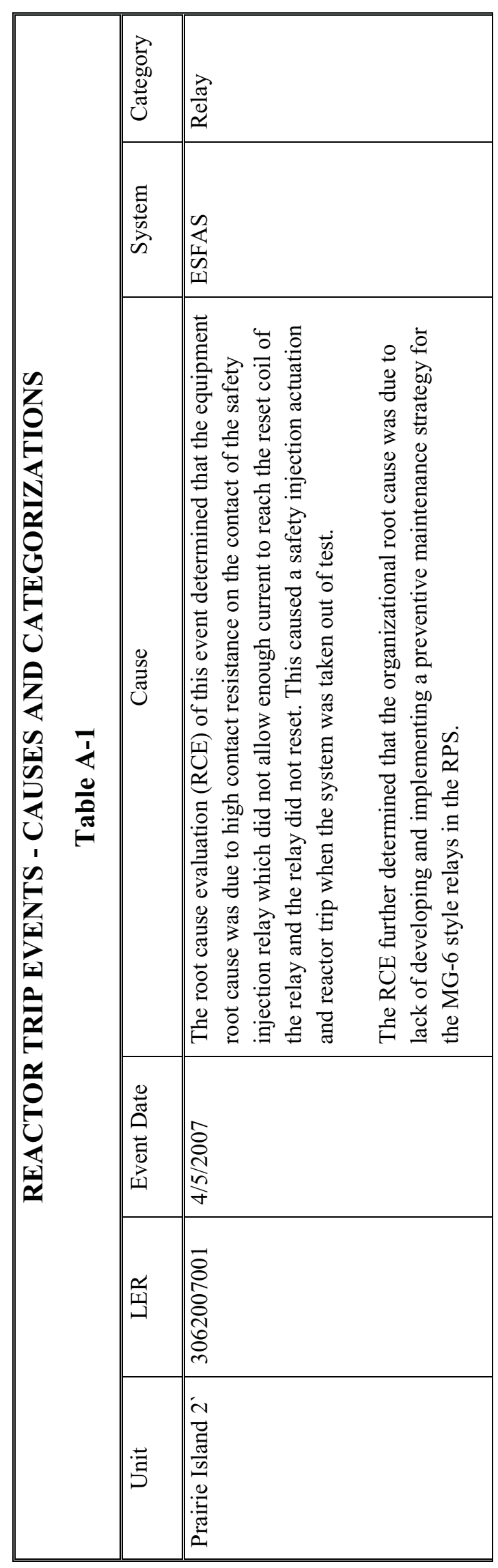




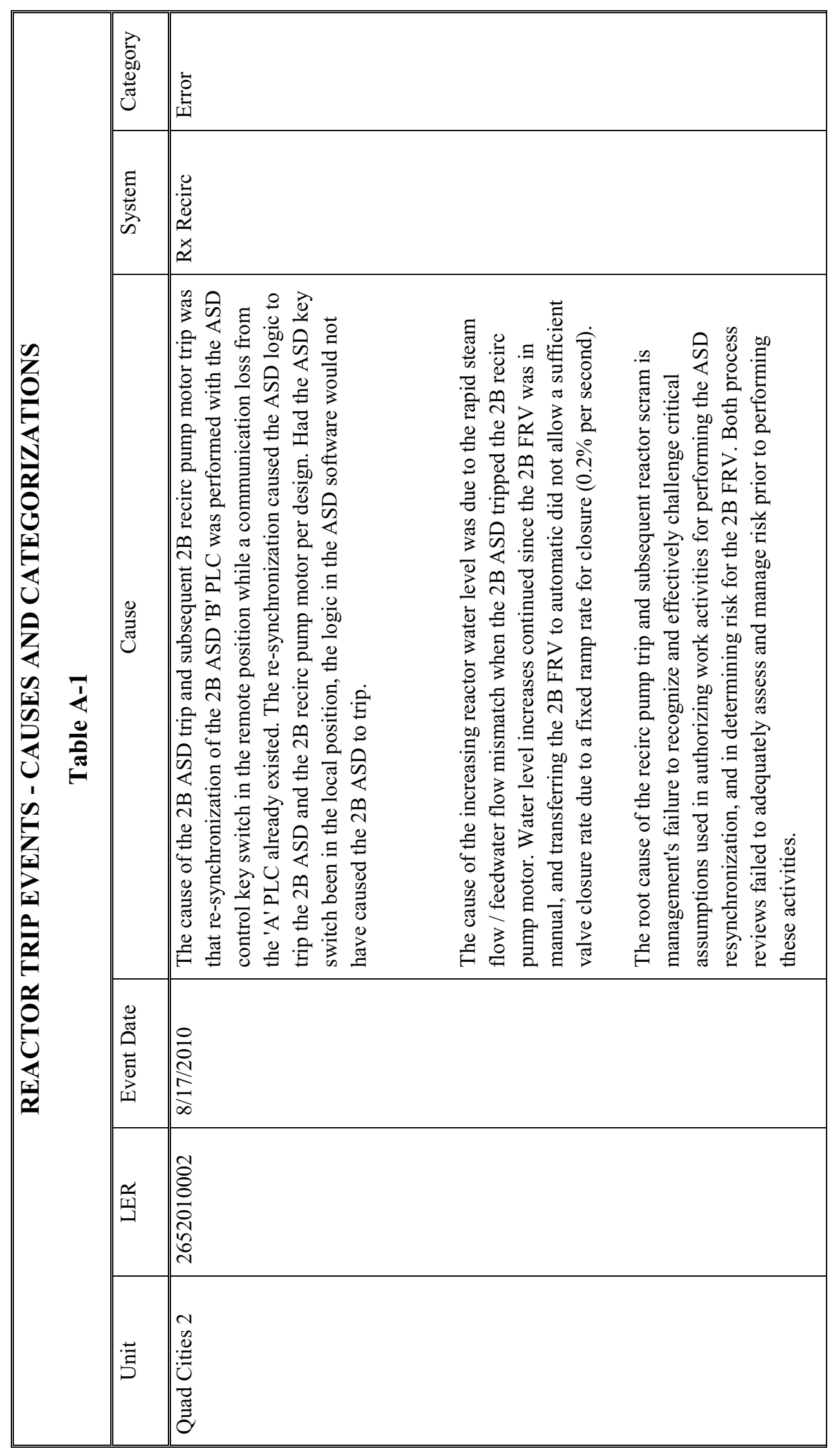




\begin{tabular}{|c|c|c|c|c|}
\hline \multirow{6}{*}{ 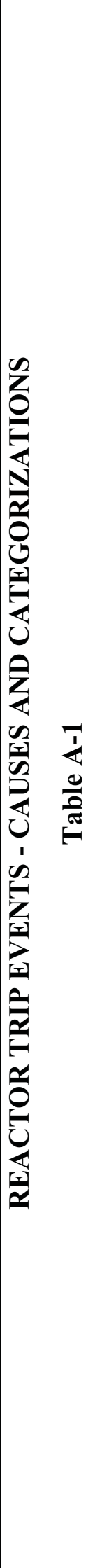 } & 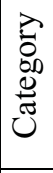 & \multicolumn{2}{|l|}{$\mid \frac{0}{0}$} & \multirow{2}{*}{ 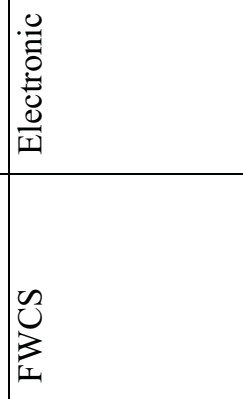 } \\
\hline & & $\tilde{n}$ & & \\
\hline & 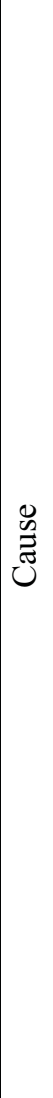 & 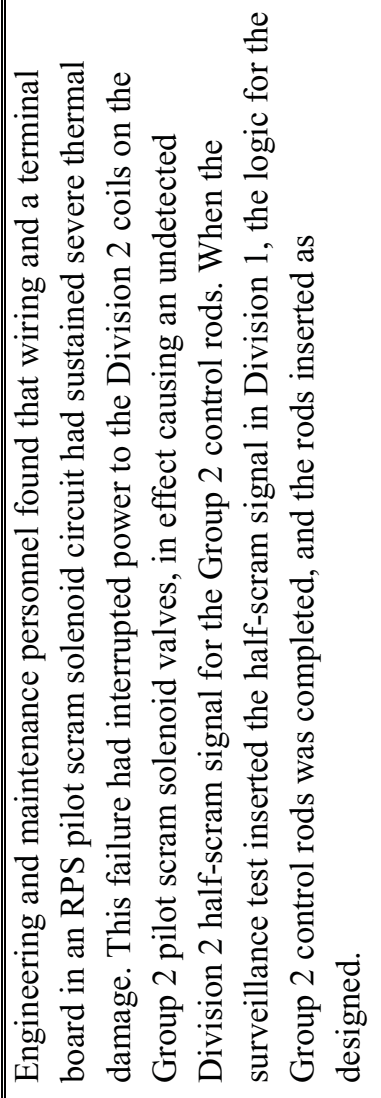 & 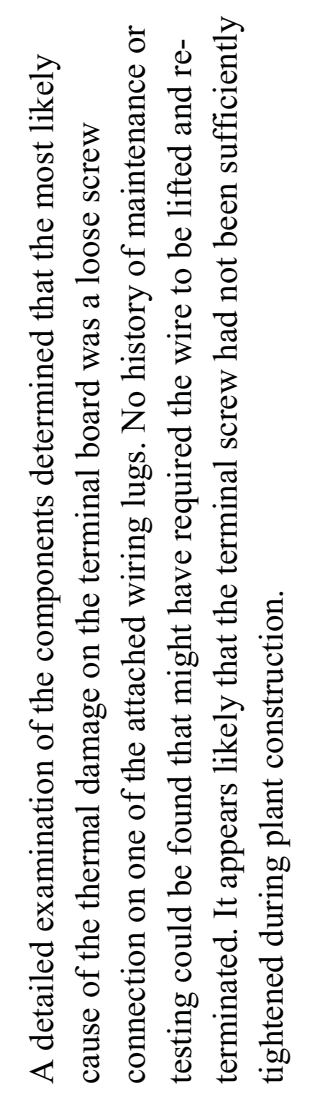 & 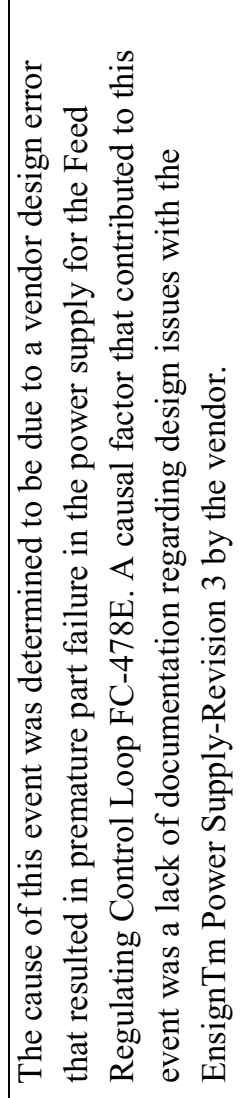 \\
\hline & 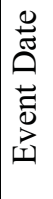 & 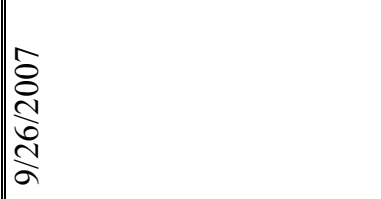 & & 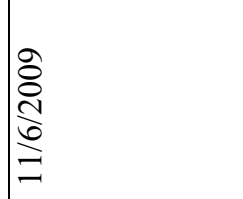 \\
\hline & 茎 & $\begin{array}{l}n \\
0 \\
0 \\
0 \\
0 \\
0 \\
0 \\
o \\
f \\
f\end{array}$ & & 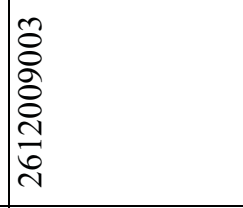 \\
\hline & $\overline{5}$ & 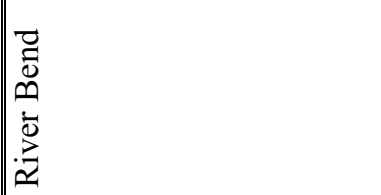 & & 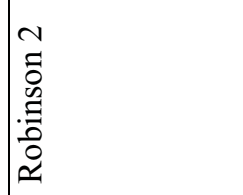 \\
\hline
\end{tabular}




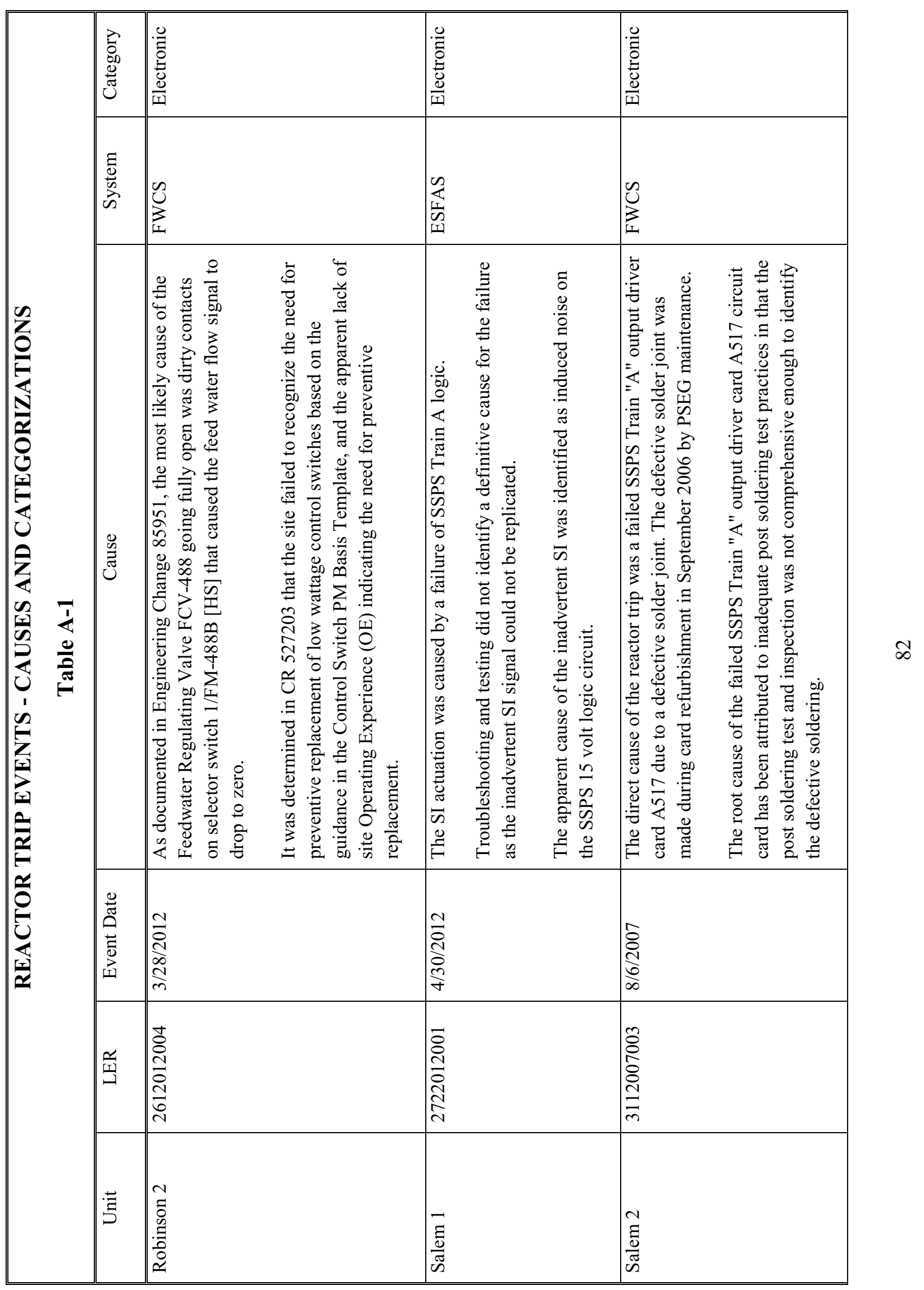




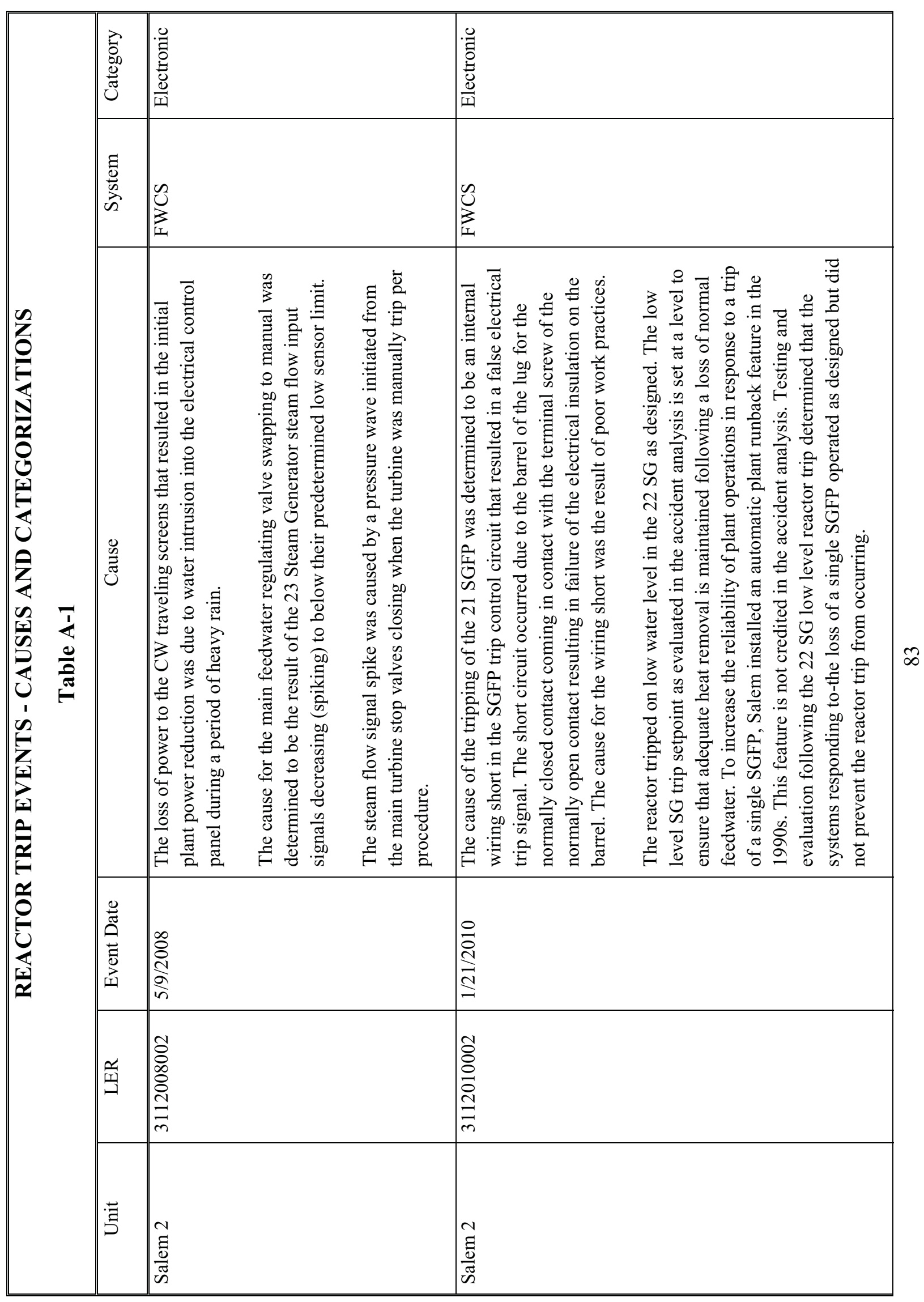




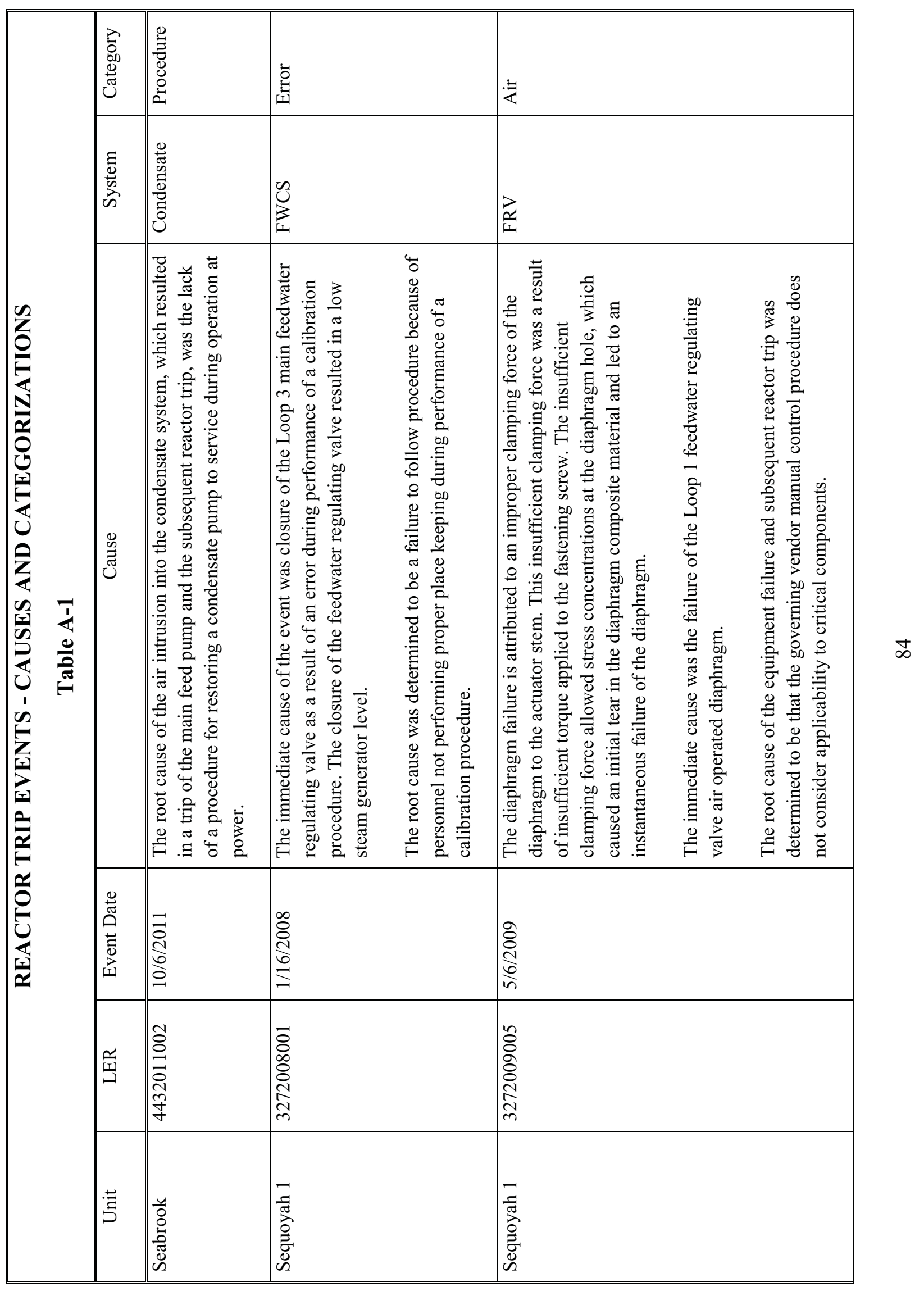




\begin{tabular}{|c|c|c|c|c|c|}
\hline \multirow{6}{*}{ 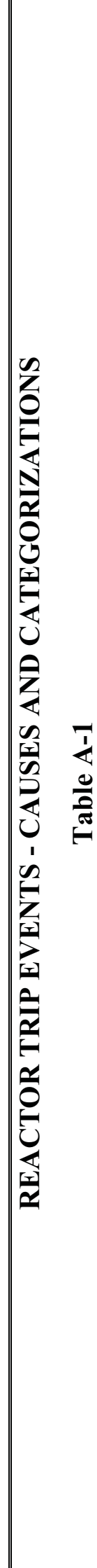 } & 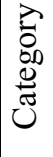 & \multicolumn{2}{|l|}{$\mid \frac{\mathscr{y}}{\overline{0}}$} & \multicolumn{2}{|l|}{ : } \\
\hline & 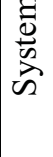 & $\int_{i}^{\infty}$ & & 胥 & \\
\hline & 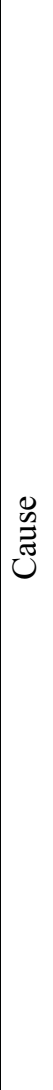 & 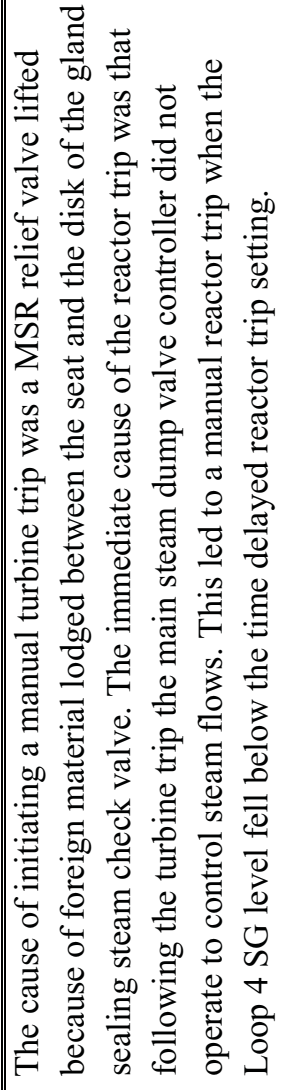 & 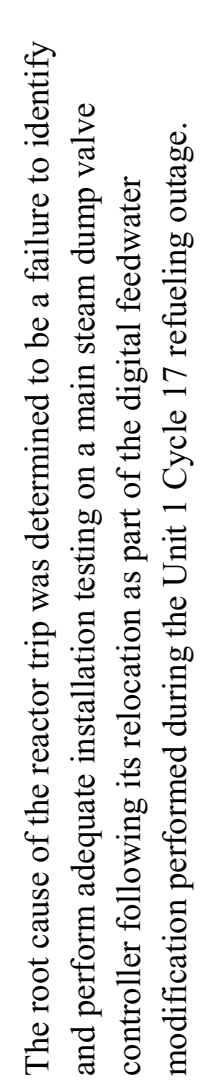 & 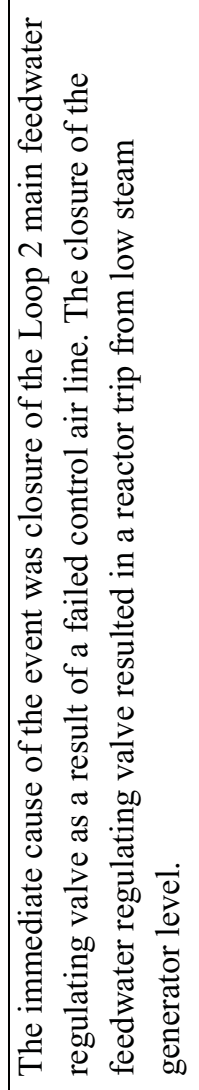 & 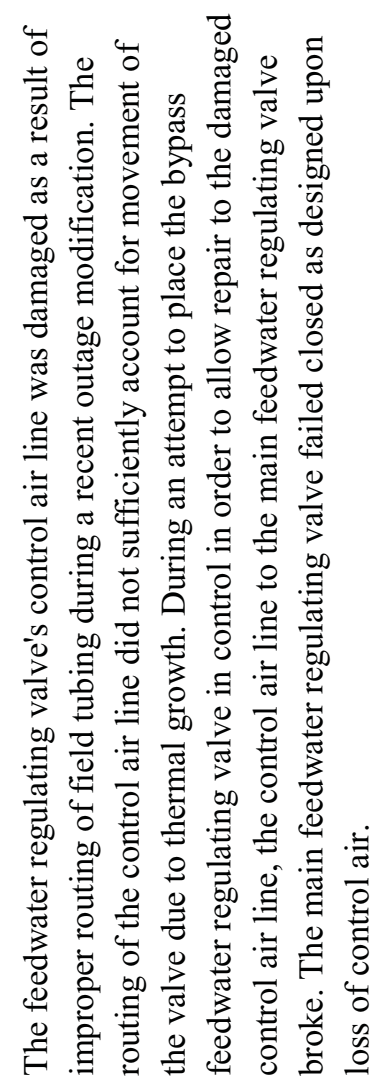 \\
\hline & 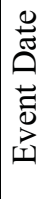 & 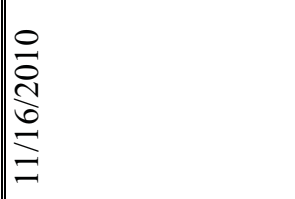 & & 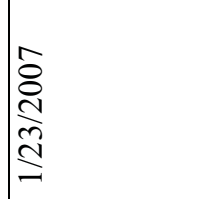 & \\
\hline & 㽣 & 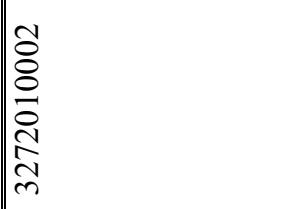 & & 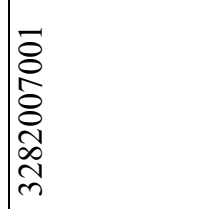 & \\
\hline & $\overline{5}$ & 宽 & & 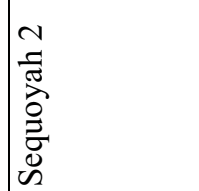 & \\
\hline
\end{tabular}




\begin{tabular}{|c|c|c|c|c|c|c|c|}
\hline \multirow{6}{*}{ 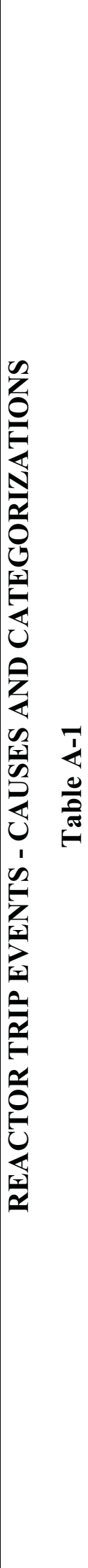 } & 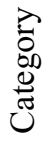 & \multicolumn{2}{|l|}{ 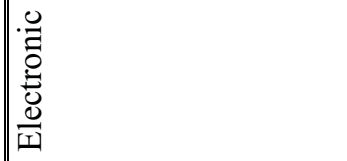 } & \multicolumn{2}{|l|}{ 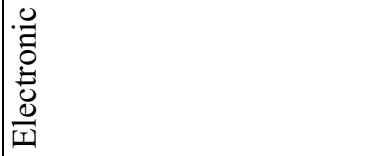 } & \multicolumn{2}{|l|}{\begin{tabular}{|l} 
泀 \\
|
\end{tabular}} \\
\hline & 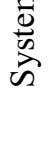 & $\sum_{|l| l}^{i}$ & & $\begin{array}{l}\tilde{\nu} \\
z_{I}\end{array}$ & & $\frac{\tilde{n}}{2}$ & \\
\hline & 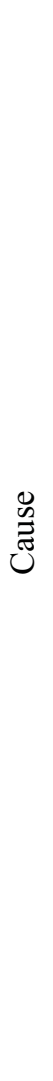 & 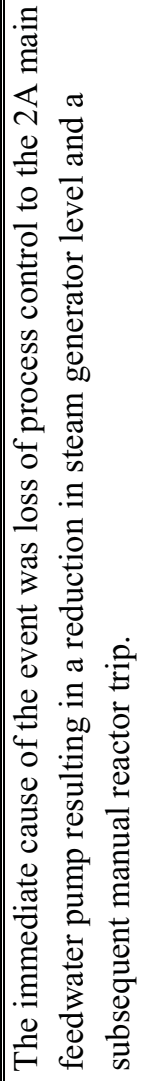 & 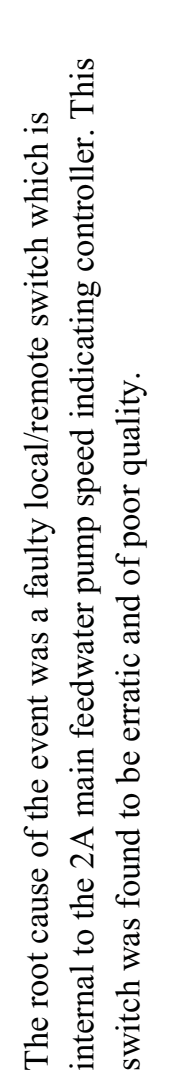 & 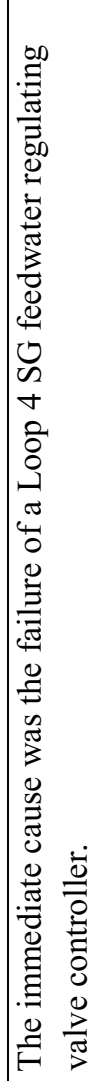 & 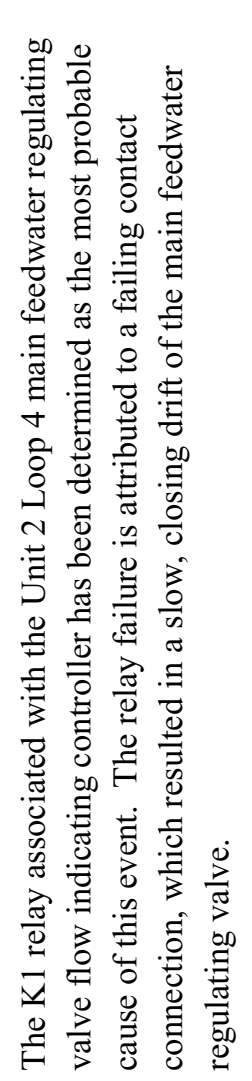 & 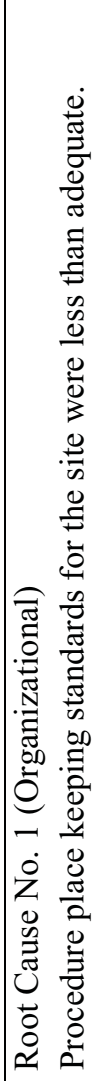 & 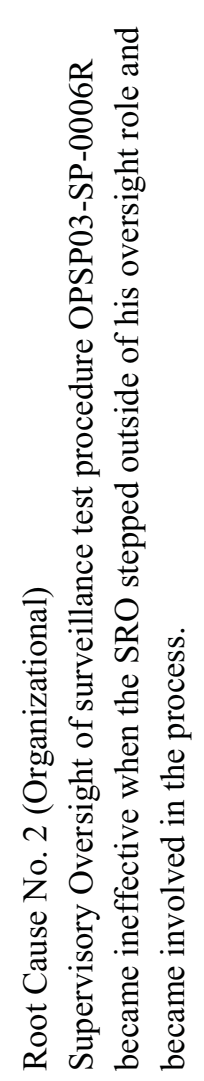 \\
\hline & 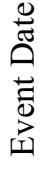 & 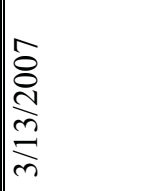 & & $\begin{array}{l}\infty \\
\stackrel{\infty}{0} \\
\stackrel{N}{N} \\
\stackrel{3}{\Xi}\end{array}$ & & 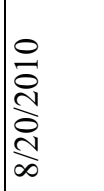 & \\
\hline & 舀 & 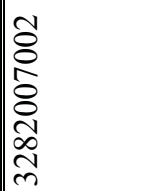 & & $\begin{array}{l}\overrightarrow{8} \\
\infty \\
\infty \\
\stackrel{8}{ } \\
\infty \\
\infty \\
心\end{array}$ & & 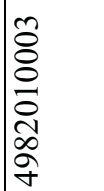 & \\
\hline & 责 & 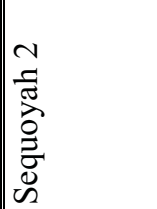 & & 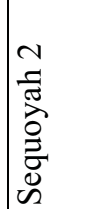 & & 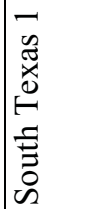 & \\
\hline
\end{tabular}




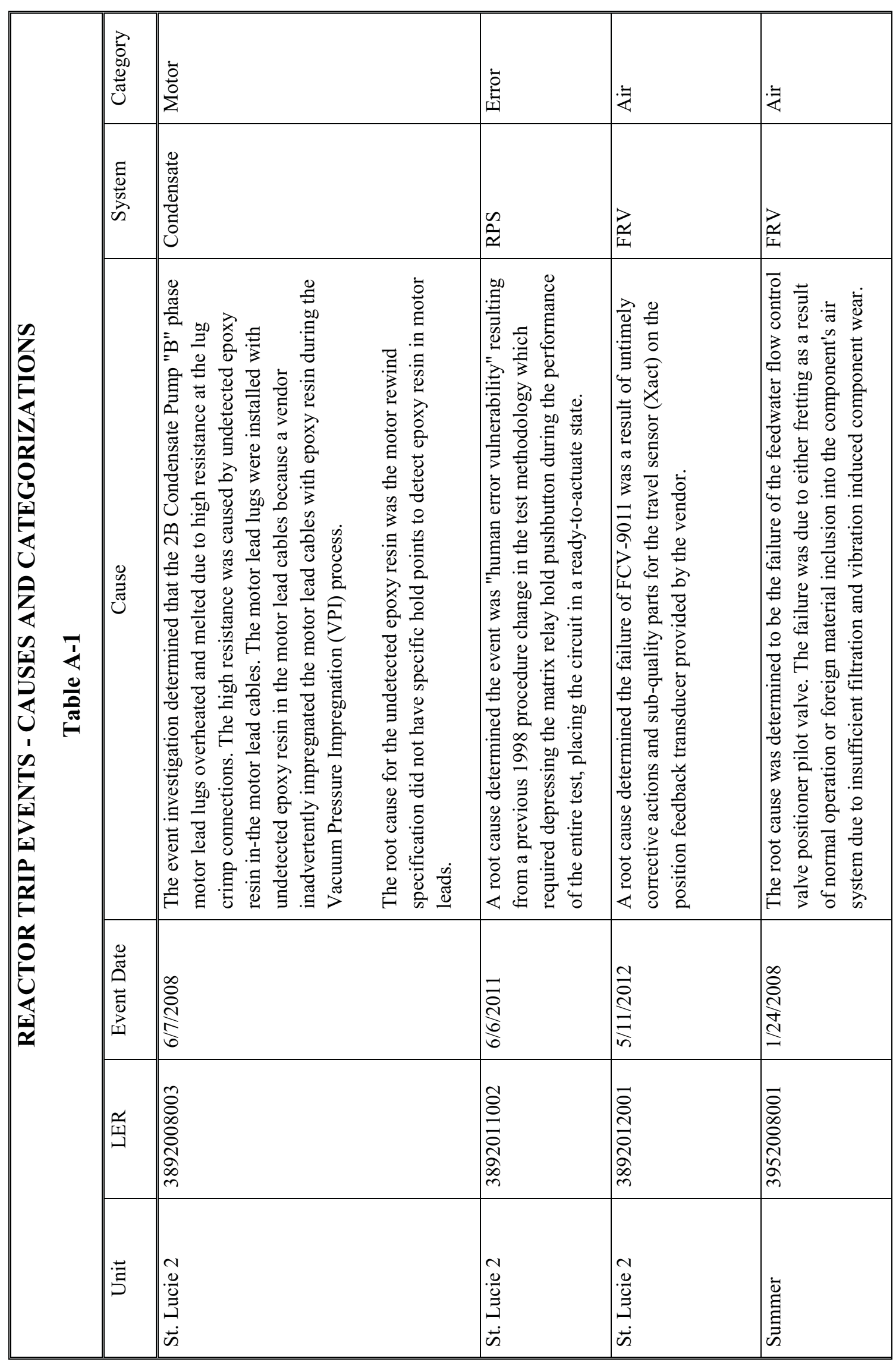




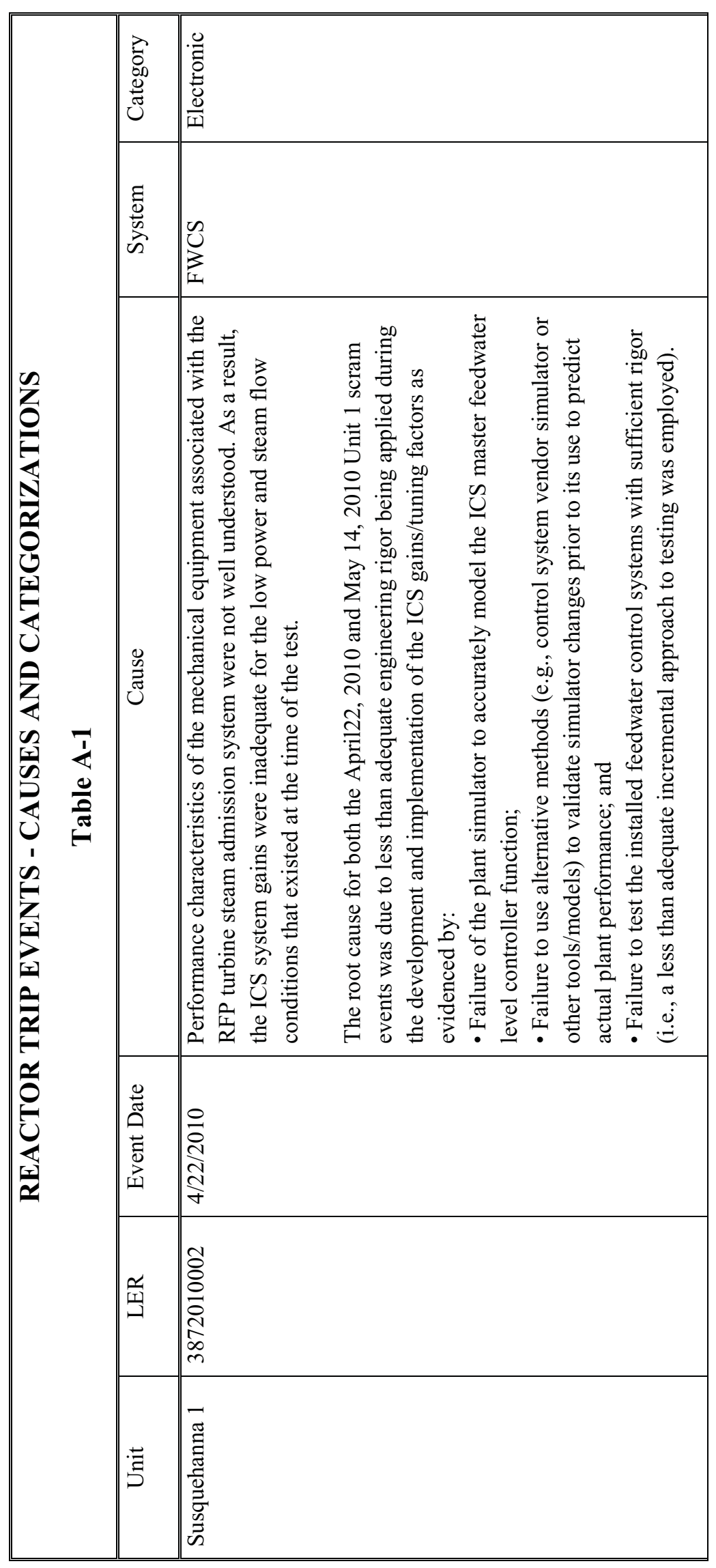




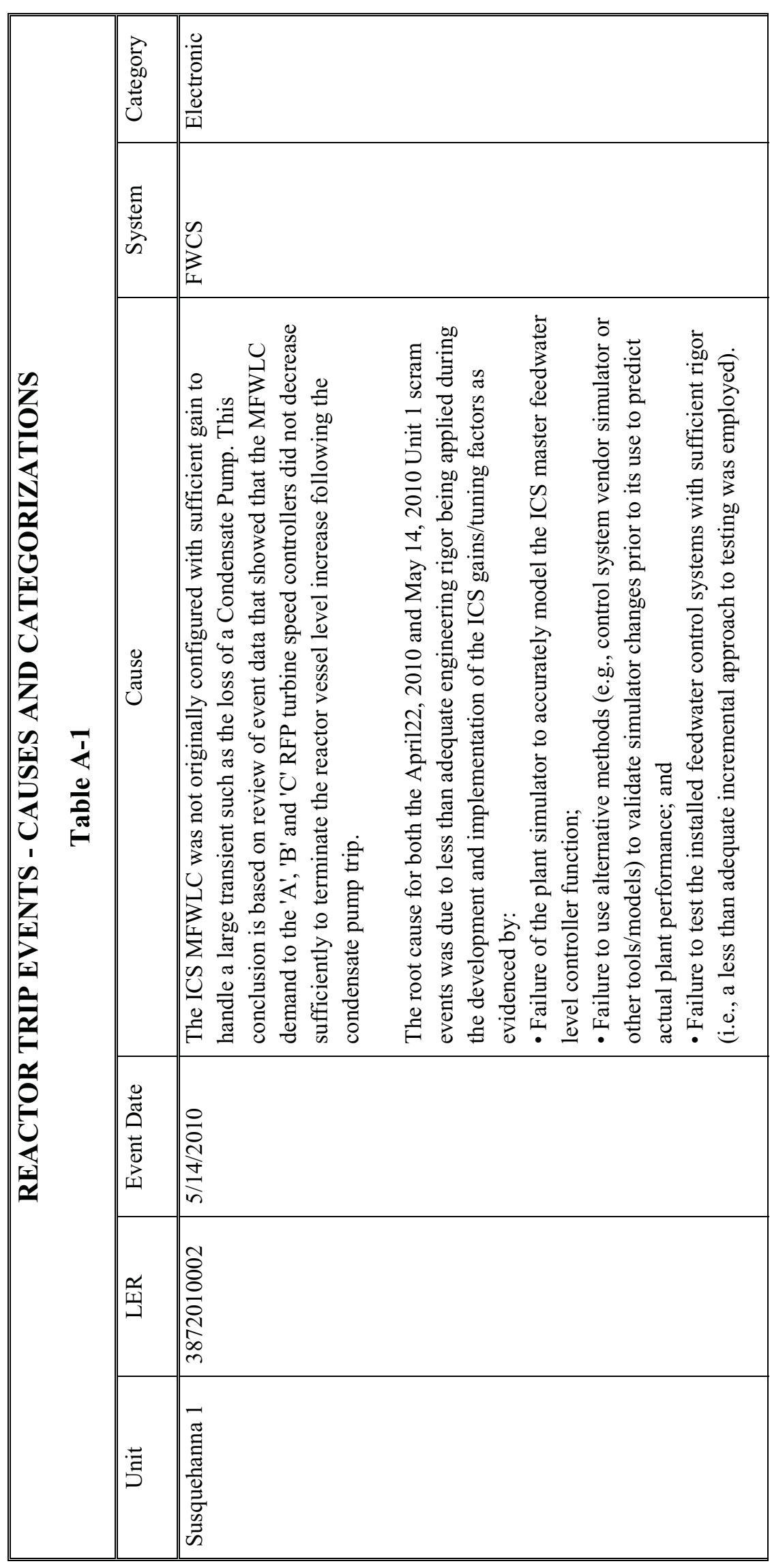




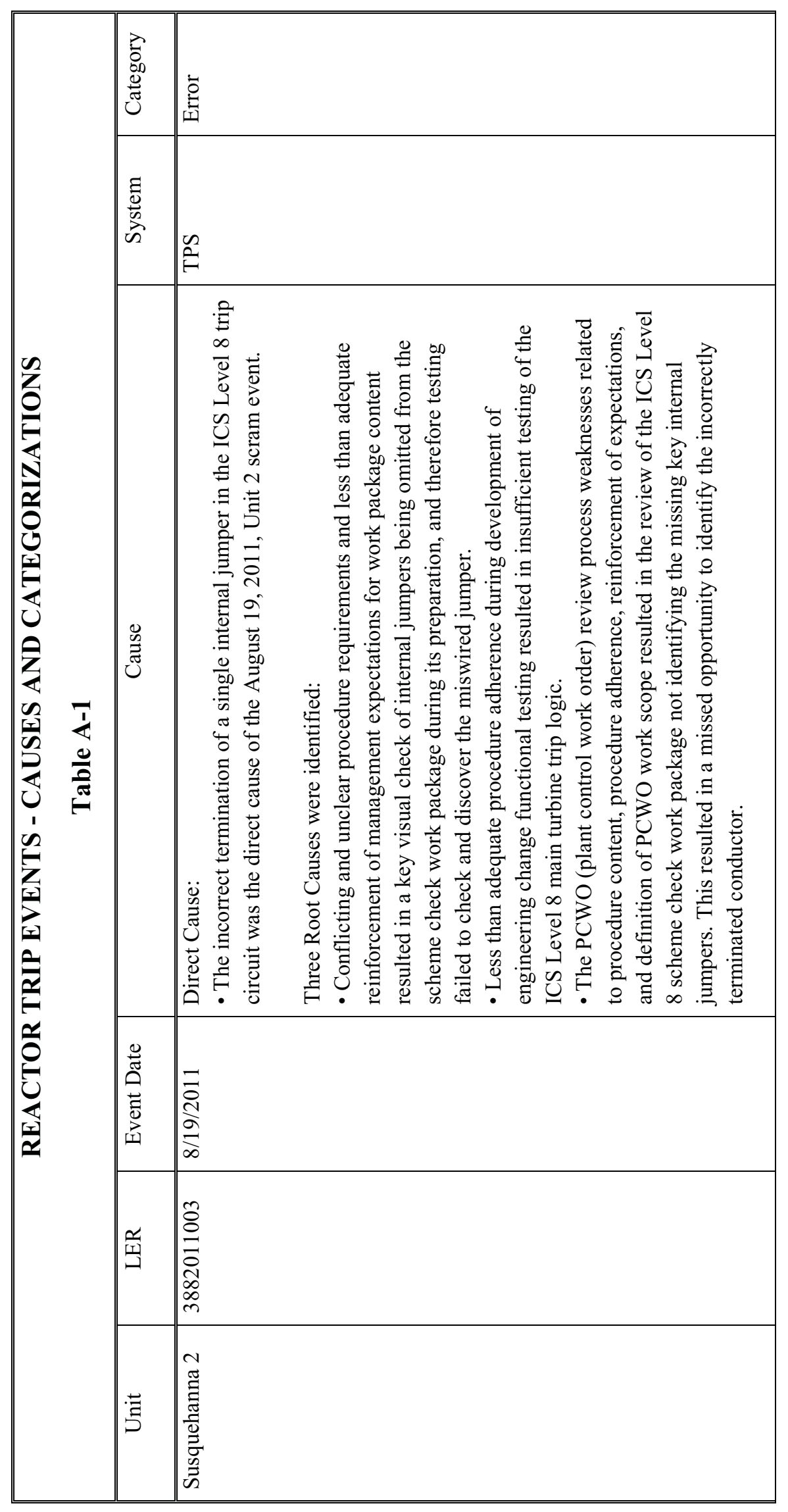




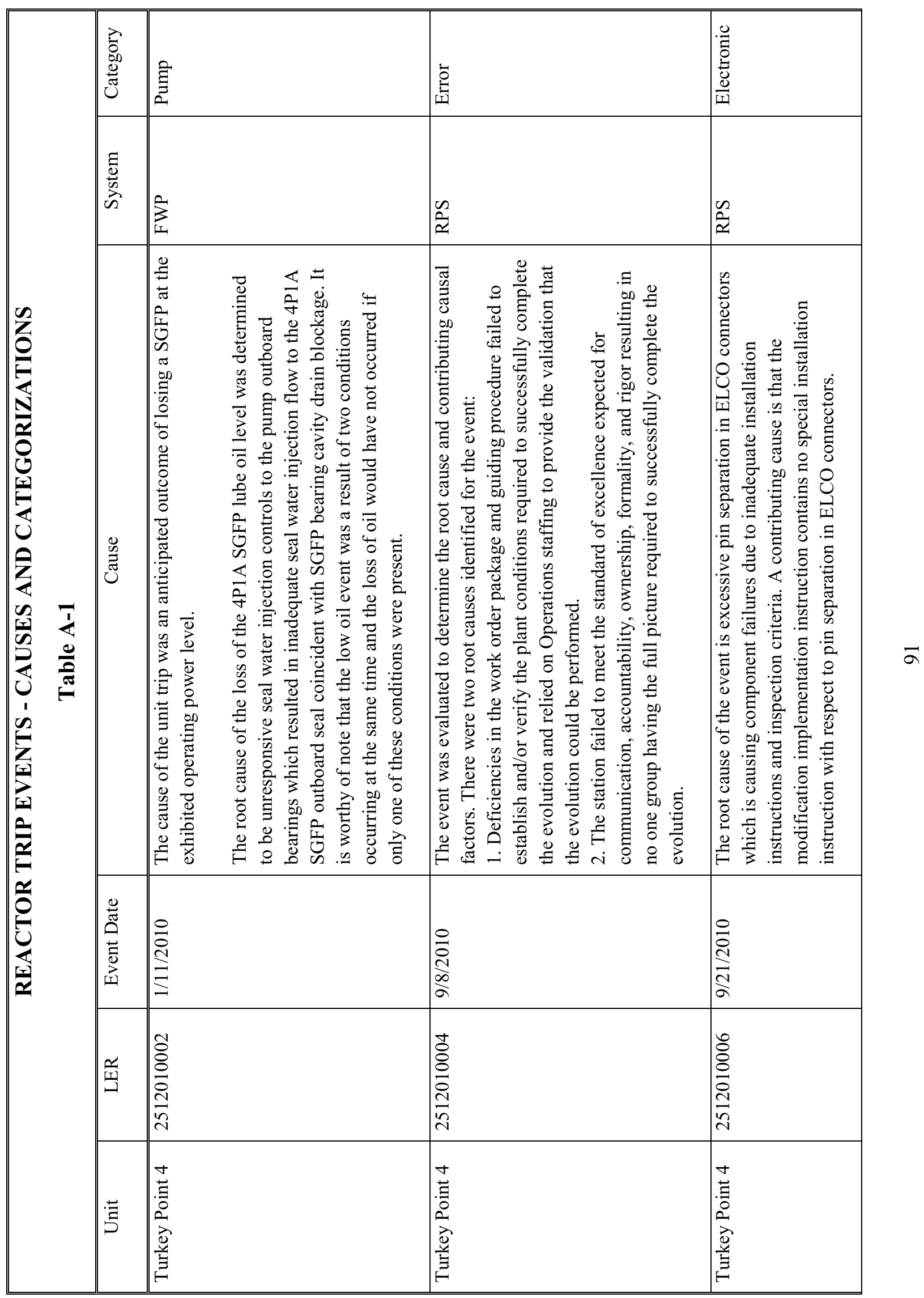




\begin{tabular}{|c|c|c|c|}
\hline \multirow{6}{*}{ 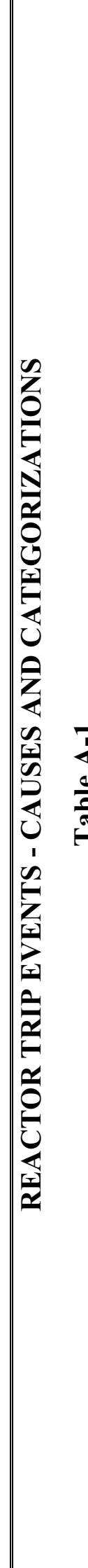 } & 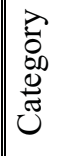 & 营 & 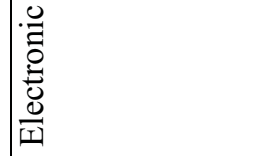 \\
\hline & 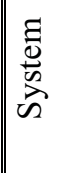 & 离 & $\sum_{i}^{\vec{z}}$ \\
\hline & 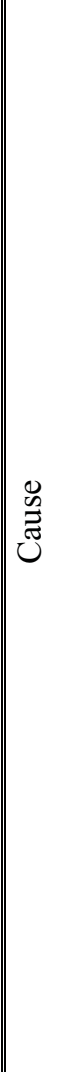 & 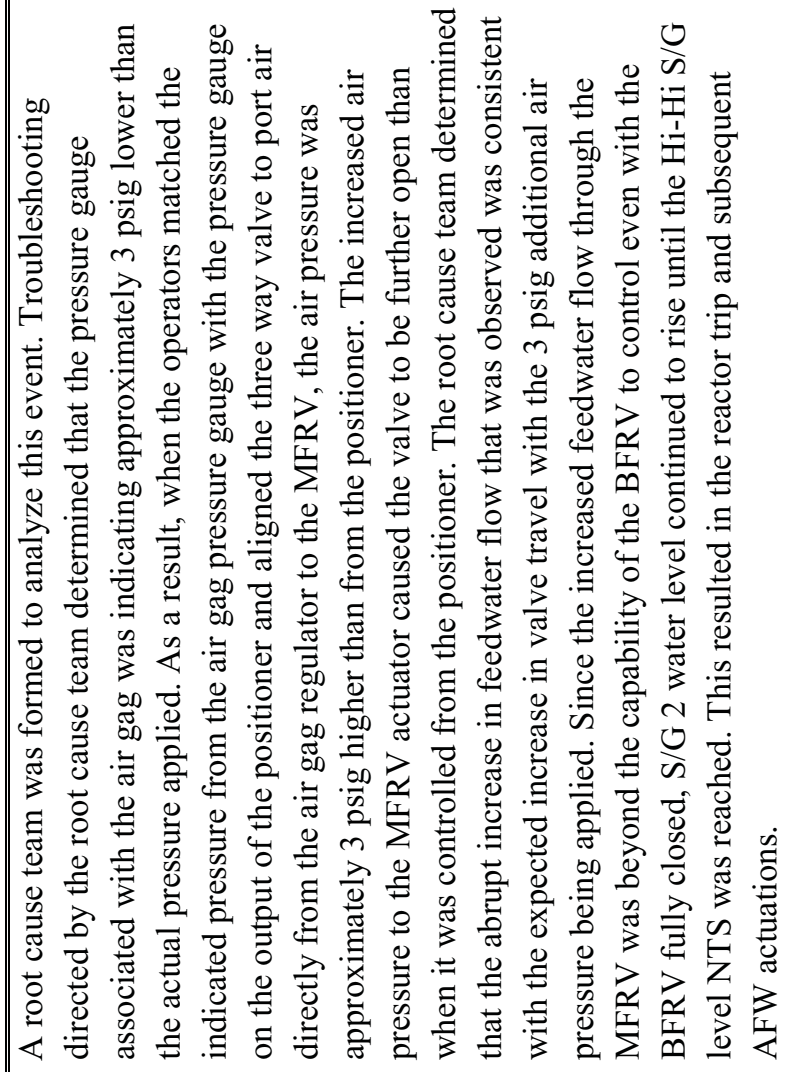 & 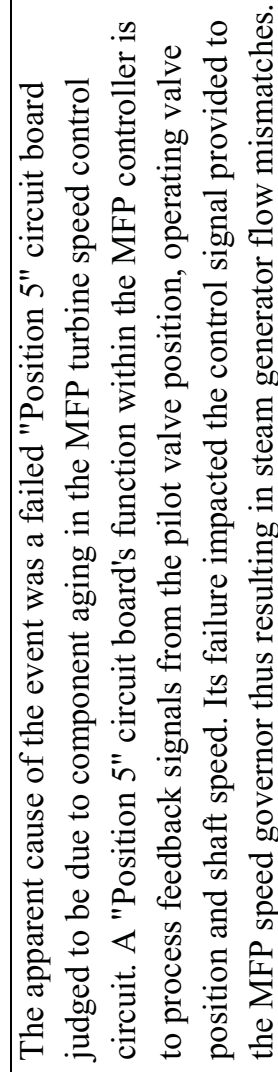 \\
\hline & 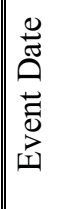 & 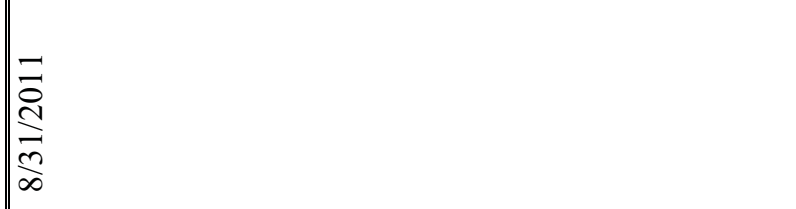 & $\frac{f}{\frac{\gamma}{\mathcal{T}}}$ \\
\hline & 舀 & 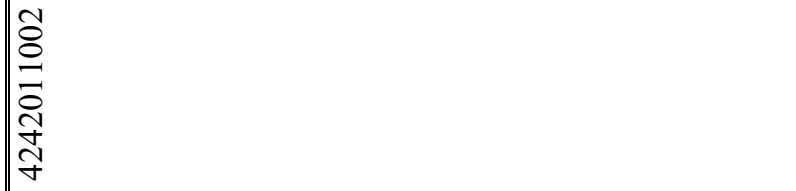 & 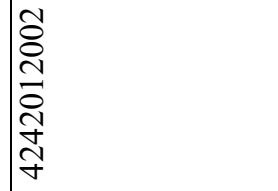 \\
\hline & 搞 & $\frac{\overrightarrow{0}}{\vec{b}}$ & 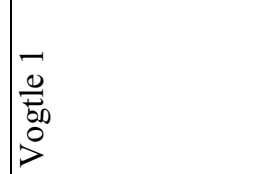 \\
\hline
\end{tabular}




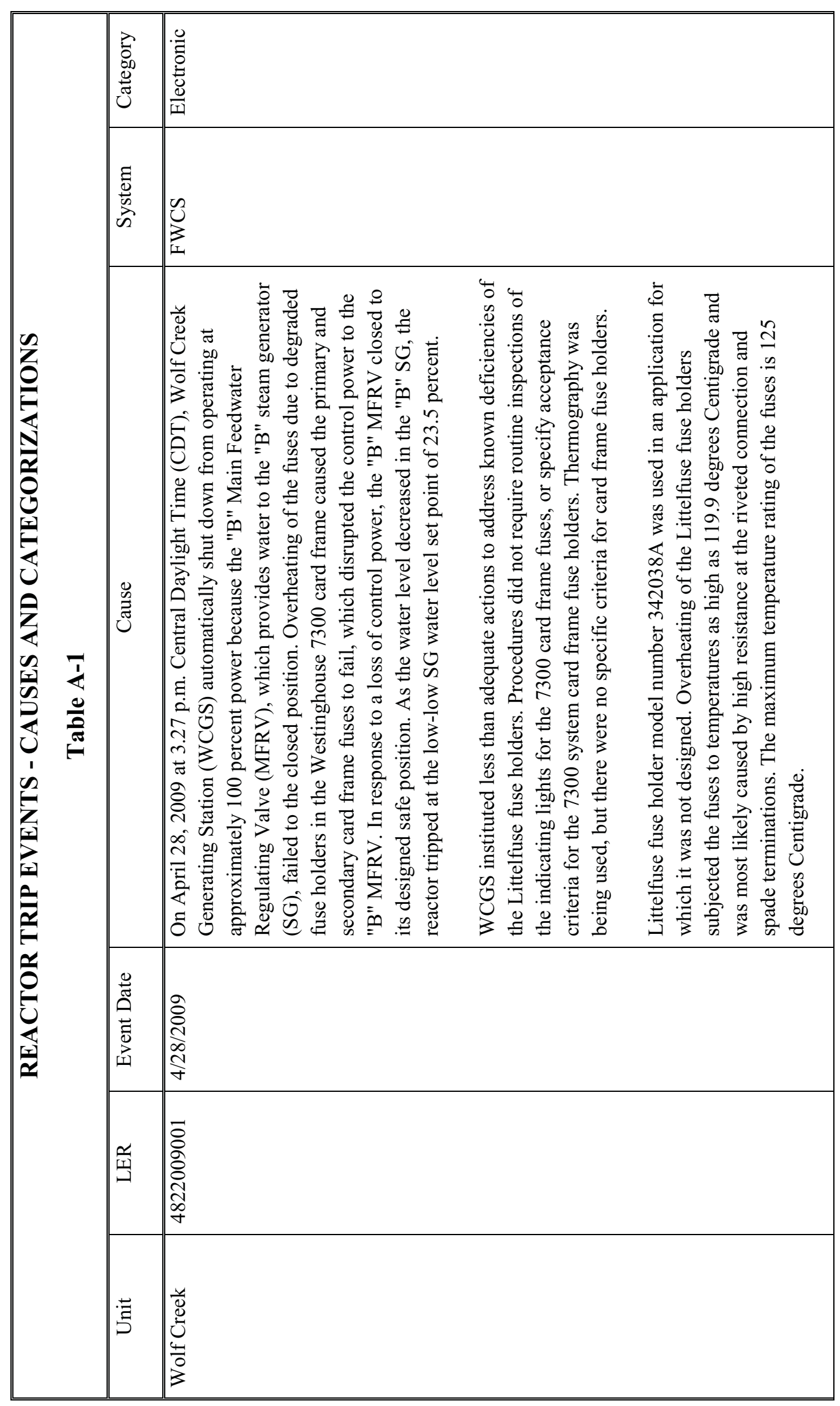




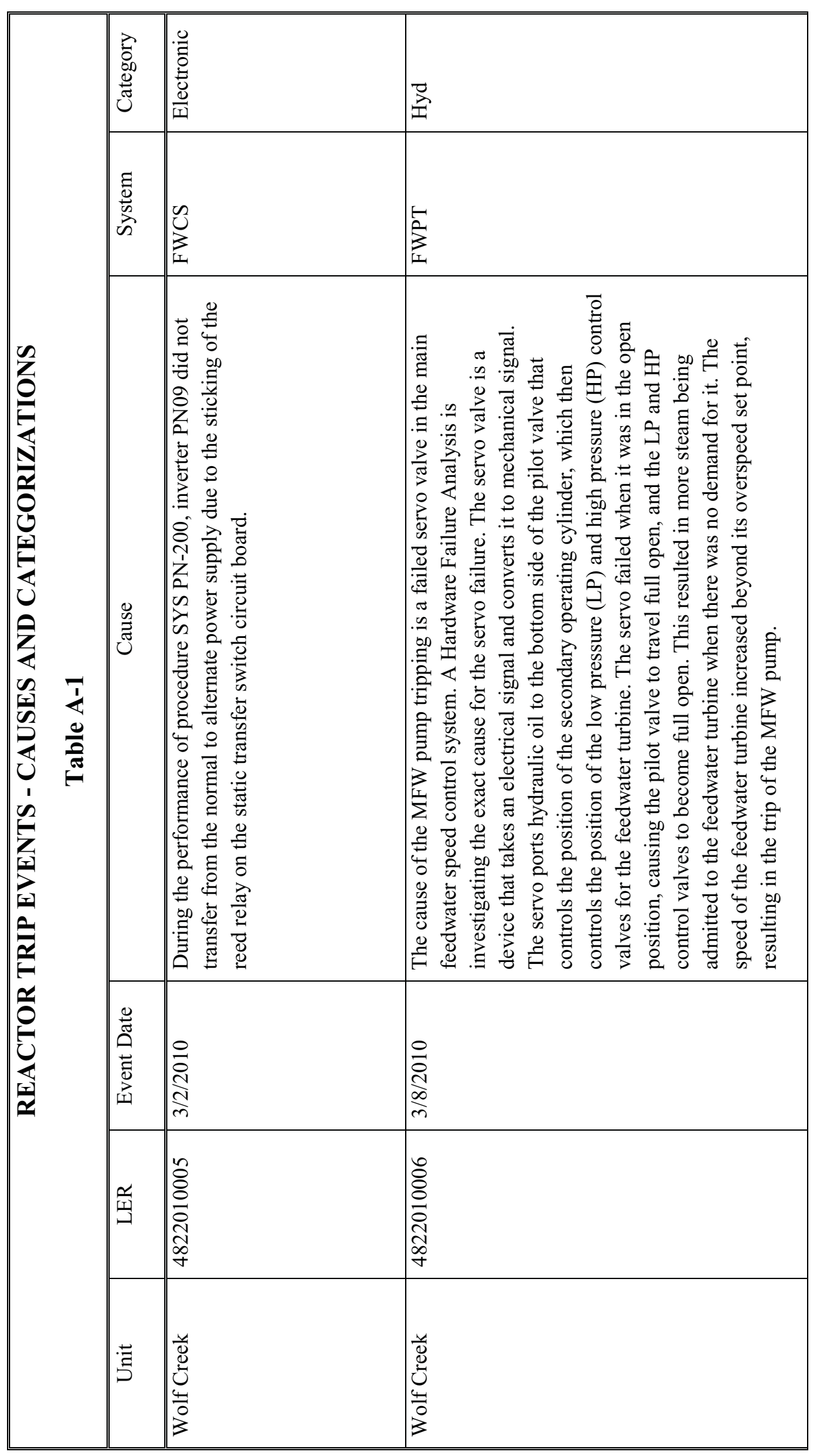




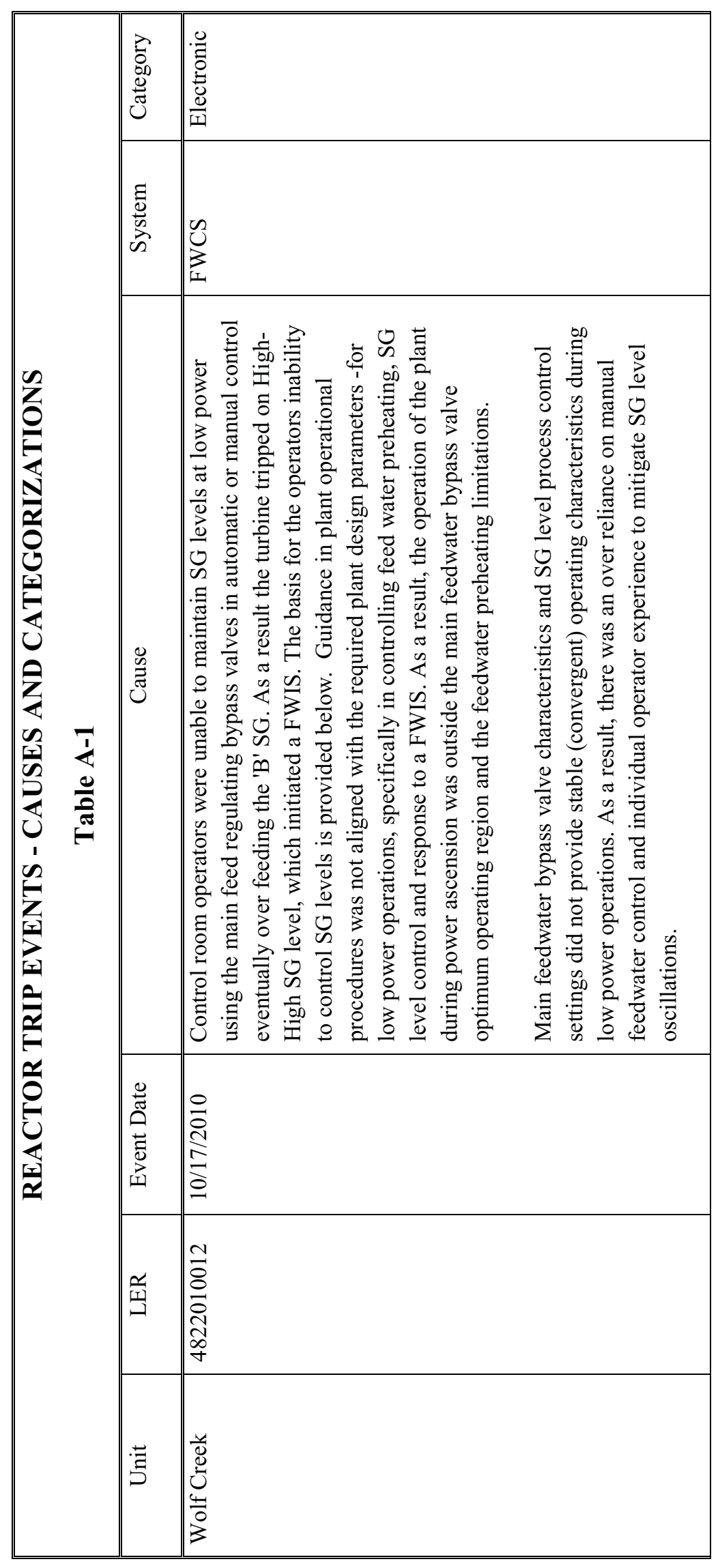




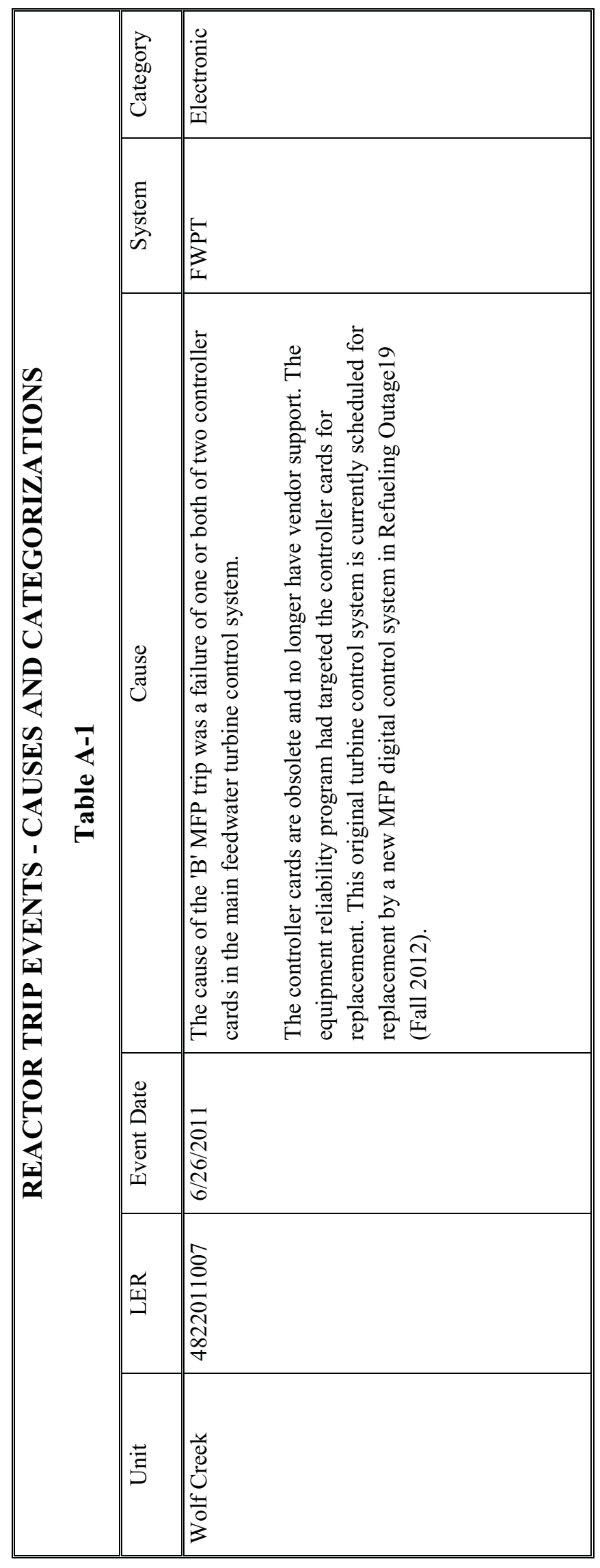

